NBER WORKING PAPER SERIES

UNDERSTANDING INFLATION AS A JOINT MONETARY-FISCAL PHENOMENON

Eric M. Leeper

Campbell Leith

Working Paper 21867

http://www.nber.org/papers/w21867

\author{
NATIONAL BUREAU OF ECONOMIC RESEARCH \\ 1050 Massachusetts Avenue \\ Cambridge, MA 02138 \\ January 2016
}

This paper has benefited from collaborations and discussions with many coauthors and colleagues and we thank them. We also thank Jon Faust, Ding Liu, Jim Nason, Charles Nolan, Fei Tan, and Todd Walker for conversations and Bob Barsky, John Cochrane, John Taylor, and Harald Uhlig for comments. The views expressed herein are those of the authors and do not necessarily reflect the views of the National Bureau of Economic Research.

NBER working papers are circulated for discussion and comment purposes. They have not been peerreviewed or been subject to the review by the NBER Board of Directors that accompanies official NBER publications.

(C) 2016 by Eric M. Leeper and Campbell Leith. All rights reserved. Short sections of text, not to exceed two paragraphs, may be quoted without explicit permission provided that full credit, including $\odot$ notice, is given to the source. 
Understanding Inflation as a Joint Monetary-Fiscal Phenomenon

Eric M. Leeper and Campbell Leith

NBER Working Paper No. 21867

January 2016

JEL No. E31,E52,E58,E61,E62,E63

\section{ABSTRACT}

We develop the theory of price-level determination in a range of models using both ad hoc policy rules and jointly optimal monetary and fiscal policies and discuss empirical issues that arise when trying to identify monetary-fiscal regime. The article concludes with directions in which theoretical and empirical developments may go. The article is prepared for the Handbook of Macroeconomics, volume 2 (John B. Taylor and Harald Uhlig, editors, Elsevier Press).

Eric M. Leeper

Department of Economics

Indiana University

105 Wylie Hall

Bloomington, IN 47405

and Center for Applied Economics and Policy Research

and also NBER

eleeper@indiana.edu

Campbell Leith

Department of Economics

University of Glasgow

Glasgow, G12 8QQ, Scotland

campbell.leith@glasgow.ac.uk 


\title{
UnDERSTANDING INFLATION AS A JoInT Monetary-Fiscal Phenomenon*
}

\author{
Eric M. Leeper ${ }^{\dagger} \quad$ Campbell Leith ${ }^{\ddagger}$
}

\section{Contents}

1 Introduction 1

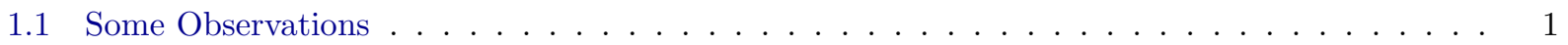

1.2 Our Remit. . . . . . . . . . . . . . . . . . . . . . . . 3

1.3 What is the Fiscal Theory? . . . . . . . . . . . . . . . . . . . . . . 3

1.3.1 Real vs. Nominal Government Debt ..................... . . . . . . .

1.3.2 Themes of the Chapter . . . . . . . . . . . . . . . . . . 6

1.4 Overview of the Chapter . . . . . . . . . . . . . . . . . . . . . . 8

2 Endowment Economies with Ad Hoc Policy Rules 9

2.1 A Simple Model . . . . . . . . . . . . . . . . . . . . . . . . . . 9

2.1.1 Policy Rules. . . . . . . . . . . . . . . . . . . . . . . . . . 11

2.1.2 Solving the Model . . . . . . . . . . . . . . . . . . . . . . . . . . . 12

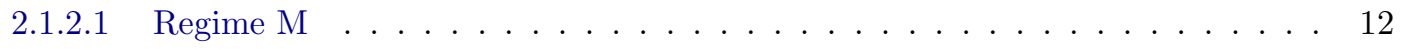

2.1.2.2 Regime F. . . . . . . . . . . . . . . . . . . . . 14

2.2 The Role of Maturity Structure . . . . . . . . . . . . . . . . . . . . . . 17

2.2.1 A General Maturity Structure . . . . . . . . . . . . . . . . . . . 17

2.2.1.1 An Illustrative Example . . . . . . . . . . . . . . . . . . . . . . . . 19

2.2.2 A Useful Special Case . . . . . . . . . . . . . . . . . . . . . . 21

2.3 Maturity Structure in Regime F . . . . . . . . . . . . . . . . . . . . . . . . . . 22

2.3.1 Increase in Government Spending . . . . . . . . . . . . . . . . . . . . . . . 26

2.3.1.1 Policy Under Regime M . . . . . . . . . . . . . . . . . . . . 26

2.3.1.2 Policy Under Regime F . . . . . . . . . . . . . . . . . . . . . 27

*January 5, 2016. This paper has benefited from collaborations and discussions with many coauthors and colleagues and we thank them. We also thank Jon Faust, Ding Liu, Jim Nason, Charles Nolan, Fei Tan, and Todd Walker for conversations and Bob Barsky, John Cochrane, John Taylor, and Harald Uhlig for comments.

${ }^{\dagger}$ Indiana University and NBER; eleeper@indiana.edu.

${ }^{\ddagger}$ University of Glasgow; Campbell.Leith@glasgow.ac.uk 
3 Production Economies with Ad Hoc Policy Rules 22

3.1 A Conventional New Keynesian Model . . . . . . . . . . . . . . . . . . . . . . . . 29

3.1 .1 Policy Rules . . . . . . . . . . . . . . . . . . . . . . . . 30

3.1 .2 Solving the Model in Regime F . . . . . . . . . . . . . . . . . . . 30

3.2 Maturity Structure in Regime $\mathrm{F} \ldots \ldots \ldots \ldots \ldots \ldots$

3.2 .1 Impacts of Fiscal Shocks . . . . . . . . . . . . . . . . . . . . 35

3.2 .2 Impacts of Monetary Shocks _ . . . . . . . . . . . . . . . . . . . . . 40

4 Endowment Economies with Optimal Monetary and Fiscal Policies 42

4.1 Connections to the Optimal Policy Literature . . . . . . . . . . . . . . . . . . 43

4.2 The Model . . . . . . . . . . . . . . . . . . . . . . . . 45

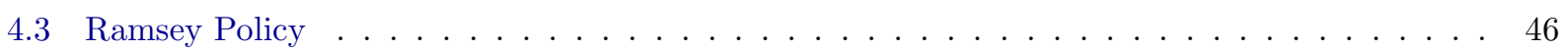

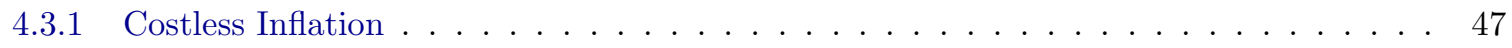

4.3 .2 Real Economy . . . . . . . . . . . . . . . . . . . . . . 48

4.3 .3 Intermediate Case . . . . . . . . . . . . . . . . . . . . . . . . . . 49

4.4 Numerical Results . . . . . . . . . . . . . . . . . . . . . . 50

4.5 Ramsey Policy with a General Maturity Structure . . . . . . . . . . . . . . . . 53

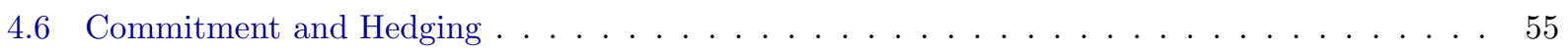

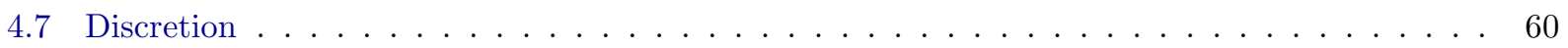

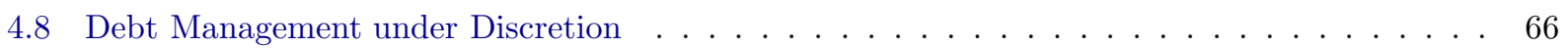

5 Production Economies with Optimal Monetary and Fiscal Policies $\quad 69$

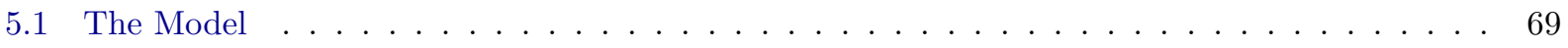

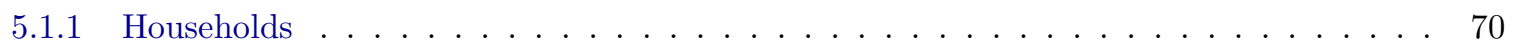

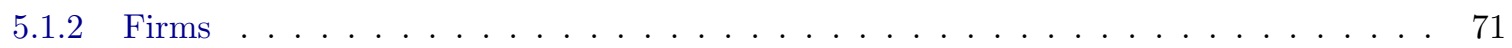

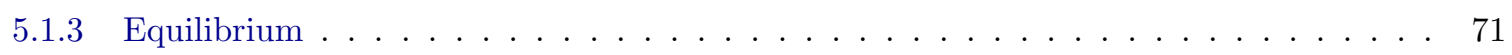

5.1 .4 Government Budget Identity . . . . . . . . . . . . . . . . . . . 71

5.2 Commitment Policy in the New Keynesian Model . . . . . . . . . . . . . . . . . . 72

5.3 Numerical Results . . . . . . . . . . . . . . . . . . . . . . . . . . . . . . . . . . . . .

5.4 An Independent Central Bank . . . . . . . . . . . . . . . . . . . . . . 75

5.5 Discretion in the New Keynesian Economy . . . . . . . . . . . . . . 76

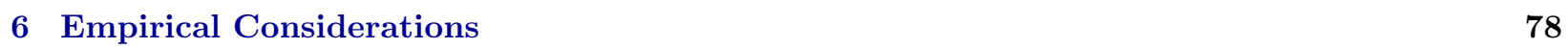

6.1 Distinguishing Regimes $\mathrm{M}$ and $\mathrm{F} \ldots \ldots \ldots \ldots \ldots \ldots \ldots$

6.2 Some Suggestive Empirical Evidence . . . . . . . . . . . . . . . . . . . . 80

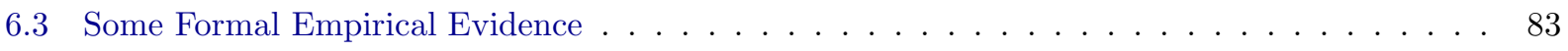

6.4 Regime Switching Policies . . . . . . . . . . . . . . . . . . . . 85

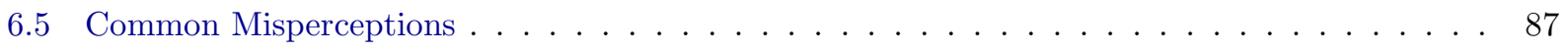

7 Practical Implications $\quad 90$

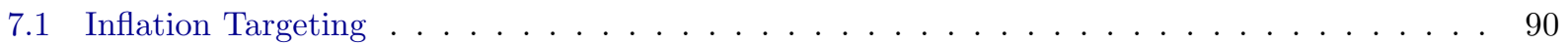

7.2 Returning to "Normal" Monetary Policy . . . . . . . . . . . . . . . . . . . . 93

7.3 Why Central Banks Need to Know the Prevailing Regime . . . . . . . . . . . . . . . 95 
8 Critical Assessment and Outlook $\quad 98$

8.1 Further Theoretical Developments . . . . . . . . . . . . . . . . . . . . . . . 98

8.1.1 Default and the Open Economy . . . . . . . . . . . . . . . . . . . . 98

8.1 .2 Better Rules . . . . . . . . . . . . . . . . . . . . . . . . . 99

8.1.3 Strategic Interactions . . . . . . . . . . . . . . . . . . . . . . 100

8.1 .4 Political Economy . . . . . . . . . . . . . . . . . . . . . . 101

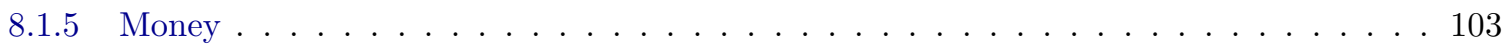

8.2 Further Empirical Work . . . . . . . . . . . . . . . . . . . . . . . . 103

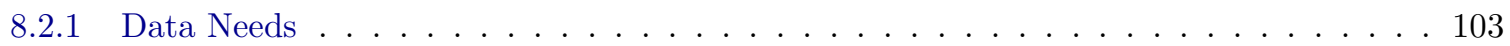

8.2 .2 Identifying Regime . . . . . . . . . . . . . . . . . . . . . . . . . . 104

8.2.3 Generalizing Regime Switching . . . . . . . . . . . . . . . . . . . . . . . . 104

8.2 .4 Historical Analyses . . . . . . . . . . . . . . . . . . . . . . . . . . 105

8.3 A Final Word . . . . . . . . . . . . . . . . . . . . . . 106

$\begin{array}{ll}\text { References } & 120\end{array}$

\section{List OF FiguRES}

1 Effects of higher transfers in the endowment economy . . . . . . . . . . . . . . . . . 25

2 Effects of higher government purchases in the endowment economy . . . . . . . . . . . . 28

3 Effects of higher deficits under alternative monetary policy rules . . . . . . . . . . . 36

4 Effects of higher deficits under alternative maturity structures . . . . . . . . . . . . . . 37

5 Effects of monetary contraction under alternative monetary policy rules . . . . . . . . . . . 40

6 Effects of monetary contraction under alternative maturity structures . . . . . . . . . . . . . 42

7 Optimal policy for transfers shock with different debt level and maturities . . . . . . . . . . 51

8 Optimal policy for government spending with different debt levels and maturities . . . . . . . 52

$9 \quad$ Optimal policy for anticipated government spending with different debt levels and maturities 53

10 Optimal hedging under commitment . . . . . . . . . . . . . . . . . . 60

11 Optimal time-consistent policy . . . . . . . . . . . . . . . . . . . . 65

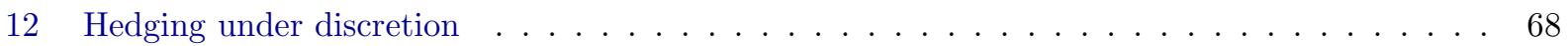

13 Hedging and time-consistent policy . . . . . . . . . . . . . . . . . . . . 69

14 Optimal policy for transfers with different debt levels and maturities . . . . . . . . . . . . 73

15 Optimal policy for government spending . . . . . . . . . . . . . . . . . . . . . 74

16 Optimal policy for government spending with an independent central bank . . . . . . . . 76

17 New Keynesian model under discretion . . . . . . . . . . . . . . . . . . . . . . . . 78

\section{List OF TABLES}

1 Net general government debt as percent of GDP . . . . . . . . . . . . . . . . . . 2

2 Fiscal financing of debt-financed fiscal expansion . . . . . . . . . . . . . . . . . . . . . . . 39

3 Fiscal financing of monetary policy contraction . . . . . . . . . . . . . . . . . . . . . 43

4 Estimated fiscal financing of debt-financed government spending expansion . . . . . . . . 85 


\section{INTRODUCTION}

There is a long tradition in macroeconomics of modeling inflation in stable economies by focusing on monetary policy and abstracting from fiscal policy. ${ }^{1}$ As the global financial crisis and its aftermath rocked the world economy, the tenability of that modeling approach has been strained.

This chapter introduces readers to the interactions between monetary and fiscal policies and their role in determining macroeconomic outcomes, particularly the aggregate price level. By incrementally widening the scope of those interactions and considering both simple ad hoc rules and optimal policy, we aim to make accessible the intricacies that policy interactions entail. We hope the material will entice young macroeconomists to engage a set of issues that we regard as both not fully resolved and fundamental to macroeconomic policy analysis.

\subsection{SOME OBSERVATIONS}

Let's start with a few observations of economic developments since 2008.

1. Many countries reacted to the financial crisis and recession that began in 2008 with joint policy actions that sharply reduced monetary policy interest rates and implemented large fiscal stimulus packages.

2. Central banks reacted to the financial crisis by purchasing large quantities of private assets and government bonds in actions that bear a striking resemblance to fiscal policy [Brunnermeier and Sannikov (2013), Leeper and Nason (2014)].

3. Sovereign debt crises in the euro zone culminated in the European Central Bank's 2012 policy of "outright monetary transactions," a promise to purchase sovereign debt in secondary markets in unlimited quantities for countries that satisfied conditionality restrictions.

4. Rapid adoption of fiscal austerity measures beginning in 2010 and 2011 created challenges for central banks that were already operating at or near the lower limits for nominal interest rates.

5. Exploding central bank balance sheets also grew riskier, increasing concerns about whether the requisite fiscal backing or support for monetary policy is guaranteed [Del Negro and Sims (2015a)].

\footnotetext{
${ }^{1}$ Focusing on stable economies rules out hyperinflations, which are widely believed to have fiscal origins.
} 


\begin{tabular}{|l|r|r|}
\hline & 2008 & 2015 \\
\hline Euro area & 54.0 & 74.0 \\
Japan & 95.3 & 140.0 \\
United Kingdom & 47.5 & 85.0 \\
United States & 50.4 & 80.9 \\
\hline
\end{tabular}

Table 1: Net general government debt as percent of GDP. Projections for 2015. Source: International Monetary Fund (2014)

6. In 2013, Japan's newly elected prime minister Shinzō Abe adopted "Abenomics," a mix of fiscal stimulus, monetary easing and structural reforms designed to re-inflate a Japanese economy that has languished since the early 1990s.

7. Table 1 reports that government debt expansions during the recession were significant: net debt as a share of GDP rose between 37 and 79 percent across four advancedeconomy country groups. As central banks begin to raise interest rates toward more normal levels, these debt expansions will carry with them dramatically higher debt service to create fresh fiscal pressures. The Congressional Budget Office (2014) projects that U.S. federal government net interest payments will rise dramatically as a share of GDP from 2014 to 2024. Evidently, there are substantial fiscal consequences from central bank exits from very low policy interest rates.

8. With an increasing number of central banks now paying interest on reserves at rates close to those on short-term government bonds, one important distinction between high-powered money and nominal government bonds has disappeared, removing a principal distinction between monetary and fiscal policy [Cochrane (2014)].

9. Sovereign debt troubles in the Euro Area and political polarization in many countries remind us that every country faces a fiscal limit, which is the point at which the adjustments in primary surpluses needed to stabilize debt are not assured. Uncertainty about future fiscal adjustments can untether fiscal expectations, making it difficult or impossible for monetary policy to achieve its objectives [Davig, Leeper, and Walker $(2010,2011)]$.

10. Exacerbating the fiscal fallout from the crisis, aging populations worldwide create long-run fiscal stress whose resolution in most countries is uncertain. This kind of uncertainty operates at low frequencies and may conflict with the long-run objectives of monetary policy [Carvalho and Ferrero (2014)].

It is hard to think about these developments without bringing monetary and fiscal policy 
jointly into the analysis. Several of these examples also run counter to critical maintained assumptions in monetarist/Wicksellian perspectives, including:

- fiscal policies will adjust government revenues and expenditures as needed to finance and stabilize government debt; this ensures that fiscal actions are "self-correcting" and need not concern monetary policymakers;

- sufficiently creative monetary policies - which include interest rate settings, quantitative easing, credit easing, government debt management, forward guidance - can always achieve desired inflation and macroeconomic objectives;

- impacts of monetary policy on fiscal choices are small enough to be of negligible importance to monetary policy decisions, freeing central banks to focus on a narrow set of goals.

As even this handful of examples makes clear, it is unlikely to be fruitful to interpret recent macroeconomic policy issues by studying monetary or fiscal policy in isolation. This chapter takes that premise as given to explore how macro policies interact to determine aggregate prices and quantities.

\subsection{OUR REMIT}

We were invited to write a chapter on the "fiscal theory of the price level," an assignment that we gladly accepted, but chose to broaden to the theory of price-level determination. A broader perspective, like the observations above, brings monetary and fiscal policy jointly into the picture to produce a more general understanding of the inflation process than either the monetarist/Wicksellian or the fiscal theory alone provide. We show that only in very special circumstances can the two perspectives be treated as distinct theories. Despite this broader perspective, both to fulfill our remit and to draw attention to aspects of monetary and fiscal policy interaction that are often overlooked, the chapter will often (but not solely) focus on the mechanisms that the fiscal theory emphasizes.

\subsection{What is the Fiscal Theory?}

We consider a class of dynamically efficient models with monetary policy, a maturity structure for nominal government debt, taxes - distorting or lump-sum - government expenditurespurchases or transfers - and a government budget identity. In models of this kind, four key features of equilibrium may emerge: 
1. There is a prominent role for nominal government debt revaluations that stabilize debt through surprise changes in inflation and bond prices.

2. It is possible for monetary-fiscal policy mixes to permit nominal government debt expansions or increases in the monetary policy interest rate instrument to increase nominal private wealth, nominal aggregate demand, and the price level.

3. Expectations of fiscal policy are equally important to those of monetary policy in determining prices and, sometimes, quantities, as in Brunner and Meltzer (1972), Tobin (1980), and Wallace (1981). ${ }^{2}$

4. Debt management policies matter for equilibrium dynamics, contributing an additional instrument to the standard macroeconomic policy toolkit, as Tobin (1963) argued.

Analyses of the implications of these features in this class of models constitute what we call the "fiscal theory of the price level." 3

The fiscal theory is a complement to, rather than a substitute for, conventional views of price-level determination. It emerges by filling in the fiscal sides of models and broadening the rules that monetary and fiscal authorities obey. By doing so, the fiscal theory extracts what assumptions about fiscal behavior are required to deliver conventional views. More importantly, being explicit about both monetary and fiscal behavior reveals that a far richer set of equilibria can arise from the previously suppressed, but undeniable, fact that monetary and fiscal policies are intrinsically intertwined.

The chapter aims to be constructive and instructive, so it does not re-fight the battles that surround the fiscal theory. Accusations against the fiscal theory include: it confuses equilibrium conditions with budget constraints; it violates Walras' law; it treats private agents and the government differently; it is merely an equilibrium selection device; it is little more than a retread of Sargent and Wallace's (1981) unpleasant monetarist arithmetic. ${ }^{4}$ Each of these arguments has been discussed at length in Sims (1999a), Cochrane (2005), and Leeper and Walker (2013). Rehashing those debates detracts from the chapter's aims.

Cochrane (2011b, 2014) and Sims (1999b, 2013) two leading proponents of the fiscal theory, explore a wide range of issues through the lens of the fiscal theory to reach conclusions

\footnotetext{
${ }^{2}$ Brunner and Meltzer anticipate the fiscal theory by showing that a government debt expansion unaccompanied by higher base money is inflationary when the fiscal deficit is held constant. But they dismiss this result on the grounds that "Price-level changes of this kind have not been important [foonote 13]."

${ }^{3}$ Early contributors to the theory include Begg and Haque (1984), Auernheimer and Contreras (1990) Leeper (1991), Sims (1994), Woodford (1995) and Cochrane (1999).

${ }^{4}$ These accusations appear in Kocherlakota and Phelan (1999), McCallum (2001), Bassetto (2002), Buiter (2002), and Ljungqvist and Sargent (2004).
} 
that contrast sharply with conventional perspective. This chapter also re-examines some practical issues in the light of the fiscal theory.

Most of the chapter focuses on the nature of equilibrium, including price-level determination, in models with nontrivial specifications of monetary and fiscal policy behavior. In this sense, the chapter, like the fiscal theory itself, echoes Wallace's (1981) insight that the effects of central bank open-market operations hinge on the precise sense in which fiscal policy is held constant. Under some assumptions on fiscal behavior, open-market operations are neutral, but different fiscal behavior permits monetary policy actions to have different impacts. Wallace did not explore the nature of price-level determination in the presence of nominal government bonds, which the fiscal theory emphasizes, but his results nonetheless foreshadow the newer literature. We also examine interactions in the opposite direction: how monetary policy behavior can influence the impacts of fiscal actions.

\subsubsection{Real vs. Nominal Government Debt}

Central to the fiscal theory is the distinction between real and nominal government debt. This distinction matters little in conventional views that maintain that future revenues and expenditures always adjust to stabilize government debt. But the presence - in fact, the prevalence, of nominal government debt in many countries-lies at the core of the fiscal theory. ${ }^{5}$

Real debt can take the form of inflation-indexed bonds or bonds denominated in units whose supply the country does not control. Real debt is a claim to real goods, which the government must acquire through taxation. This imposes a budget constraint that the government's choices must satisfy. If the government does not have the taxing capacity to acquire the goods necessary to finance outstanding debt, it has no option other than outright default. Under the gold standard with fixed parities, countries effectively issued real debt because the real value of government bonds was determined by factors outside their control - worldwide supply and demand for gold.

Nominal debt is much like government-issued money: it is merely a claim to fresh currency in the future. The government may choose to raise taxes to acquire the requisite currency or it may opt to print up new currency, if currency creation is within its purview. Because the value of nominal debt depends on the price level and bond prices, the government really does not face a budget constraint when all its debt is nominal. Some readers may object to the idea that a government doesn't face a budget constraint, but the logic here is exactly the logic that underlies fiat currency. By conventional quantity theory reasoning, the central bank is free to double or half the money supply without fear of violating a budget constraint

\footnotetext{
${ }^{5}$ See Cochrane (2011b) and Sims (2013).
} 
because the price level will double or half to maintain the real value of money. The direct analog to this reasoning is that the government is free to issue any quantity of nominal bonds, whose real value adjusts with the price level, without reference to a budget constraint. Of course, as with a money rain, by doing so the government is giving up control of the price level.

Member nations of the European Monetary Union issue debt denominated in euros, their home currency, but because monetary policy is under the control of the ECB rather than individual nations, the debt is effectively real from the perspective of member nations. The United States issues indexed debt, but it comprises only 10 percent of the debt outstanding. Even in the United Kingdom, which is known for having a thick market in indexed bonds, the percentage is only about 20. Five percent or less of total debt issued is indexed in the Euro Area, Japan, Australia, and Sweden.

\subsubsection{Themes of the Chapter}

Several themes run through this paper. First, it is always the joint behavior of monetary and fiscal policies that determine inflation and stabilize debt. While this point might seem obvious - echoing, as it does, a viewpoint that dates back at least to Friedman (1948) it is easily missed in the classes of models and descriptions of policy typically employed in modern macroeconomic policy analyses. In those models, inflation appears to be determined entirely by monetary policy behavior - specifically, by the responsiveness of monetary policy to inflation - while debt dynamics seem to be driven only by fiscal behavior - the strength of primary surplus responses to debt. Of course, in equilibrium the two policies must interact in particular ways to deliver a determinate equilibrium with bounded debt, but this point is often swept under the carpet in order to focus the analysis solely on monetary policy. ${ }^{6}$

In dynamic models, macroeconomic policies have two fundamental tasks to achieve: determine the price level and stabilize debt. Two distinct monetary-fiscal policy mixes can accomplish those tasks. A second theme is that it is useful for some purposes to categorize those policy mixes in terms of "active" or "passive" policy behavior. ${ }^{7}$ An active authority pursues its objectives unconstrained by the state of government debt and is free to set its control variables as it sees fit. But then the other authority must behave passively to stabilize debt, constrained by the active authority's actions and private sector behavior. A determinate bounded equilibrium requires the mix of one active and one passive policy; that mix achieves the two macroeconomic objectives of delivering unique inflation and stable debt

\footnotetext{
${ }^{6}$ See, for example, Woodford (2003) and Galí (2008).

${ }^{7}$ Leeper (1991) develops this categorization to study bounded equilibria.
} 
processes. $^{8}$ The combination of active monetary and passive fiscal policies delivers the usual monetarist/new Keynesian setup in which monetary policy can target inflation and fiscal policy exhibits Ricardian equivalence. We call this policy mix regime M, but it also goes by the label "monetary dominance." An alternative combination of passive monetary and active fiscal policies gives fiscal policy important effects on inflation, while monetary policy ensures that debt is stable. The latter policy regime has been given the unfortunate label "the fiscal theory of the price level." The fiscal theory mix is called regime F or "fiscal dominance."

Third, regime $\mathrm{F}$ policies produce equilibria in which the maturity structure of government debt affects equilibrium dynamics, as Cochrane (2001) and Sims (2011) emphasize. In contrast, without frictions that make short and long debt imperfect substitutes and in the special case of flexible prices and lump-sum taxes, maturity structure is irrelevant in regime M. Under the fiscal theory, long debt permits both current and future inflation (bond prices) to adjust to shocks that perturb the market value of debt, which serves to make inflation and, if prices are sticky, real activity less volatile than they would be if all debt were one-period.

Fourth, only in the special cases of flexible prices and lump-sum fiscal shocks/surplus adjustments can simple active monetary policy rules hit their inflation target in regime $\mathrm{M}$. More generally, with sticky prices and distortionary taxation, we observe revaluation effects and pervasive interactions between monetary and fiscal policy across both the $\mathrm{M}$ and $\mathrm{F}$ regimes.

Fifth, the "active/passive" rubrics also lose their usefulness once one considers optimal policies. Jointly optimal monetary and fiscal policies generally combine elements of both regimes $\mathrm{M}$ and $\mathrm{F}$ : when long-maturity government debt is outstanding, it is always optimal to stabilize debt partly through distorting taxes and partly through surprise changes in inflation and bond prices [Cochrane (2001), Sims (2013), Leeper and Zhou (2013)]. How important inflation is as a debt stabilizer - or in Sims's (2013) terminology, a "fiscal cushion" — depends on model specifics: the maturity structure of debt, the costliness of inflation variability, the level of outstanding government debt, whether optimal policy is with commitment or discretion, proximity of the economy to its fiscal limit, and so forth.

The fact that key features of the fiscal theory emerge as jointly optimal monetary and fiscal policy elevates the theory from a theoretical oddity to an integral part of macroeconomic policies that deliver desirable outcomes.

\footnotetext{
${ }^{8}$ There are unbounded equilibria also. Sims (2013) and Cochrane (2011a) emphasize the possibility of solutions with unbounded inflation; McCallum (1984) and Canzoneri, Cumby, and Diba (2001b) display solutions with unbounded debt that hinge on the presence of non-distorting taxes.
} 


\subsection{Overview of the Chapter}

As we progress through the chapter we gradually widen the extent of monetary and fiscal policy interactions. We start with a simple flexible-price endowment economy subject to shocks to lump-sum transfers. This environment limits the extent of monetary and fiscal interactions to the revaluation effects emphasized by the fiscal theory and supports the strong dichotomy between the $\mathrm{M}$ and $\mathrm{F}$ regimes. Even in this simple environment, though, there are important spillovers between monetary and fiscal policy under either regime when we allow for either government spending or monetary policy shocks.

We then turn to consider the same rules in a production economy subject to nominal rigidities, but where we retain the assumption that taxes are lump sum. This adds a new channel for monetary and fiscal interactions because monetary policy can affect real interest rates when prices are sticky which, in turn, influence debt dynamics through real debt service costs. We then generalize this further by adding distortionary taxation to a new Keynesian economy. Then tax policy affects inflation through its impact on marginal costs, government spending feeds into aggregate demand, and monetary policy affects real interest rates to influence the size of the tax base. In this richer specification, equilibrium outcomes are always the result of interactions between monetary and fiscal policy and a key issue is the balance between monetary and fiscal policy in the control of inflation and stabilization of debt. We show that the conventional policy assignment of delegating monetary policy to achieve an inflation target and fiscal policy to stabilize debt is not always optimal.

Most expositions of the fiscal theory posit simple ad hoc rules for monetary and fiscal behavior and characterize the nature of equilibria under alternative settings of those rules. This chapter follows that path in the next two sections to derive clean analytical results that explain how the fiscal theory operates and how it differs from alternative policy mixes. Then the paper turns to study jointly optimal monetary and fiscal policies as an alternative vehicle for describing the economic mechanisms that underlie the fiscal theory. Optimal policies make clear that the distinguishing features of the fiscal theory are generally part of a policy mix that produces desirable economic outcome. But the incentive to use surprise inflation to stabilize debt, especially when debt levels are high, can also create significant timeconsistency issues when policymakers cannot credibly commit. When private agents know that policymakers may be tempted to induce inflation surprises to reduce the debt burden, economic agents raise their inflation expectations as debt levels rise until that temptation has been offset. This produces a sizeable debt stabilization bias that drives policymakers to reduce debt levels rapidly, at large cost in terms of social welfare, to avoid the high equilibrium rates of inflation associated with the temptation to inflate that debt away. We 
explore the sharp contrast between time-consistent and time-inconsistent optimal policy in this context in detail.

After those purely theoretical explorations, the paper turns to consider the empirical relevance of those mechanisms. We describe some subtle issues that arise in efforts to identify monetary-fiscal regime. The chapter then discusses three practical applications of the theory: fiscal prerequisites for successful inflation targeting, consequences of alternative fiscal reactions to a return to more normal levels of interest rates, and why the central bank needs understand the prevailing monetary-fiscal regime in order to conduct monetary policy. To wrap up, we describe outstanding issues in both theoretical and empirical analyses of monetary and fiscal policy interactions to point out directions for future research.

\section{Endowment Economies with Ad Hoc Policy Rules}

This section aims to present the distinguishing features of the fiscal theory listed in section 1.3 in the simplest possible model. A representative consumer lives forever and receives a constant endowment of goods, $y$, each period. The economy is cashless and financial markets are complete.

\subsection{A Simple Model}

The consumer optimally chooses consumption, $c_{t}$, may buy or sell nominal assets, $D_{t}$, at price $Q_{t, t+1}$, receives lump-sum transfers from the government, $z_{t}$, and pays lump-sum taxes, $\tau_{t} \cdot{ }^{9}$ The representative household maximizes

$$
E_{0}\left\{\sum_{t=0}^{\infty} \beta^{t} U\left(c_{t}\right)\right\}
$$

with $0<\beta<1$, subject to the sequence of flow budget constraints

$$
P_{t} c_{t}+P_{t} \tau_{t}+E_{t}\left[Q_{t, t+1} D_{t}\right]=P_{t} y+P_{t} z_{t}+D_{t-1}
$$

given $D_{-1} \cdot Q_{t, t+1}$ is the nominal price at $t$ of an asset that pays $\$ 1$ in period $t+1$ and $P_{t}$ is the general price level in units of mature government bonds required to purchase one unit of goods. Government bonds sold at $t$, which are included in $D_{t}$, pay gross nominal interest $R_{t}$ in period $t+1$. Letting $m_{t, t+1}$ denote the real contingent claims price, a no-arbitrage

\footnotetext{
${ }^{9} D_{t}$ consists of privately-issued, $B_{t}^{p}$, and government issued, $B_{t}$, assets. Government bonds cost $\$ 1 / R_{t}$ per unit and are perfectly safe pure discount bonds.
} 
condition implies that

$$
Q_{t, t+1}=m_{t, t+1} \frac{P_{t}}{P_{t+1}}
$$

The short-term nominal interest rate, $R_{t}$, which is also the central bank's policy instrument, is linked to the nominal bond price: $1 / R_{t}=E_{t}\left[Q_{t, t+1}\right]$.

Setting government purchases of goods to zero, ${ }^{10}$ the primary surplus is simply $s_{t} \equiv \tau_{t}-z_{t}$. The household's intertemporal budget identity comes from iterating on (1) and imposing the no-arbitrage condition, (2), and the transversality condition

$$
\lim _{T \rightarrow \infty} E_{t}\left[m_{t, T} \frac{D_{T-1}}{P_{T}}\right]=0
$$

to yield

$$
E_{t} \sum_{j=0}^{\infty} m_{t, t+j} c_{t+j}=\frac{D_{t-1}}{P_{t}}+E_{t} \sum_{j=0}^{\infty} m_{t, t+j}\left(y-s_{t+j}\right)
$$

where $m_{t, t+j} \equiv \prod_{k=0}^{j} m_{t+k, t+k+1}$ is the real discount factor, with $m_{t, t}=1$.

After imposing equilibrium in the goods market, $c_{t}=y$, the real discount factor is constant, $m_{t, t+1}=\beta$, and the nominal interest rate obeys a Fisher relation

$$
\frac{1}{R_{t}}=\beta E_{t} \frac{P_{t}}{P_{t+1}}=\beta E_{t} \frac{1}{\pi_{t+1}}
$$

where $\pi_{t} \equiv P_{t} / P_{t-1}$ is the gross inflation rate. In equilibrium there will be no borrowing or lending among private agents, so the household's bond portfolio consists entirely of government bonds. Imposing both bond and goods market clearing and the constant real discount factor the household's intertemporal constraint produces the ubiquitous equilibrium condition

$$
\frac{B_{t-1}}{P_{t}}=E_{t} \sum_{j=0}^{\infty} \beta^{j} s_{t+j}
$$

Cochrane (2001) refers to (6) as an "equilibrium valuation equation" because it links the market value of debt outstanding at the beginning of period $t, B_{t-1} / P_{t}$, to the expected present value of the cash flows that back debt, primary surpluses. Notice that we derived this valuation equation entirely from private optimizing behavior and market clearing, without reference to government behavior or to the government's budget identity. The valuation equation imposes no restrictions on the government's choices of future surpluses, in the same way that the Fisher relation does not limit the central bank's choices of the nominal interest rate.

\footnotetext{
${ }^{10}$ We shall relax this assumption below.
} 
For each date $t$, equations (5) and (6) constitute two equilibrium conditions in four unknowns: $R_{t}, P_{t}, E_{t}\left(1 / P_{t+1}\right), E_{t} \sum_{j=0}^{\infty} \beta^{j} s_{t+j}$. Private sector behavior alone cannot uniquely determine the equilibrium. We turn now to a class of monetary and fiscal policy rules that may deliver determinate equilibria.

\subsubsection{Policy Rules}

The central bank obeys a simple interest rate rule, come to be called a Taylor (1993) rule, that makes deviations of the nominal interest rate from steady state proportional to deviations of inflation from steady state

$$
\frac{1}{R_{t}}=\frac{1}{R^{*}}+\alpha_{\pi}\left(\frac{1}{\pi_{t}}-\frac{1}{\pi^{*}}\right)+\varepsilon_{t}^{M}
$$

where $\varepsilon_{t}^{M}$ is an exogenous shock to monetary policy. The government sets deviations of the primary surplus from steady state proportional to steady-state deviations of debt

$$
s_{t}=s^{*}+\gamma\left(\frac{1}{R_{t-1}} \frac{B_{t-1}}{P_{t-1}}-\frac{b^{*}}{R^{*}}\right)+\varepsilon_{t}^{F}
$$

where $\varepsilon_{t}^{F}$ is an exogenous fiscal shock to the primary surplus. The inverse of the nominal interest rate is the price of nominal debt so $\frac{1}{R_{t-1}} \frac{B_{t-1}}{P_{t-1}}$ is the real market value of debt issued at $t-1$. Policy choices must be consistent with the government's flow budget identity

$$
\frac{1}{R_{t}} \frac{B_{t}}{P_{t}}+s_{t}=\frac{B_{t-1}}{P_{t}}
$$

where the steady state of the model is

$$
\frac{B}{P}=b^{*}, \quad s^{*}=\left(\beta^{-1}-1\right) \frac{b^{*}}{R^{*}}, \quad R^{*}=\frac{\pi^{*}}{\beta}, \quad m^{*}=\beta
$$

It is convenient to express things in terms of the inverse of inflation (i.e. deflation)and real debt, so let $\nu_{t} \equiv \pi_{t}^{-1}$ and $b_{t} \equiv B_{t} / P_{t}$. Combining the monetary policy rule with the Fisher equation yields the difference equation in deflation

$$
E_{t}\left(\nu_{t+1}-\nu^{*}\right)=\frac{\alpha_{\pi}}{\beta}\left(\nu_{t}-\nu^{*}\right)+\frac{1}{\beta} \varepsilon_{t}^{M}
$$

Combining the fiscal rule and the government's flow budget identity, taking expectations 
and employing the Fisher relation yields real debt dynamics

$$
E_{t}\left(\frac{b_{t+1}}{R_{t+1}}-\frac{b^{*}}{R^{*}}\right)=\left(\beta^{-1}-\gamma\right)\left(\frac{b_{t}}{R_{t}}-\frac{b^{*}}{R^{*}}\right)-E_{t} \varepsilon_{t+1}^{F}
$$

Equations (9) and (10) constitute a system of expectational difference equations in inflation and real debt, which is driven by the exogenous policy disturbances $\varepsilon^{M}$ and $\varepsilon^{F}$. Given the consumer's discount factor, $\beta$, this system appears as though inflation dynamics depend only on the monetary policy choice of $\alpha_{\pi}$, while debt dynamics hinge only on the fiscal policy choice of $\gamma$ : it is not obvious that monetary and fiscal behavior jointly determine inflation and real debt. This apparent separation of the system is deceptive. Because the government issues nominal bonds, $B_{t}$, the price level appears in both equations and $1 / P_{t}$ is the value of bonds maturing at $t$.

\subsubsection{Solving THE Model}

We focus on bounded solutions. ${ }^{11}$ Stability of inflation depends on $\alpha_{\pi} / \beta$ and stability of debt depends on $\beta^{-1}-\gamma \cdot{ }^{12}$

\subsubsection{Regime $M$}

If $\alpha_{\pi} / \beta>1$, then the bounded solution for inflation is

$$
\nu_{t}=\nu^{*}-\frac{1}{\alpha_{\pi}} \sum_{j=0}^{\infty}\left(\frac{\beta}{\alpha_{\pi}}\right)^{j} E_{t} \varepsilon_{t+j}^{M}
$$

which delivers a solution for $\left\{P_{t-1} / P_{t}\right\}$ for $t \geq 0$ and the equilibrium nominal interest rate is

$$
\frac{1}{R_{t}}=\frac{1}{R^{*}}-\sum_{j=1}^{\infty}\left(\frac{\beta}{\alpha_{\pi}}\right)^{j} E_{t} \varepsilon_{t+j}^{M}
$$

\footnotetext{
${ }^{11}$ Unbounded solutions for inflation also exist, as Benhabib, Schmitt-Grohé, and Uribe (2001) show. Sims (1999b), Cochrane (2011a) and Del Negro and Sims (2015a) thoroughly explore those equilibria to argue that a determinate price level requires appropriate fiscal backing. As Del Negro and Sims (2015a, p. 3) define it: "Fiscal backing requires that explosive inflationary or deflationary behavior of the price level is seen as impossible because the fiscal authority will respond to very high inflation with higher primary surpluses and to near-zero interest rates with lower, or negative, primary surpluses." Solutions with unbounded debt inevitably rely on non-distorting taxes, which permit revenues to grow forever at the same rate as interest receipts on government bond holdings. Although such paths for revenues are equilibria in the present model, because they are infeasible in economies where taxes distort, we find them to be uninteresting.

${ }^{12} \mathrm{We}$ consider the implications of temporarily being in active-active or passive-passive regimes in Section 7.3 .
} 
In this simple model, both actual and expected inflation depend on the monetary policy parameter and shock, but they appear not to depend in any way on fiscal behavior.

This appearance is deceiving because (11) does not constitute a complete solution to the model; we also need to ensure that there is a bounded solution for real debt. If fiscal policy chooses $\gamma>\beta^{-1}-1$, then when real debt rises, future surpluses rise by more than the net real interest rate with the change in debt in order to cover both debt service and a little of the principal. In this case, the debt dynamics in (10) imply that for arbitrary deviations of real debt from steady state, $\lim _{T \rightarrow \infty} E_{t} b_{T+1}=b^{*}$, so debt eventually returns to steady state.

Digging into exactly what fiscal policy does to stabilize debt reveals the underlying policy interactions. Suppose that at time $t$ news arrives of a higher path for $\left\{\varepsilon_{t+j}^{M}\right\}$. This news reduces $\nu_{t}$, raising the price level $P_{t}$. With fiscal rule (8), in the first instance the monetary news leaves $s_{t}$ unaffected, but household holdings of outstanding bonds, $B_{t-1} / P_{t}$, decline. From the government budget identity, this implies that the market value of debt issued at $t$ also falls, even if there is no change in the price of bonds, $1 / R_{t}$

$$
\frac{B_{t}}{P_{t} R_{t}}=-s_{t}+\frac{B_{t-1}}{P_{t}}
$$

In the absence of future fiscal adjustments - such as those in which $\gamma>\beta^{-1}-1$ household wealth would decline, reducing aggregate demand and counteracting the inflationary effect of the monetary expansion. But when fiscal policy reduces surpluses with debt by more than the real interest rate, surpluses are expected to fall by an amount equal in present value to the initial drop in the value of household bond holdings. This eliminates the negative wealth effect to render monetary policy expansionary.

When the news of higher $\left\{\varepsilon_{t+j}^{M}\right\}$ extends beyond the current period, the nominal interest rate rises, reducing the price of new bonds at $t$. Lower bond prices implicitly raise interest yields on these bonds that mature in period $t+1$ to create a second channel by which monetary policy affects household wealth. As with the first channel, though, these wealth effects evaporate with the expected adjustments in surpluses.

These fiscal adjustments connect to Wallace's (1981) point that the impacts of openmarket operations hinge on the sense in which fiscal policy is "held constant." In regime $\mathrm{M}$, the "constancy" of fiscal policy is quite specific: it eliminates any monetary effects on balance sheets. By neutralizing the fiscal consequences of monetary policy actions, this regime leaves the impression that, in Friedman's (1970) famous aphorism, "inflation is always and everywhere a monetary phenomenon." Of course, it is the joint behavior of monetary and fiscal policies that delivers this impression.

Regime M also delivers the fiscal counterpart to Friedman's aphorism: Ricardian equiv- 
alence. ${ }^{13}$ A fiscal shock at $t$ that reduces the surplus by one unit is financed initially by an expansion in nominal debt of $P_{t}$ units. With inflation pinned down by expression (11), real debt also increases by $P_{t}$ units. Higher real debt, through the fiscal rule, triggers higher future surpluses whose present value equals the original debt expansion. Even in this completely standard Ricardian experiment, it is the joint policy behavior-monetary policy's aggressive response to inflation and fiscal policy's passive adjustment of surpluses - that produces the irrelevance result.

\subsubsection{Regime F}

Consider the case in which fiscal policy is active, with exogenous surpluses, so $\gamma=0$ to make the fiscal rule is $s_{t}=s^{*}+\varepsilon_{t}^{F}$. The solution for real debt is ${ }^{14}$

$$
\frac{b_{t}}{R_{t}}=\frac{b^{*}}{R^{*}}+\sum_{j=1}^{\infty} \beta^{j} E_{t} \varepsilon_{t+j}^{F}
$$

which implies that the value of debt at $t$ depends on the expected present value of surpluses from $t+1$ onward.

We can solve for inflation by combining this solution for $b_{t}$ with the government's flow budget identity, noting that $B_{t-1} / P_{t}=\nu_{t} b_{t-1}$

$$
\nu_{t}=\frac{(1-\beta)^{-1} s^{*}+\sum_{j=0}^{\infty} \beta^{j} E_{t} \varepsilon_{t+j}^{F}}{b_{t-1}}
$$

where at $t, b_{t-1}$ is predetermined, which produces the solution for the price level

$$
P_{t}=\frac{B_{t-1}}{(1-\beta)^{-1} s^{*}+\sum_{j=0}^{\infty} \beta^{j} E_{t} \varepsilon_{t+j}^{F}}
$$

News of lower surpluses raises the price level and reduces the value of outstanding debt. In contrast to regime $\mathrm{M}$ equilibria, in regime $\mathrm{F}$ nominal government debt is an important state variable. ${ }^{15}$ Higher nominal debt or higher debt service raise the price level next period. These results reflect the impacts of higher nominal household wealth. Lower future surpluses-

\footnotetext{
${ }^{13}$ Tobin (1980, p. 53) made this point: "Thus the Ricardian equivalence theorem is fundamental, perhaps indispensable, to monetarism."

${ }^{14}$ To derive (12), define $\tilde{b}_{t} \equiv B_{t} / P_{t} R_{t}$ to write the flow government budget identity as $\tilde{b}_{t}+s_{t}=R_{t-1} \nu_{t} \tilde{b}_{t-1}$. Take expectations at $t-1$, apply the Euler equation $\beta^{-1}=E_{t-1} R_{t-1} \nu_{t}$, iterate forward, and impose transversality to obtain (12).

${ }^{15}$ Debt is also a state variable in regime $\mathrm{M}$ because it contains information about future surpluses. But in $\mathrm{M}$, changes in the real value of debt induce changes in expectations of future real government claims on private resources.
} 
stemming from either lower taxes or higher transfers - or higher initial nominal assets, raise households' demand for goods when there is no prospect that future taxes will rise to offset the higher wealth. Unlike regime M, now equilibrium inflation, as given by (13), depends explicitly on current and expected fiscal choices - through the steady state surplus, $s^{*}$, and fiscal disturbances, $\sum_{j=0}^{\infty} \beta^{j} E_{t} \varepsilon_{t+j}^{F}$.

Expression (12) gives the real market value of debt. But in the absence of any stabilizing response of surpluses to real debt $(\gamma=0)$, debt's deviations from steady state are expected to grow over time at the real rate of interest, $1 / \beta$, according to (10). Such growth in debt would violate the household's transversality condition, which is inconsistent with equilibrium. To reconcile these seemingly contradictory implications of the equilibrium, we need to understand the role that monetary policy plays in regime $\mathrm{F}$.

Monetary policy ensures that actual debt, as opposed to expected debt, is stable by preventing interest payments on the debt from exploding and permitting surprise inflation to revalue government debt. In regime F, higher interest payments raise nominal wealth, increasing nominal aggregate demand and future inflation, as both (13) and (14) indicate. To understand monetary policy behavior, substitute the solution for $\nu_{t}$ from (13) into the monetary policy rule, (7). To simplify the expression, assume that the policy shocks are i.i.d. so that

$$
\frac{1}{R_{t}}-\frac{1}{R^{*}}=\frac{\alpha_{\pi}}{\beta}\left[\frac{\beta(1-\beta)^{-1} s^{*}+\beta \varepsilon_{t}^{F}}{b_{t-1}}-\frac{1}{R^{*}}\right]+\varepsilon_{t}^{M}
$$

In response to a fiscal expansion- $\varepsilon_{t}^{F}<0$ - the central bank reduces $1 / R_{t}$ by $\alpha_{\pi} \varepsilon_{t}^{F}$ to lean against the fiscally-induced inflation. A serially uncorrelated fiscal disturbance leaves the market value of debt at its steady state, $b_{t+j} / R_{t+j}=b^{*} / R^{*}$ for $j \geq 0$. This greatly simplifies the time $t+1$ version of (15) to yield

$$
\frac{1}{R_{t+1}}-\frac{1}{R^{*}}=\frac{\alpha_{\pi}}{\beta}\left(\frac{1}{R_{t}}-\frac{1}{R^{*}}\right)
$$

If monetary policy were to respond aggressively to inflation by setting $\alpha_{\pi} / \beta>1,1 / R$ would diverge to positive or negative infinity, both situations that violate lower bound conditions on the net, $R-1$, nominal interest rate. Economically, these exploding paths stem from strong wealth effects that arise from ever-growing interest receipts to holders of government bonds. When $\alpha_{\pi} / \beta>1$ the central bank raises the nominal interest rate by a factor that exceeds the real interest rate, which increases private agents' nominal wealth and inflation in the next period; this process repeats in subsequent periods. Active monetary policy essentially converts stable fiscally-induced inflation into explosive paths.

Existence of equilibrium requires that the monetary reaction to inflation not be too 
strong - specifically, that $\alpha_{\pi} / \beta<1$, what is called "passive monetary policy." A pegged nominal interest rate, $\alpha_{\pi}=0$, is the easiest case to understand. By holding the nominal rate fixed at $R^{*}$, monetary policy prevents the fiscal expansion from affecting future inflation by fixing interest payments on the debt. A one-time reduction in $s_{t}$ that is financed by new nominal bond sales, raises $P_{t}$ enough to keep $B_{t} / P_{t}$ unchanged. But the higher price level also reduces the real value of existing nominal debt, $B_{t-1} / P_{t}$, and in doing so reduces the implicit real interest payments. In terms of the flow budget identity

$$
\frac{b^{*}}{R^{*}}+s_{t}=\frac{B_{t-1}}{P_{t}}
$$

where real debt remains at steady state because $\gamma=0$ implies that expected surpluses are unchanged. The larger is the stock of outstanding debt, the less the price level must rise to keep the budget in balance.

More interesting results emerge when there is some monetary policy response to inflation$0<\alpha_{\pi}<\beta{ }^{16}$ When monetary policy tries to combat fiscal inflation by raising the nominal interest rate, inflation is both amplified and propagated. Pegging $R_{t}$ forces all inflation from a fiscal shock to occur at the time of the shock. Raising $R_{t}$ permits the inflation to persist and the more strongly monetary policy reacts to inflation, the longer the inflation lasts.

Difference equations (15) and (16) make the monetary policy impacts clear. When $\alpha_{\pi}=0$, a shock to $\varepsilon_{t}^{F}$ has no effect on the nominal interest rate. But the larger is $\alpha_{\pi}$, though still less than $\beta$, the stronger are the effects of $\varepsilon_{t}^{F}$ on future nominal interest rates and, through the Fisher relation, future inflation.

Even though the transitory fiscal expansion has no effect on real debt, higher nominal rates bring forth new nominal bond issuances that are proportional to the increases in the price level. Higher nominal debt coupled with higher interest on the debt increase interest payments that raise household nominal wealth in the future. Because future taxes do not rise to offset that wealth increase, aggregate demand and the price level rise in the future.

Expression (15) reveals that an exogenous monetary contraction-lower $\varepsilon_{t}^{M}$ that raises $R_{t}$-triggers exactly the same macroeconomic effects as an exogenous fiscal expansion. Higher interest rates raise debt service and nominal wealth, which increases inflation in the future. In this simple model with a fixed real interest rate, only this perverse implication for monetary policy obtains. We shall discuss the effects of monetary policy contractions in a production economy with longer-maturity debt in section below. ${ }^{17}$

\footnotetext{
${ }^{16}$ Impulse responses to this case are considered in section 2.3 below.

${ }^{17}$ The result that a monetary contraction raises future inflation is reminiscent of Sargent and Wallace's (1981) unpleasant monetarist arithmetic, but the mechanism is completely different. In Sargent and Wallace, tighter money today implies looser money in the future and the higher future inflation can feed back to reduce
} 


\subsection{The Role of Maturity Structure}

Tobin (1963) discusses debt management in the context of the "monetary effect of the debt," contrasting this to the "direct fiscal effect" that is determined by the initial increase in the bond-financed deficit. The monetary effect stems from the maturity structure of the debt, which Tobin reasons outlasts the direct effects because it endures over the maturity horizon of the debt. Changes in the maturity composition of debt operate through impacts on the size and composition of private wealth and such changes can affect the macro economy, even if they do not entail changing the overall size of the debt. This section obtains closely related impacts from maturity structure in regime $\mathrm{F}$.

The section introduces a full maturity structure of government debt in general form to derive the bond valuation equation and develop some intuition about the role that maturity plays in the endowment economy in regime F. It then uses a simple special case to make transparent the mechanisms at work in regime $\mathrm{F} .{ }^{18}$

\subsubsection{A General Maturity Structure}

Let $B_{t}(t+j)$ denote the nominal quantity of zero-coupon bonds outstanding in period $t$ that matures in period $t+j$ and let the dollar-price of those bonds be $Q_{t}(t+j)$. The government's flow budget identity at $t$ is

$$
B_{t-1}(t)-\sum_{j=1}^{\infty} Q_{t}(t+j)\left[B_{t}(t+j)-B_{t-1}(t+j)\right]=P_{t} s_{t}
$$

In a constant-endowment economy, the bond pricing equations are

$$
Q_{t}(t+k)=\beta^{k} E_{t} \frac{P_{t}}{P_{t+k}}
$$

for $k=1,2, \ldots$. These pricing equations imply the no-arbitrage condition that links the price of a $k$-period bond to the expected sequence of $k 1$-period bonds

$$
Q_{t}(t+k)=E_{t}\left[Q_{t}(t+1) Q_{t+1}(t+2) \cdot \ldots \cdot Q_{t+k-1}(t+k)\right]
$$

To derive the bond valuation equation with a general maturity structure, define

$$
B_{t-1} \equiv B_{t-1}(t)+\sum_{j=1}^{\infty} Q_{t}(t+j) B_{t-1}(t+j)
$$

money demand today. Their result does not stem from wealth effects of monetary policy.

${ }^{18}$ These derivations draw on Cochrane $(2001,2014)$. 
as the portfolio of bonds outstanding at the end of period $t-1$, and rewrite the government budget identity as

$$
\frac{B_{t-1}}{P_{t}}=Q_{t}(t+1) \frac{B_{t}}{P_{t}}+s_{t}
$$

Iterating on this bond portfolio version of the constraint, taking expectations and imposing the bond-pricing relations and the consumer's transversality condition yields the valuation equation

$$
\frac{B_{t-1}}{P_{t}}=\sum_{j=0}^{\infty} \beta^{j} E_{t} s_{t+j}
$$

or, in terms of the underlying bonds

$$
\frac{B_{t-1}(t)}{P_{t}}+\sum_{j=1}^{\infty} \beta^{j} E_{t} \frac{B_{t-1}(t+j)}{P_{t+j}}=\sum_{j=0}^{\infty} \beta^{j} E_{t} s_{t+j}
$$

Use (18) to repeatedly substitute out future price levels to make explicit how maturity structure enters the valuation equation

$$
\begin{aligned}
& \frac{B_{t-1}(t)}{P_{t}}=E_{t}\{s_{t}+\beta \underbrace{\left[1-\frac{B_{t-1}(t+1)}{B_{t}(t+1)}\right]}_{\text {weight on } t+1} s_{t+1} \\
& +\beta^{2} \underbrace{\left\{1-\left[\frac{B_{t-1}(t+2)}{B_{t+1}(t+2)} \frac{B_{t-1}(t+1)}{B_{t}(t+1)}\left(1-\frac{B_{t}(t+2)}{B_{t+1}(t+2)}\right)\right]\right\}}_{\text {weight on } t+2} s_{t+2}+\ldots\}
\end{aligned}
$$

We write this valuation equation more compactly by defining

$$
\Lambda_{t}(t+k) \equiv \frac{B_{t}(t+k)-B_{t-1}(t+k)}{B_{t+k-1}(t+k)}
$$

as newly issued debt that matures in period $t+k$ as a share of total outstanding debt in period $t+k-1$ that matures at $t+k$. We can now define the maturity weight on the surplus 
at $t+k, L_{t, t+k}$, as depending recursively on these ratios

$$
\begin{aligned}
L_{t, t} & =1 \\
L_{t, t+1} & =\Lambda_{t}(t+1) \\
L_{t, t+2} & =\Lambda_{t+1}(t+2) L_{t, t+1}+\Lambda_{t}(t+2) \\
L_{t, t+3} & =\Lambda_{t+2}(t+3) L_{t, t+2}+\Lambda_{t+1}(t+3) L_{t, t+1}+\Lambda_{t}(t+3) \\
\vdots & \\
L_{t, t+k} & =\sum_{j=0}^{k-1} \Lambda_{t+j}(t+k) L_{t, t+j}
\end{aligned}
$$

The compact form of valuation equation (19) is now

$$
\frac{B_{t-1}(t)}{P_{t}}=\sum_{j=0}^{\infty} \beta^{j} E_{t}\left[L_{t, t+j} s_{t+j}\right]
$$

Given a sequence of surpluses, $\left\{s_{t}\right\}$, discount factors and maturity determine the expected present value of surpluses. Shortening maturity (e.g., reducing $\left.\frac{B_{t-1}(t+1)}{B_{t}(t+1)}\right)$ raises the weights on $s_{t+1}, s_{t+2}, s_{t+3}$, raising that present value - the backing of debt-and the value of debt. Shortening maturity of bonds due at $t+k$ raises weights on all $s_{t+j}, j \geq k$. In this sense, shortening maturity can offset a decline in surpluses.

Surprise changes in future maturity structure appears as innovations in the weights, $L_{t, t+j}$, in valuation equation (20). If primary surpluses are given, an unanticipated shortening of maturity of bonds held by the public would, by raising the value of outstanding debt, reduce the current price level. Viewed through the lens of the fiscal theory, the Federal Reserve's "operation twist" in 2011 would have a contractionary effect on the economy initially. ${ }^{19}$ As the example to which we now turn illustrates, the lower price level at $t$ would ultimately be offset by a higher future price level.

\subsubsection{An Illustrative Example}

To cleanly illustrate the role that changes in maturity structure play in determining the timing of inflation, we examine an example from Cochrane (2014). We use the same constant endowment economy, but it operates only in periods $t=0,1,2$ and then ends; we set the real interest rate to zero, so the discount factor is $\beta=1$. The government issues one- and

\footnotetext{
${ }^{19}$ The premise of the Fed's actions was that if short and long bonds are imperfect substitutes, then increasing demand for long bonds would reduce long-term interest rates. Lower long rates, it was hoped, would stimulate business investment and the housing market.
} 
two-period nominal bonds at the beginning of time, $t=0$, denoted by $B_{0}(1)$ and $B_{0}(2)$, and uses surpluses in periods 1 and $2, s_{1}$ and $s_{2}$, to retire the debt. At date $t=1$ the government may choose to issue new one-period debt, $B_{1}(2)$, so the change in debt at $t=1$ is $B_{1}(2)-B_{0}(2)$. The three potentially different quantities of bonds sell at nominal prices $Q_{0}(1), Q_{0}(2), Q_{1}(2)$ that obey (17) with $\beta=1 .^{20}$

Given initial choices of debt, $B_{0}(1)$ and $B_{0}(2)$, the government's budget identities in periods 1 and 2 are

$$
\begin{aligned}
& B_{0}(1)=P_{1} s_{1}+Q_{1}(2)\left[B_{1}(2)-B_{0}(2)\right] \\
& B_{1}(2)=P_{2} s_{2}
\end{aligned}
$$

When primary surpluses are given at $\left\{s_{1}, s_{2}\right\}$, expression (22) immediately yields the price level in period 2 as

$$
\frac{B_{1}(2)}{P_{2}}=s_{2}
$$

because $B_{1}(2)$ is predetermined in period 2 .

Now impose the asset-pricing relations on the bond prices in the period 1 government budget identity, (21), to obtain the bond valuation equation

$$
\frac{B_{0}(1)}{P_{1}}=s_{1}+\left[\frac{B_{1}(2)-B_{0}(2)}{B_{1}(2)}\right] E_{1} s_{2}
$$

$P_{1}$ depends on the choice of newly issued bonds in period 1 .

Solving for expected inflation and bond prices yields

$$
\begin{aligned}
& E_{0}\left(\frac{1}{P_{2}}\right)=Q_{0}(2)=E_{0}\left(\frac{s_{2}}{B_{1}(2)}\right)=E_{0}\left[\frac{1}{B_{0}(2)+\left(B_{1}(2)-B_{0}(2)\right)}\right] s_{2} \\
& E_{0}\left(\frac{1}{P_{1}}\right)=Q_{0}(1)=\frac{E_{0}\left[s_{1}\right]}{B_{0}(1)}+\frac{1}{B_{0}(1)} E_{0}\left[\frac{B_{1}(2)-B_{0}(2)}{B_{1}(2)}\right] s_{2}
\end{aligned}
$$

So the term structure of interest rates also depends on choices about maturity structure.

We can derive more explicitly solutions for the actual or realized price level at $t=1$ in terms of innovations

$$
B_{0}(1)\left(E_{1}-E_{0}\right)\left(\frac{1}{P_{1}}\right)=\left(E_{1}-E_{0}\right) s_{1}+\left(E_{1}-E_{0}\right)\left(\frac{B_{1}(2)-B_{0}(2)}{B_{1}(2)}\right) s_{2}
$$

Surprise increases in the price level in period 1 depend negatively on innovations in time 1 and time 2 surpluses and on unexpected lengthening of the maturity of bonds due in period

\footnotetext{
${ }^{20}$ We normalize the initial price level to be $P_{0}=1$.
} 
2.

These derivations show that the government can achieve any path of the nominal term structure - and in this example, expected inflation - that it wishes by adjusting maturity structure. By unexpectedly selling less time-2 debt, the government reduces the claims to time-2 surpluses, which reduces the revenues that can be used to payoff period-1 bonds. This raises inflation in period 1 . That increase in inflation comes from reducing $B_{1}(2)$, which lowers the price level in period 2, as seen from

$$
\left(E_{1}-E_{0}\right)\left(\frac{B_{1}(2)}{P_{2}}\right)=\left(E_{1}-E_{0}\right) s_{2}
$$

If $s_{2}$ is given, selling less $B_{1}(2)$ requires $P_{2}$ to fall.

\subsubsection{A Useful Special Case}

Suppose that the maturity structure declines at a constant rate $0 \leq \rho \leq 1$ each period so that the pattern of bonds issued at $t-1$ obeys

$$
B_{t-1}(t+j)=\rho^{j} B_{t-1}^{m}
$$

where $B_{t-1}^{m}$ is the portfolio of these specialized bonds in $t-1$. When $\rho=0$ all bonds are one-period, whereas when $\rho=1$ all bonds are consols. The average maturity of the portfolio is $1 /(1-\beta \rho)$.

With this specialization, the government's flow constraint is

$$
B_{t-1}^{m}\left[1-\sum_{j=1}^{\infty} Q_{t}(t+j) \rho^{j}\right]=P_{t} s_{t}+B_{t}^{m} \sum_{j=1}^{\infty} Q_{t}(t+j) \rho^{j-1}
$$

If we define the price of the bond portfolio as

$$
P_{t}^{m} \equiv \sum_{j=1}^{\infty} Q_{t}(t+j) \rho^{j-1}
$$

then the government's budget identity becomes

$$
B_{t-1}^{m}\left(1+\rho P_{t}^{m}\right)=P_{t} s_{t}+P_{t}^{m} B_{t}^{m}
$$

Bond portfolio prices obey the recursion

$$
P_{t}^{m}=Q_{t}(t+1)\left[1+\rho E_{t} P_{t+1}^{m}\right]=R_{t}^{-1}\left[1+\rho E_{t} P_{t+1}^{m}\right]
$$


This shows that a constant geometric decay rate in the maturity structure of zero-coupon bonds is equivalent to the interpretation of bonds that pay geometrically decaying coupon payments, as in Woodford (2001) and Eusepi and Preston (2013).

Let $R_{t+1}^{m}$ denote the gross nominal return on the bond portfolio between $t$ and $t+1$. Then $R_{t+1}^{m}=\left(1+\rho P_{t+1}^{m}\right) / P_{t}^{m}$ and the no-arbitrage condition implies that

$$
\frac{1}{R_{t}}=\beta E_{t} \nu_{t+1}=E_{t}\left(\frac{1}{R_{t+1}^{m}}\right)
$$

Combining (24) and (25) and iterating forward connects bond prices to expected paths of the short-term nominal interest rate and inflation

$$
P_{t}^{m}=\sum_{j=0}^{\infty} \rho^{j} E_{t}\left(\prod_{i=0}^{j} R_{t+i}^{-1}\right)=\beta \sum_{j=0}^{\infty}(\beta \rho)^{j} E_{t}\left(\prod_{i=0}^{j} \nu_{t+i+1}\right)
$$

\subsection{Maturity Structure in Regime F}

Ricardian equivalence in regime $\mathrm{M}$ makes the maturity structure of debt irrelevant for inflation, so in this section we focus solely on regime F. When surpluses are exogenous $(\gamma=0)$, the debt valuation equation becomes ${ }^{21}$

$$
\frac{\left(1+\rho P_{t}^{m}\right) B_{t-1}^{m}}{P_{t}}=(1-\beta)^{-1} s^{*}+\sum_{j=0}^{\infty} \beta^{j} E_{t} \varepsilon_{t+j}^{F}
$$

In contrast to the situation with only one-period debt $(\rho=0)$ when fiscal news appeared entirely in jumps in the price level, now there is an additional channel through which debt can be revalued: bond prices that reflect expected inflation over the entire duration of debt. News of lower future surpluses reduces the value of debt through both a higher $P_{t}$ and a lower $P_{t}^{m}$. By (26), the lower bond price portends higher inflation and higher one-period nominal interest rates. The ultimate mix between current and future inflation is determined by the monetary policy rule. Long-term debt opens a new channel for monetary and fiscal policy to interact.

No-arbitrage condition (26) reveals a key aspect of regime F equilibria with long debt. With the simplified maturity structure, $\rho$ determines the average maturity of the zero-coupon bond portfolio. A given future inflation rate has a larger impact on the price of bonds, the larger is $\rho$ or the longer is the average maturity of debt. The maturity parameter serves as an

\footnotetext{
${ }^{21}$ To derive (20), convert the nominal budget identity in (23) into a difference equation in the real value of debt, $P^{m} B^{m} / P$, impose pricing equations (24) and (25), using the fact that $\beta^{-1}=E_{t-1}\left[\nu_{t}\left(1+\rho P_{t}^{m}\right) / P_{t-1}^{m}\right]$, iterate forward and impose the household's transversality condition for debt.
} 
additional discount factor, along with $\beta$, so more distant inflation rates have a smaller impact on bond prices than do rates in the near future. Of course, the date $t$ expected present value of inflation influences only the price of bonds that are outstanding at the beginning of $t$, namely, $B_{t-1}^{m}$.

To understand monetary policy's influence on the timing of inflation, note that when monetary policy is passive, $\alpha_{\pi} / \beta<1$, (9) implies that $k$-step-ahead expected inflation is

$$
E_{t} \nu_{t+k}=\left(\frac{\alpha_{\pi}}{\beta}\right)^{k}\left(\nu_{t}-\nu^{*}\right)+\nu^{*}
$$

which may be substituted into the pricing equation that links $P_{t}^{m}$ to the term structure of inflation rates, $(26)$, to yield ${ }^{22}$

$$
\rho P_{t}^{m}=\sum_{j=1}^{\infty}(\beta \rho)^{j} E_{t}\left\{\prod_{i=0}^{j-1}\left[\left(\frac{\alpha_{\pi}}{\beta}\right)^{i+1}\left(\nu_{t}-\nu^{*}\right)+\nu^{*}\right]\right\}
$$

Monetary policy's reaction to inflation - through $\alpha_{\pi}$-interacts with the average maturity of debt - $\rho$ - to determine how current inflation $-\nu_{t}$, which is given by (13) in regime F-affects the price of bonds. More aggressive monetary policy and longer maturity debt both serve to amplify the impact of current inflation on bond prices, suggesting that higher $\alpha_{\pi}$ and higher $\rho$ permit fiscal disturbances to have a smaller impact on current inflation at the cost of a larger impact on future inflation.

Consider two polar cases of passive monetary policy. When $\alpha_{\pi}=0$, so the central bank pegs the nominal interest rate and bond prices at $\rho P_{t}^{m}=\beta \rho \nu^{*} /\left(1-\beta \rho \nu^{*}\right)$, the valuation expression becomes

$$
\left(\frac{1}{1-\beta \rho \nu^{*}}\right) \nu_{t} b_{t-1}^{m}=(1-\beta)^{-1} s^{*}+\sum_{j=0}^{\infty} \beta^{j} E_{t} \varepsilon_{t+j}^{F}
$$

where we define $b_{t-1}^{m} \equiv B_{t-1}^{m} / P_{t-1}$. In this case, expected inflation returns to target immediately, $E_{t} \nu_{t+j}=\nu^{*}$ for $j \geq 1$.

The second case is when monetary policy reacts as strongly as possible to inflation, while still remaining passive: $\alpha_{\pi}=\beta .^{23}$ Then $\rho P_{t}^{m}=\beta \rho \nu_{t} /\left(1-\beta \rho \nu_{t}\right)$ and the valuation equation

\footnotetext{
${ }^{22}$ Here we shut down the exogenous monetary policy shock, $\varepsilon_{t}^{M} \equiv 0$.

${ }^{23}$ If monetary policy were to turn active while fiscal policy remained active then we would have an unstable equilibrium. The implications of temporarily being in such a regime are considered in Section 7.3.
} 
is $^{24}$

$$
\left(\frac{\nu_{t}}{1-\beta \rho \nu_{t}}\right) b_{t-1}^{m}=(1-\beta)^{-1} s^{*}+\sum_{j=0}^{\infty} \beta^{j} E_{t} \varepsilon_{t+j}^{F}
$$

Now inflation follows a martingale with $E_{t} \nu_{t+j}=\nu_{t}$ for $j \geq 1$.

The two polar cases are starkly different. By pegging the nominal interest rate, monetary policy anchors expected inflation on the steady state (target) inflation rate and bond prices are constant. The full impact of a lower present value of surpluses must be absorbed by higher current inflation - lower $\nu_{t}$-alone. But when monetary policy raises the nominal rate with current inflation by a proportion equal to the discount factor, higher current inflation is expected to persist indefinitely. Bond prices fall by the expected present value of that higher inflation rate, discounted at the rate $\beta \rho$. With the required change in inflation spread evenly over the term to maturity of outstanding debt, when fiscal news arrives, inflation needs to rise by far less than it does when bond prices are pegged. Of course, the "total" - present value -inflation effect of the fiscal shock is identical in the two cases. Although aggressive monetary policy cannot diminish the total inflationary impact, it can influence the timing of when inflation occurs.

We can consider both these polar cases and the intermediate case where $0<\alpha_{\pi}<\beta$, by solving the model numerically in the presence of transfer shocks. ${ }^{25}$ These are calibrated following Bi, Leeper, and Leith (2013). We assume that the steady-state ratio of transfersto-GDP is 0.18 , government spending is 21 percent of GDP and taxes amount to 41 percent of GDP implying an (annualized) steady state debt-GDP ratio of 50 percent. Transfers fluctuate according to an autoregressive process with persistence parameter of $\rho_{z}=0.9$, and variance of $\left(0.005 z^{*}\right)$. In this simple model with an active fiscal policy that does not respond to debt levels, the equilibrium outcome depends on the maturity of the debt stock and the responsiveness of monetary policy to inflation.

Figure 1 plots the response to an increase in transfers. Each column represents a different value of the response of monetary policy to inflation. Monetary policy pegs the nominal rate in the first column so the paths of all variables are the same across maturities: the entire adjustment occurs through surprise inflation in the initial period. In the second column $\alpha_{\pi}=0.5$. Now differences emerge across maturities. With one-period debt the magnitude of the initial jump in inflation is the same as under a pegged interest rate because this is the price level jump that is required to reduce the real value of debt to be consistent with lower surpluses. But the monetary policy reaction keeps inflation high for a prolonged period even

\footnotetext{
${ }^{24}$ This result requires that $\beta \rho \nu_{t}<1$ for all realizations of $\nu_{t}$, so there cannot be "too much" deflation.

${ }^{25}$ The solution procedure follows Leith and Liu (2014), which relies on Chebyshev collocation methods and Guass-Hermite quadrature to evaluate the expectations terms.
} 
though it is only the initial jump in inflation that serves to reduce the debt burden. As average maturity increases, the initial jump in inflation becomes smaller. A sustained rise in interest rates depresses bond prices, which allow the bond valuation equation to be satisfied at lower initial inflation rates. It is the surprise change in the path of inflation that occurs over the life of the maturing debt stock that reduces the real value of debt. With a positive value of $\alpha_{\pi}$, any jump in inflation is sustained, which unexpectedly reduces the real returns that bondholders receive before that debt is rolled over. As we increase the responsiveness of interest rate to inflation further to $\alpha_{\pi}=0.9$, the surprise inflation needed to deflate the real value of debt remains unchanged for single period debt, but is dramatically reduced for longer period debt. When $\alpha_{\pi}=0.99$, as demonstrated analytically above, and $\rho>0$, the rate of inflation follows a near-random walk, jumping to the level needed to satisfy the valuation equation.
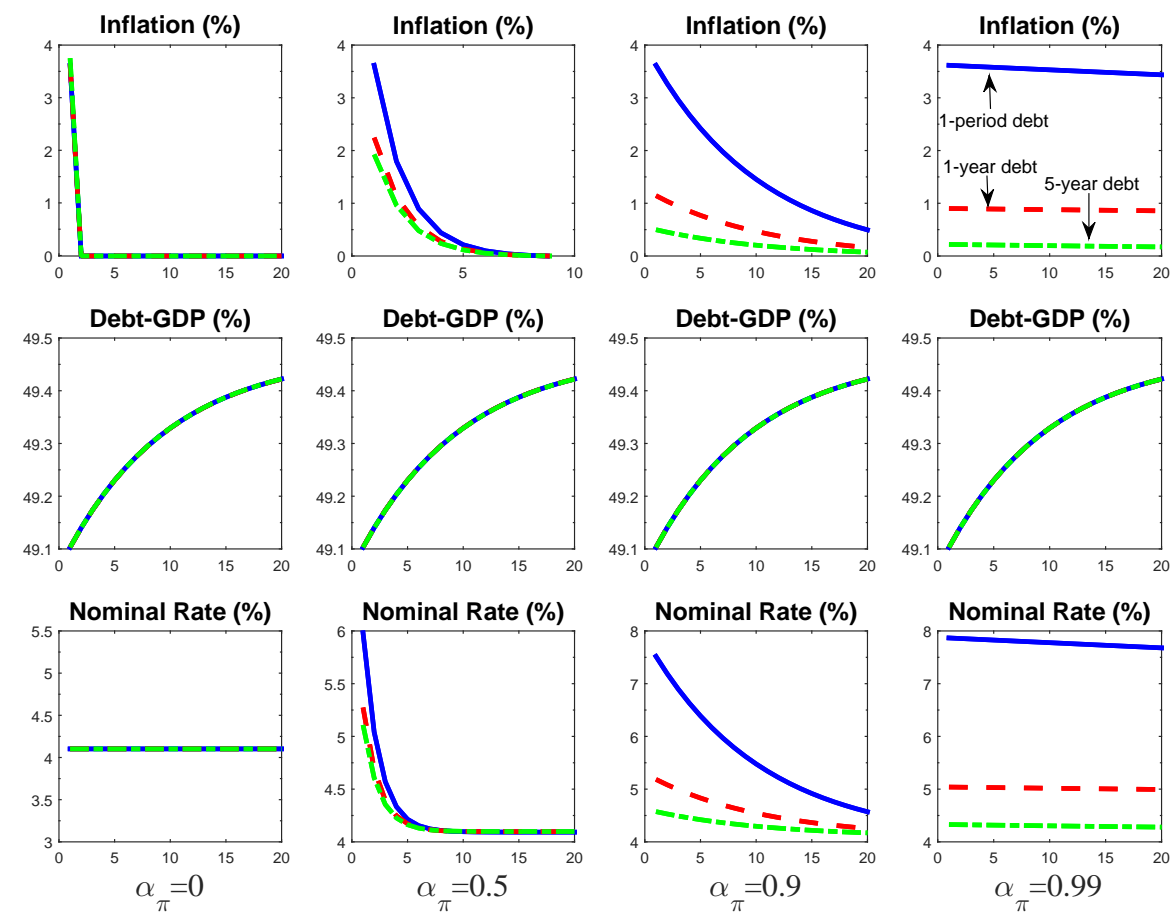

Figure 1: Responses to an increase in transfers under alternative monetary policy rules and alternative maturity structures.

The timing of the transfer shock - whether it is i.i.d. or persistent, realized immediately or in the future - doesn't matter beyond the change in the expected discounted value of surpluses that it produces. That present value must be financed with a path of inflation that combines current inflation surprises, and through bond prices, future inflation surprises, to ensure solvency. An anticipated increase in transfers produces surprise inflation today that 
reduces the current value of the outstanding debt stock, but whose value increase after the increase in transfers is realized.

This result foreshadows an important aspect of optimal policy, which sections 4 and 5 explore: monetary policy can smooth the distortionary effects of fiscally-induced inflation. The above analysis uses an endowment economy subjected to transfer shocks. That environment has the feature that under regime $\mathrm{M}$, monetary policy can perfectly control inflation, while under regime F, prices are determined by the needs of fiscal solvency - the dichotomy across regimes that was emphasized in the original fiscal theory. The more general case breaks the dichotomy to produce interactions between monetary and fiscal policy in both policy regimes. This situation can arise even in the endowment economy when we consider government spending shocks rather than shocks to lump-sum transfers.

\subsubsection{InCREase in Government Spending}

Government spending has implications for both monetary and fiscal policy. The direct impact on the government's finances is obvious. But given the resource constraint, $y=c_{t}+g_{t}$, variations in public consumption will have a one-for-one impact on private consumption which affects the stochastic discount factor. Through this channel government purchases carry additional effects on inflation and debt dynamics. Again we distinguish between the $\mathrm{M}$ and $\mathrm{F}$ regimes, although monetary and fiscal policy will interact under both.

\subsubsection{Policy Under Regime $M$}

When monetary policy is active and fiscal policy is passive, the analysis of the case of transfer shocks largely carries through, although with some additional monetary and fiscal interactions. Substituting the Fisher relation into the monetary policy rule yields the deflation dynamics $^{26}$

$$
v_{t}-v^{*}=\frac{\beta}{\alpha_{\pi}} E_{t}\left[\frac{u^{\prime}\left(c_{t+1}\right)}{u^{\prime}\left(c_{t}\right)} v_{t+1}-v^{*}\right]
$$

which can be solved forward as

$$
v_{t}=\frac{\alpha_{\pi}-\beta}{\alpha_{\pi}} E_{t} \sum_{i=0}^{\infty}\left(\frac{\beta}{\alpha_{\pi}}\right)^{i} \frac{u^{\prime}\left(c_{t+i}\right)}{u^{\prime}\left(c_{t}\right)} v^{*}
$$

\footnotetext{
${ }^{26}$ When the real interest rate can vary, the Fisher relation is

$$
\frac{1}{R_{t}}=\beta E_{t} \frac{u^{\prime}\left(c_{t+1}\right)}{u^{\prime}\left(c_{t}\right)} \nu_{t+1}
$$
}


Inflation deviates from target in proportion to the deviations of the real interest rate path from steady state. Higher government spending raises the real interest rate and inflation.

Debt dynamics emerge from three distinct impacts of government spending: the direct effect on the fiscal surplus, the surprise inflation that arises in conjunction with the monetary policy rule, and movements in real interest rates. Monetary policy can insulate inflation from government spending shocks by reacting to real interest rates, as well as inflation, with the rule

$$
\frac{1}{R_{t}}=\frac{1}{R^{*}} E_{t} \frac{u^{\prime}\left(c_{t+1}\right)}{u^{\prime}\left(c_{t}\right)}+\alpha_{\pi}\left(\nu_{t}-\nu^{*}\right)
$$

By this rule, the policymaker accommodates changes in the natural rate of interest caused by fluctuations in public consumption without deviating from the inflation target. To see this, combine this rule with the Fisher equation to get

$$
v_{t}-v^{*}=\frac{\beta}{\alpha_{\pi}} E_{t} \frac{u^{\prime}\left(c_{t+1}\right)}{u^{\prime}\left(c_{t}\right)}\left(v_{t+1}-v^{*}\right)
$$

Policy rule (27) implies that inflation/deflation is always equal to target, $v_{t}=v^{*}$. If the monetary policy rule does not respond to fiscal variables, inflation will be influenced by government spending shocks. Inflation can be insulated from fiscal shocks by allowing monetary policy to directly respond to the effects of fiscal policy on the natural rate of interest.

\subsubsection{Policy Under Regime F}

In regime $\mathrm{F}$ government spending shocks require jumps in inflation to satisfy the bond valuation equation ${ }^{27}$

$$
\begin{aligned}
\left(1+\rho P_{t}^{m}\right) \frac{B_{t-1}^{m}}{P_{t}} & =E_{t} \sum_{i=0}^{\infty} \beta^{i} \frac{u^{\prime}\left(c_{t+i}\right)}{u^{\prime}\left(c_{t}\right)} s_{t+i} \\
& =E_{t} \sum_{i=0}^{\infty} \beta^{i} \frac{u^{\prime}\left(c_{t+i}\right)}{u^{\prime}\left(c_{t}\right)} s^{*}-E_{t} \sum_{i=0}^{\infty} \beta^{i} \frac{u^{\prime}\left(c_{t+i}\right)}{u^{\prime}\left(c_{t}\right)} \varepsilon_{t+i}^{G}
\end{aligned}
$$

An increase in government spending increases the marginal utility of consumption, which increases real interest rates and requires a larger initial jump in inflation and drop in bond prices. Bond prices themselves are directly affected by the change in private consumption that arises when the government absorbs a larger share of resources, as the bond-pricing equation shows

$$
P_{t}^{m}=\beta E_{t}\left(1+\rho P_{t+1}^{m}\right) v_{t+1} \frac{u^{\prime}\left(c_{t+1}\right)}{u^{\prime}\left(c_{t}\right)}
$$

\footnotetext{
${ }^{27}$ Shutting down shocks to lump-sum taxes and transfers, the surplus is defined as $s_{t}=\tau^{*}-z^{*}-g_{t}$, where $g_{t}=g^{*} \varepsilon_{t}^{G}$, and $\ln \varepsilon_{t}^{g}=\rho_{g} \ln \varepsilon_{t-1}^{g}+\xi_{t}$.
} 
Bond prices fall initially and then gradually increase as the period of raised public consumption passes.

Adopting a specific form of utility, $u\left(c_{t}\right)=c_{t}^{1-\sigma} /(1-\sigma)$, with $\sigma=2$, we can solve the model in the face of autocorrelated government spending shocks with $\rho_{g}=0.9$, and variance of $0.005 g^{*}$. As before, the stochastic model is solved non-linearly using Chebyshev collocation methods [see Leith and Liu (2014)]. Figure 2 reflects the response to government spending shocks which are broadly consistent with the impacts of transfer shocks that appear in figure 1. The main difference is that the growth in consumption as government spending returns to steady state is equivalent to an increase in the real interest rate. However the main message that single period debt requires an initial jump in inflation to stabilize debt and that this jump is unaffected by the description of the monetary policy parameter $\alpha_{\pi}$ remains. However, once debt maturity extends beyond a single period prolonging the initial jump in inflation can serve to reduce the magnitude of that initial jump. That is a sustained rise in inflation can also serve to satisfy the government's intertemporal budget identity through reducing bond prices. Essentially the inflation surprise is spread throughout the life-to-maturity of the outstanding debt stock.
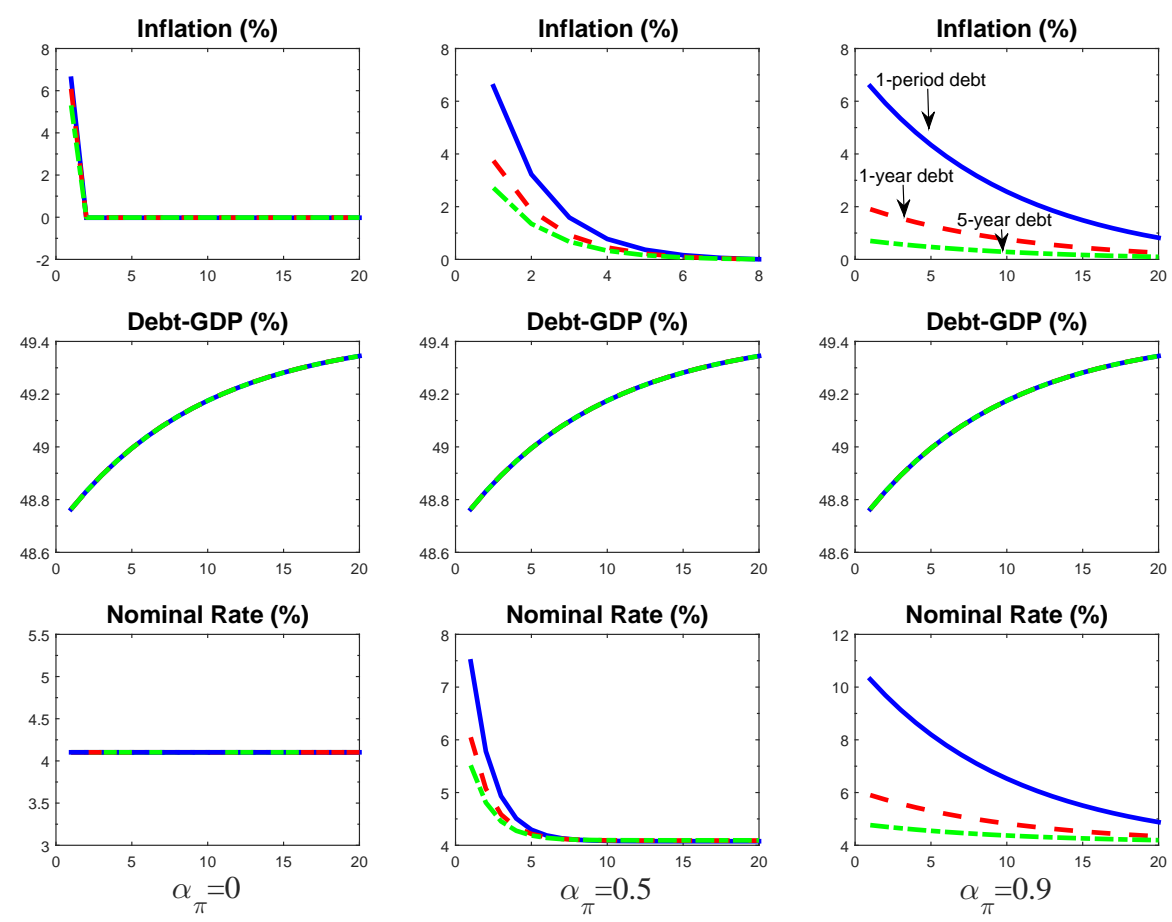

Figure 2: Responses to an increase in government purchases under alternative monetary policy rules and alternative maturity structures. 


\section{Production Economies with Ad Hoc Policy Rules}

The endowment economy is useful for understanding the mechanisms that underlie the fiscal theory. But the exogeneity of the real interest rate and the constancy of output limit a complete understanding of the theory and, in some cases, distort that understanding. We now turn to a conventional model in which inflation and output are determined jointly. In extending the analysis to the new Keynesian model we are widening the potential channels through which monetary and fiscal policy interact. To do so incrementally, we assume that taxes remain lump sum so that the effects of monetary policy on output do not affect the tax base to which a distortionary tax is applied. This means that the extra channel we are adding by introducing nominal inertia to a production economy is that monetary policy has influence over ex-ante real interest rates as well as nominal interest rates. This in turn means that the policymaker can ensure the bond valuation equation holds following fiscal shocks through a reduction in ex-ante real interest rates and not just ex-post real interest rates through inflation surprises. ${ }^{28}$ When we consider optimal policy in the new Keynesian model we shall allow taxes to distort behavior.

\subsection{A Conventional New Keynesian Model}

Endogenous output together with sticky prices allow both monetary policy and, in the case of regime F, fiscal policy to have real effects on the economy. We use a textbook version of a new Keynesian model of the kind that Woodford (2003) and Galí (2008) present. Because existing literature, including those two textbooks, thoroughly examines the nature of regime $\mathrm{M}$ equilibria, our exposition focuses exclusively on regime $\mathrm{F}^{29}$

The model's key features include: a representative consumer and firm; monopolistic competition in final goods; Calvo (1983) sticky prices in which a fraction $1-\phi$ of goods suppliers sets a new price each period; a cashless economy with one-period nominal bonds, $B_{t}$, that sell at price $1 / R_{t}$, where $R_{t}$ is also the monetary policy instrument; for now, government purchases are zero, so the aggregate resource constraint is $c_{t}=y_{t}$; an exogenous primary government surplus, $s_{t}$, with lump-sum taxes; and shocks only to monetary and fiscal policies. $^{30}$ We solve a version of the model that is log-linearized around the deterministic steady

\footnotetext{
${ }^{28}$ By introducing this channel we could, in fact, turn off the revaluation effects stressed by the fiscal theory by assuming debt was solely real but still consider equilibria where monetary policy was passive and fiscal active. In this sense, as we widen the range of monetary and fiscal interactions, unconventional policy assignments do not necessarily require the revaluation mechanisms inherent in the fiscal theory to support determinate equilibria.

${ }^{29}$ We draw from Woodford (1998a), but Kim (2003), Cochrane (2014) and Sims (2011) study closely related models.

${ }^{30}$ Because these shocks have no effects on the natural rate of output, there is no distinction between deviations in output from steady state and the output gap.
} 
state with zero inflation.

Let $\hat{x}_{t} \equiv \ln \left(x_{t}\right)-\ln \left(x^{*}\right)$ denote log-deviations of a variable $x_{t}$ from its steady state value. Private-sector behavior reduces to a consumption-Euler equation

$$
\widehat{y}_{t}=E_{t} \widehat{y}_{t+1}-\sigma\left(\hat{R}_{t}-E_{t} \hat{\pi}_{t+1}\right)
$$

and a Phillips curve

$$
\hat{\pi}_{t}=\beta E_{t} \hat{\pi}_{t+1}+\kappa \widehat{y}_{t}
$$

where $\sigma \equiv-\frac{u^{\prime}\left(y^{*}\right)}{u^{\prime \prime}\left(y^{*}\right) y^{*}}$ is the intertemporal elasticity of substitution, $\omega \equiv \frac{w^{\prime}\left(y^{*}\right)}{w^{\prime \prime}\left(y^{*}\right) y^{*}}$ is the elasticity of supply of goods, $\kappa \equiv \frac{(1-\phi)(1-\phi \beta)}{\phi} \frac{\omega+\sigma}{\sigma(\omega+\theta)}$ is the slope of the Phillips curve, and $\theta$ is the elasticity of substitution among differentiated goods. The parameters obey $0<\beta<$ $1, \sigma>0, \kappa>0$.

\subsubsection{Policy Rules}

Monetary policy follows a conventional interest rate rule

$$
\hat{R}_{t}=\alpha_{\pi} \hat{\pi}_{t}+\alpha_{y} \widehat{y}_{t}+\varepsilon_{t}^{M}
$$

and fiscal policy sets the surplus process, $\left\{\hat{s}_{t}\right\}$, exogenously, where $\hat{s}_{t} \equiv\left(s_{t}-s^{*}\right) / s^{*}$. By setting the surplus exogenously, we are implicitly assuming that taxes are lump sum so that any variations in real activity do not impact on the size of the tax base.

Policy choices must satisfy the flow budget identity, $\frac{1}{R_{t}} \frac{B_{t}}{P_{t}}+s_{t}=\frac{B_{t-1}}{P_{t}}$, which is linearized as,

$$
\hat{b}_{t}-\hat{R}_{t}+\left(\beta^{-1}-1\right) \hat{s}_{t}=\beta^{-1}\left(\hat{b}_{t-1}-\hat{\pi}_{t}\right)
$$

where $b_{t}$ is real debt at the end of period $t$ and $\pi_{t}$ is the inflation rate between $t-1$ and $t$. Although this linearized budget identity does not appear to contain the steady-state debt to GDP ratio, the calibration of the surplus shock does implicitly capture the underlying steady-state level of debt.

\subsubsection{Solving the Model in Regime F}

The four-equation system-(28)-(31) - together with exogenous $\left\{\hat{s}_{t}\right\}$ yields solutions for $\left\{\widehat{y}_{t}, \hat{\pi}_{t}, \hat{R}_{t}, \hat{b}_{t}\right\}$. Woodford (1998a) shows that a unique equilibrium requires that monetary policy react relatively weakly to inflation and output: $\alpha_{\pi}$ and $\alpha_{y}$ must satisfy

$$
-1-\frac{1+\beta}{\kappa} \alpha_{y}-\frac{2(1+\beta)}{\kappa \sigma}<\alpha_{\pi}<1-\frac{1-\beta}{\kappa} \alpha_{y}
$$


For practical reasons, we restrict $\alpha_{\pi}$ 's lower bound to 0 . In this case, when monetary policy does not respond to output, this reduces to the condition that passive monetary policy requires $0 \leq \alpha_{\pi}<1$. In the analytical results that follow, we use this simplified policy rule; numerical results will bring the output response of monetary policy back in.

Substituting the simplified version of the monetary policy rule $\left(\alpha_{y}=0\right)$ into the government budget identity and iterating forward immediately yields several robust features of regime $\mathrm{F}$ equilibria

$$
E_{t} \sum_{j=0}^{\infty} \beta^{j} \hat{\pi}_{t+j}=\left(\frac{1}{1-\alpha_{\pi} \beta}\right)\left[\hat{b}_{t-1}-(1-\beta) E_{t} \sum_{j=0}^{\infty} \beta^{j} \hat{s}_{t+j}+\beta E_{t} \sum_{j=0}^{\infty} \beta^{j} \varepsilon_{t+j}^{M}\right]
$$

Although expression (32) is not an equilibrium solution to the model (since we still need to solve the path for inflation) it highlights several features that the solution displays. First, higher initial debt, a lower expected path of surpluses or a higher expected path of the monetary shock all raise the present value of inflation. Second, a stronger response of monetary policy to inflation, but still consistent with existence of a bounded equilibrium, amplifies those inflationary effects. Dependence of inflation on the debt stock and surpluses is ubiquitous in regime F. Perversely, a higher path of the monetary shock or a higher value for $\alpha_{\pi}$ constitute a tightening of policy, yet they raise inflation.

In the flexible-price case, $\kappa=\infty$, so $\hat{y}_{t} \equiv 0$, and a solution for equilibrium inflation is immediate. This case collapses back to the endowment economy in section 2.1.2.2 with a constant real rate and the simple Fisher relation $\hat{R}_{t}=E_{t} \hat{\pi}_{t+1}$. Combine the monetary policy rule with $\alpha_{y}=0$ with the Fisher relation to solve for expected inflation

$$
E_{t} \hat{\pi}_{t+j}=\alpha_{\pi}^{j} \hat{\pi}_{t}+\alpha_{\pi}^{j-1} \varepsilon_{t}^{M}+\alpha_{\pi}^{j-2} E_{t} \varepsilon_{t+1}^{M}+\ldots+\alpha_{\pi} E_{t} \varepsilon_{t+j-2}^{M}+E_{t} \varepsilon_{t+j-1}^{M}
$$

and use this expression to replace expected inflation rates in (32). Equilibrium inflation is

$$
\hat{\pi}_{t}=\hat{b}_{t-1}+\beta\left(1-\alpha_{\pi} \beta\right) E_{t} \sum_{j=0}^{\infty} \beta^{j} \varepsilon_{t+j}^{M}-(1-\beta) E_{t} \sum_{j=0}^{\infty} \beta^{j} \hat{s}_{t+j}
$$

Actual inflation rises with initial debt, a higher path of the monetary policy shock or a lower path for surpluses. The effects of surpluses on inflation are independent of the monetary policy choice of $\alpha_{\pi}$, although we saw above that those fiscal effects on expected inflation are amplified by more aggressive monetary policy.

Solving the sticky-price new Keynesian model is more complicated. When $0<\kappa<\infty$, both output and the real interest rate are endogenous. Defining the real interest rate as 
$\hat{r}_{t+j} \equiv \hat{R}_{t+j-1}-\hat{\pi}_{t+j}$, write the bond valuation equation as

$$
\hat{\pi}_{t}-E_{t} \sum_{j=1}^{\infty} \beta^{j} \hat{r}_{t+j}=\hat{b}_{t-1}-(1-\beta) E_{t} \sum_{j=0}^{\infty} \beta^{j} \hat{s}_{t+j}
$$

News about lower future surpluses shows up as a mix of higher current inflation and a lower path for the real interest rate. Lower real rates, in turn, transmit into higher output. Fiscal expansions have the old-Keynesian effects - higher real activity and inflation - and monetary policy behavior determines the split between them.

Combining the Euler equation, the Phillips curve and the monetary policy rule produces a second-order difference equation in inflation

$$
E_{t} \hat{\pi}_{t+2}-\frac{1+\beta+\sigma \kappa}{\beta} E_{t} \hat{\pi}_{t+1}+\frac{1+\alpha_{\pi} \sigma \kappa}{\beta} \hat{\pi}_{t}=-\frac{\sigma \kappa}{\beta} \varepsilon_{t}^{M}
$$

One can show that, given the restrictions on the underlying model parameters, this difference equation has two real roots, one inside $\left|\lambda_{1}\right|<1$ and one outside $\left|\lambda_{2}>1\right|$ the unit circle, which yields the solution for expected inflation ${ }^{31}$

$$
E_{t} \hat{\pi}_{t+1}=\lambda_{1} \hat{\pi}_{t}+\left(\beta \lambda_{2}\right)^{-1} \sigma \kappa E_{t} \sum_{j=0}^{\infty} \lambda_{2}^{j} \varepsilon_{t+j}^{M}
$$

We can now solve for the $j$-step-ahead expectation of inflation by defining the operator $\mathcal{B}^{-j} x_{t} \equiv E_{t} x_{t+j}$ and iterating on (33)

$$
\mathcal{B}^{-j} \hat{\pi}_{t}=\lambda_{1}^{j} \hat{\pi}_{t}+\frac{\sigma \kappa}{\lambda_{2} \beta} \frac{1}{1-\lambda_{2}^{-1} \mathcal{B}^{-1}}\left(\lambda_{1}^{j-1}+\lambda_{1}^{j-2} \mathcal{B}^{-1}+\ldots+\mathcal{B}^{-j+1}\right) \varepsilon_{t}^{M}
$$

This yields the solution expected discounted inflation that appears in (32)

$$
E_{t} \sum_{j=0}^{\infty} \beta^{j} \hat{\pi}_{t+j}=\frac{1}{1-\lambda_{1} \beta} \hat{\pi}_{t}+\frac{\sigma \kappa}{\lambda_{2}\left(1-\lambda_{1} \beta\right)} \frac{1}{\left(1-\lambda_{2}^{-1} \mathcal{B}^{-1}\right)\left(1-\beta \mathcal{B}^{-1}\right)} \varepsilon_{t}^{M}
$$

Using this expression for discounted inflation in (32) delivers a solution for equilibrium

\footnotetext{
${ }^{31}$ Letting $\gamma_{1} \equiv(1+\beta+\sigma \kappa) / \beta$ and $\gamma_{0} \equiv\left(1+\alpha_{\pi} \sigma \kappa\right) / \beta$, the roots are $\lambda_{1}=(1 / 2)\left(\gamma_{1}-\sqrt{\gamma_{1}^{2}-4 \gamma_{0}}\right)$ and $\lambda_{2}=(1 / 2)\left(\gamma_{1}+\sqrt{\gamma_{1}^{2}-4 \gamma_{0}}\right)$. These derivations owe much to Tan (2015) who employs the techniques that Tan and Walker (2014) develop.
} 
inflation

$$
\begin{aligned}
\hat{\pi}_{t} & =\left(\frac{1-\lambda_{1} \beta}{1-\alpha_{\pi} \beta}\right)\left[\hat{b}_{t-1}-\left(\frac{1-\beta}{1-\beta \mathcal{B}^{-1}}\right) \hat{s}_{t}\right] \\
& +\left[\frac{1-\lambda_{1} \beta}{1-\alpha_{\pi} \beta}-\frac{\sigma \kappa}{\lambda_{2}} \frac{1}{\left(1-\lambda_{2}^{-1} \mathcal{B}^{-1}\right)}\right] \frac{1}{1-\beta \mathcal{B}^{-1}} \varepsilon_{t}^{M}
\end{aligned}
$$

It is straightforward to show how the monetary policy parameter affects inflation

$$
\frac{\partial \lambda_{1}}{\partial \alpha_{\pi}}>0, \quad \frac{\partial \lambda_{2}}{\partial \alpha_{\pi}}<0, \quad \frac{\partial\left[\lambda_{2}\left(1-\lambda_{1} \beta\right)\right]}{\partial \alpha_{\pi}}<0 \quad \frac{\partial\left(\frac{1-\lambda_{1} \beta}{1-\alpha_{\pi} \beta}\right)}{\partial \alpha_{\pi}}>0
$$

More aggressive monetary policy-larger $\alpha_{\pi}$-affects the equilibrium in the following ways

- amplifies the impacts on inflation from outstanding debt and exogenous disturbances to monetary policy and surpluses

- makes the effects of these shocks on inflation more persistent

Evidently, if fiscal policies set surpluses exogenously, monetary policy is impotent to offset fiscal effects on inflation. And adopting a more hawkish monetary policy stance has the perverse effect of amplifying and propagating the effects of shocks on inflation.

In this basic new Keynesian model, fiscal disturbances are transmitted to output through the path of the ex-ante real interest rate, as the consumption-Euler equation, (28), makes clear. Define the one-period real interest rate as $\hat{r}_{t} \equiv \hat{R}_{t}-E_{t} \hat{\pi}_{t+1}$. To simplify expressions, temporarily shut down the monetary policy shock, $\varepsilon_{t}^{M} \equiv 0$. Date the solution for inflation from (34) at $t+1$, take expectations, and substitute the monetary policy rule for the interest rate. After some tedious algebra, the equilibrium real interest rate is

$$
\hat{r}_{t}=\frac{\left(\alpha_{\pi}-\lambda_{1}\right)\left(1-\lambda_{1} \beta\right)}{1-\alpha_{\pi} \beta}\left[\hat{b}_{t-1}-(1-\beta) \sum_{j=0}^{\infty} \hat{s}_{t+j}\right]
$$

The lead coefficient, $\alpha_{\pi}-\lambda_{1}$, depends on monetary policy behavior and on all the model parameters. Because its sign can be positive or negative, lower expected surpluses may lower or raise the short-term real interest rate on impact.

Substituting the monetary policy rule into the definition of the real interest rate and suppressing the monetary policy shock, yields

$$
\hat{r}_{t} \equiv \alpha_{\pi} \hat{\pi}_{t}-E_{t} \hat{\pi}_{t+1}
$$


Using the Phillips curve to eliminate inflationary expectations we obtain

$$
\hat{r}_{t} \equiv\left(\alpha_{\pi}-\beta^{-1}\right) \hat{\pi}_{t}-\beta^{-1} \kappa \widehat{y}_{t}
$$

which shows that a given level of positive inflation and output deviations from steady state will be consistent with lower real interest rates the smaller is the monetary policy response to inflation. The intuition is very similar to that in the endowment economy: a passive monetary policy that responds to inflation generates a sustained rise in inflation which does not facilitate the stabilization of single-period debt. In the new Keynesian case such a policy response mitigates the reduction in debt service costs which are an additional channel through which the passive monetary policy stabilizes debt in a sticky-price economy.

\subsection{Maturity Structure in Regime F}

We introduce the simplified maturity structure that section 2.2.2 describes, in which government debt maturity decays at the constant rate $\rho$ each period, into the new Keynesian model of section 3.1. The no-arbitrage condition links bond prices to the one-period nominal interest rate

$$
\hat{P}_{t}^{m}=-\hat{R}_{t}+\beta \rho E_{t} \hat{P}_{t+1}^{m}
$$

which implies the term structure relation

$$
\begin{aligned}
\hat{P}_{t}^{m} & =-E_{t} \sum_{j=0}^{\infty}(\beta \rho)^{j} \hat{R}_{t+j} \\
& =-\frac{1}{1-\beta \rho \mathcal{B}^{-1}}\left[\alpha_{\pi} \hat{\pi}_{t}+\varepsilon_{t}^{M}\right]
\end{aligned}
$$

where we have substituted the simpler monetary policy rule in for the nominal interest rate.

The government's flow budget identity is

$$
\beta(1-\rho) \hat{P}_{t}^{m}+\beta \hat{b}_{t}^{m}+(1-\beta) \hat{s}_{t}+\hat{\pi}_{t}=\hat{b}_{t-1}^{M}
$$

where we are defining $b_{t}^{m} \equiv B_{t}^{m} / P_{t}$ to be the real face value of outstanding debt. ${ }^{32}$ Because bond prices depend on the expected infinite path of inflation and the monetary policy shock, analytical solutions along the lines of section 3.1.2, though feasible, are cumbersome. For

\footnotetext{
${ }^{32}$ The real market value is $P_{t}^{m} B_{t}^{m} / P_{t}$. To derive (35), we use the steady-state relationships $P^{m *}=$ $1 /\left(\beta^{-1}-\rho\right)$ and $s^{*} / b^{m *}=(1-\beta) /(1-\beta \rho)$ in log-linearizing the government budget identity.
} 
example, the analog to the discounted inflation expression, (32), is

$$
\frac{1}{1-\beta \mathcal{B}^{-1}}\left[1-\frac{\alpha_{\pi} \beta(1-\rho)}{1-\beta \rho \mathcal{B}^{-1}}\right] \hat{\pi}_{t}=\hat{b}_{t-1}^{m}-\left(\frac{1-\beta}{1-\beta \mathcal{B}^{-1}}\right) \hat{s}_{t}+\frac{\beta(1-\rho)}{\left(1-\beta \mathcal{B}^{-1}\right)\left(1-\beta \rho \mathcal{B}^{-1}\right)} \varepsilon_{t}^{M}
$$

which collapses to (32) when $\rho=0$ so all debt is one period. The solution for equilibrium inflation, like that when there is only one-period debt in equation (34), depends on all the parameters of the model through the eigenvalues $\lambda_{1}$ and $\lambda_{2}$, but the analytical expression for inflation is too complex to offer useful intuition.

One-period debt makes the value of debt depend only on the current nominal interest rate and, through the monetary policy rule, current inflation. A maturity structure makes that value depend on the entire expected path of nominal interest rates. This gives monetary policy an expanded role in debt stabilization, allowing expected future monetary policy to affect the value of current debt. This additional channel operates through terms in $1 /\left(1-\beta \rho \mathcal{B}^{-1}\right)$ that create double infinite sums in the equilibrium solution.

\subsubsection{IMPACTS OF Fiscal SHOCKS}

Figures 3 and 4 illustrate the impacts of a serially correlated increase in the primary fiscal deficit financed by nominal bond sales. ${ }^{33}$ Figure 3 maintains that all debt is one period to focus on how different monetary policy rules alter the impacts of a fiscal expansion.

When monetary policy pegs the nominal interest rate- $\alpha_{\pi}=\alpha_{Y}=0$-it fixes the bond price, which front loads fiscal adjustments through current inflation and the real interest rate. Inflation rises, the real rate falls and output increases. Responses inherit the serial correlation properties of the fiscal disturbance. As monetary policy becomes progressively less passive, reacting more strongly to inflation and output, it amplifies and propagates the fiscal shock (dashed lines in figure 3). By reacting more strongly to inflation, monetary policy ensures that the real interest rate declines by less, tempering the short-run output increases.

The figure makes clear the role that debt plays in propagating shocks in regime F. Stronger and more persistent nominal interest rate increases transmit directly into stronger and more persistent growth in the nominal market value of debt. ${ }^{34}$ And persistently higher nominal debt keeps household nominal wealth and, therefore, nominal demand elevated, creating strong serial correlation in inflation and output. This internal propagation mechanism through government debt is absent from regime $\mathrm{M}$, where higher debt carries with it the

\footnotetext{
${ }^{33}$ We calibrate the model to an annual frequency, setting $\beta=0.95, \sigma=1, \kappa=0.3$. The surplus is $A R(1)$, $\hat{s}_{t}=\rho_{F P} \hat{s}_{t-1}+\varepsilon_{t}^{F}$, with $\rho_{F P}=0.6$.

${ }^{34}$ Growth in the nominal market value of debt is $P_{t}^{m} B_{t}^{M} / P_{t-1}^{m} B_{t-1}^{m}$.
} 
promise of higher taxes that eliminate wealth effects.

Figure 4 holds the monetary policy rule fixed, setting $\alpha_{\pi}=\alpha_{Y}=0.5$, to reveal how changes in maturity affect fiscal impacts. The figure contrasts one-period debt (dotteddashed lines) to an average of 5-year maturity (solid lines) and consol debt (dashed lines). Longer maturities force more of the adjustment to higher deficits into lower bond prices, which push more of the impacts into low frequency movements in long-run inflation and real interest rates. ${ }^{35}$
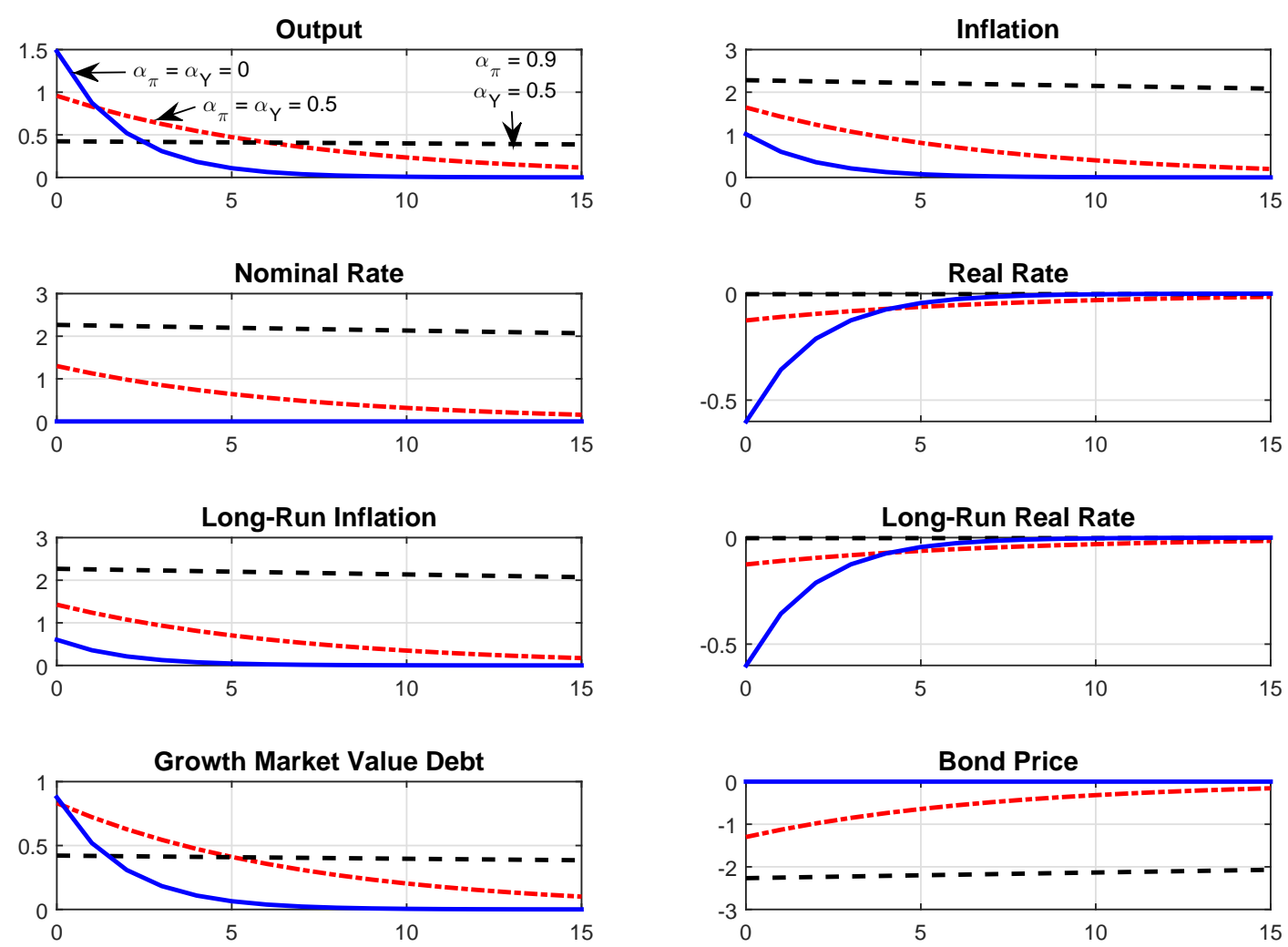

Figure 3: Responses to a 20 percent increase in the initial deficit under alternative monetary policy rules when all debt is one period. Calibration reported in footnote 33.

Although short-run inflation is higher with one-period debt, in the long run inflation is lower with shorter maturity bonds. With long debt, bond prices reflect anticipated inflation rates farther into the future, in essence spreading inflationary effects over longer horizons.

\footnotetext{
${ }^{35}$ The long-term real interest rate, $\hat{r}_{t}^{L}$, comes from combining the bond-pricing equation and the Fisher relation to yield the recursion $\hat{r}_{t}^{L}=\hat{r}_{t}+\beta \rho E_{t} \hat{r}_{t+1}^{L}$. The long-run inflation rate, $\hat{\pi}_{t}^{L}$, which is the expected path of inflation discounted by $\beta \rho$, may be computed as $\hat{\pi}_{t}^{L}=-\hat{r}_{t}^{L}-\hat{P}_{t}^{m}$.
} 
The cost of doing so is to raise the long-run inflation impacts of fiscal policy.
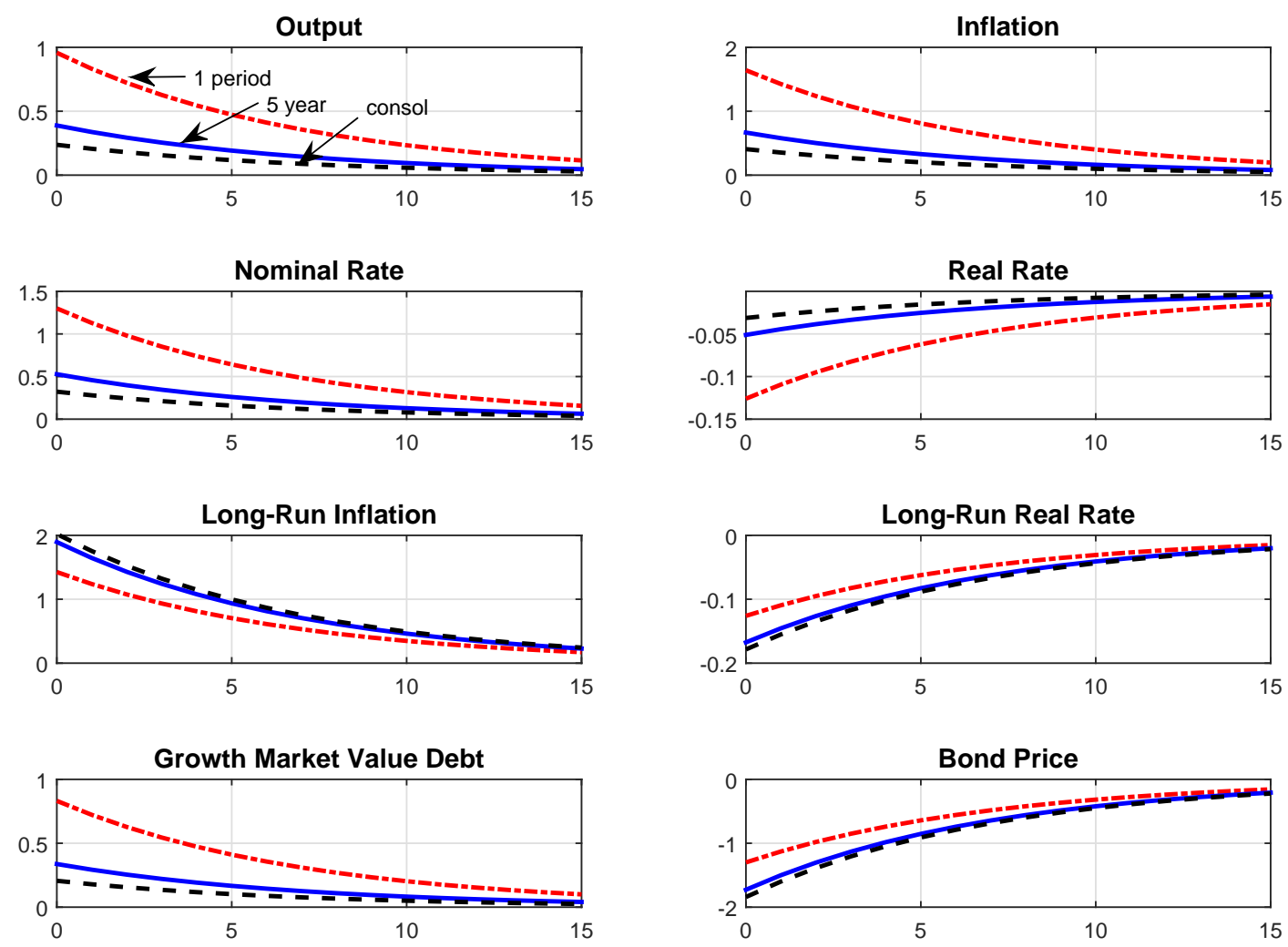

Figure 4: Responses to a 20 percent increase in the initial deficit under alternative maturity structures. Calibration reported in footnote 33.

Another way to summarize the dynamic impacts of fiscal disturbances is to ask how a shock that raises primary deficits by a certain amount gets financed intertemporally, as a function of various model parameters. Underlying the calculations in table 2 are two basic mechanisms that stabilize debt in the face of the surplus shock. First are the revaluation effects that we can summarize by examining the ex-post real return to holding government bonds in any period

$$
r_{t}^{m}=\frac{\left(1+\rho P_{t}^{m}\right)}{P_{t-1}^{m}} \frac{1}{\pi_{t}}
$$

or in linearized form

$$
\hat{r}_{t}^{m}=\rho \beta \hat{P}_{t}^{m}-\hat{\pi}_{t}-\hat{P}_{t-1}^{m}
$$

By contrasting this with the ex-ante returns the bond holders were expecting when they purchased the bonds in period $t-1$ we can identify the scale of the revaluation effects, which 
linearized, are

$$
\hat{r}_{t}^{m}-E_{t-1} \hat{r}_{t}^{m}=-\left(\hat{\pi}_{t}-E_{t-1} \hat{\pi}_{t}\right)+\rho \beta\left(\hat{P}_{t}^{m}-E_{t-1} \hat{P}_{t}^{m}\right)
$$

The first term on the right in (36) gives the losses suffered by bondholders due to surprise inflation in the initial period. The second term gives the losses suffered by holders of mature debt $(\rho>0)$ arising from jumps in bond prices caused by innovations to the expected future path of inflation. These latter revaluation effects are borne by the existing holders of government debt and arise for innovations to the path of inflation over the time to maturity of the debt stock they hold. In the sticky price economy these effects can be complemented by reductions in the ex-ante real rates of return received by future bondholders, which reduce effective debt service costs to create an additional channel through which debt can be stabilized. ${ }^{36}$

In the case of one-period debt it is only the surprise inflation in the initial period that reduces the real value of government debt. This is then combined with reductions in ex-ante real interest rates to stabilize debt. As $\alpha_{\pi}$ increases, there is less reliance on the latter effect and larger jumps in the initial rate of inflation are required to satisfy the bond valuation equation. When we move to longer period debt, there is an additional revaluation effect through the impact of innovations to the path of inflation on bond prices. With bond prices adjusting, we can have smaller, but more sustained increases in inflation that reduce the real market value of debt. These continue to be combined with reductions in ex-ante real interest rates to satisfy the bond valuation equation with these debt service cost effects falling as monetary policy becomes less passive.

To see how this affects the decomposition of the adjustment required to stabilize the debt stock in the face of a surplus shock consider the evolution of the market value of government debt

$$
\widetilde{b}_{t}=r_{t}^{m} \widetilde{b}_{t-1}-s_{t}
$$

where $\widetilde{b}_{t} \equiv \frac{P_{t}^{m} B t}{P_{t}}$. This can be linearized as

$$
\widehat{\widetilde{b}}_{t}=\hat{r}_{t}^{m}+\widehat{\widetilde{b}}_{t-1}-(1-\beta) \widehat{s}_{t}
$$

Using the expected value of surpluses, $\xi_{t} \equiv(1-\beta) E_{t} \sum_{j=0}^{\infty} \beta^{j} \widehat{s}_{t+j}$ which implies $(1-\beta) \widehat{s}_{t}=$ $\xi_{t}-\beta E_{t} \xi_{t+1}$, this becomes

$$
\beta\left(\widehat{\widetilde{b}}_{t}-E_{t} \xi_{t+1}\right)-\hat{r}_{t}^{m}=\widehat{\widetilde{b}}_{t-1}-\xi_{t}
$$

\footnotetext{
${ }^{36}$ An equivalent interpretation comes from thinking about the value of debt in the "forward" direction, as being determined by the expected present value of surpluses. Lower real interest rates raise real discount factors to increase the present value of a given strem of surpluses.
} 


\begin{tabular}{|c|c|c|c|c|c|}
\hline$\alpha_{\pi}$ & $\alpha_{Y}$ & Maturity & $\%$ due to $\hat{\pi}_{t}$ & \% due to $\hat{P}_{t}^{m}$ & $\%$ due to $\hat{r}_{t+j}^{m}$ \\
\hline 0 & 0 & 1 period & 44 & 0 & 56 \\
0.5 & 0.5 & 1 period & 71 & 0 & 29 \\
0.9 & 0.5 & 1 period & 98 & 0 & 2 \\
0.5 & 0.5 & 5 year & 29 & 59 & 12 \\
0.9 & 0.5 & 5 year & 20.4 & 79.2 & 0.4 \\
0.5 & 0.5 & consol & 18 & 75 & 7 \\
0.9 & 0.5 & consol & 6 & 94 & 0 \\
\hline
\end{tabular}

Table 2: The fiscal shock initially raises the deficit by 20 percent. "\% due to" are the ratios of the right-hand components of (37) to $\xi_{t}$, which is computed from the impulse response of $\hat{s}_{t+j}$, as described in the text. Calibration reported in footnote 33.

Iterating forward we obtain

$$
\begin{aligned}
\xi_{t} & =\widehat{\widetilde{b}}_{t-1}+\hat{r}_{t}^{m}+E_{t} \sum_{j=1}^{\infty} \beta^{j} \hat{r}_{t+j}^{m} \\
& =\widehat{\widetilde{b}}_{t-1}-\hat{P}_{t-1}^{m}+\beta \rho \hat{P}_{t}^{m}-\hat{\pi}_{t}+E_{t} \sum_{j=1}^{\infty} \beta^{j} \hat{r}_{t+j}^{m}
\end{aligned}
$$

The required adjustment is made up of surprise changes in the returns to existing bond holders $\hat{r}_{t}^{m}$ as well as expected future returns on bond holdings, $E_{t} \sum_{j=1}^{\infty} \beta^{j} \hat{r}_{t+j}^{m}$. The former is made up of jumps in the initial rate of inflation combined with changes in bond prices to the extent that bonds have a maturity greater than one period, $\rho>0$. The latter captures the reduction in ex-ante real interest rates which can occur in our sticky price economy.

Table 2 computes the objects in (37) from impulse responses to a deficit innovation. When debt is single period, bond prices do not contribute to financing the deficit. If monetary policy pegs the nominal interest rate, current inflation and future real interest rates play nearly equally important roles. As monetary policy reacts more aggressively to inflation and output, real interest rate responses are tempered, and an increasing fraction of the adjustment occurs through inflation at the time of the fiscal innovation. Longer maturity debt brings bond prices into the adjustment process, and their role grows with both the maturity of debt and the aggressiveness of monetary policy. As a consequence, current inflation moves much less. Consol bonds, together with aggressive monetary policy, push nearly all the adjustment into bond prices, with contemporaneous inflation playing only a minimal role, as the last row of the table reports. 


\subsubsection{Impacts of Monetary Shocks}

Section 2.1.2.2 describes the effects of exogenous monetary policy disturbances in an endowment economy under regime F. Because future surpluses do not adjust to neutralize the wealth effects of monetary policy, contractionary policy - a higher path for the nominal interest rate - raises household interest receipts and wealth, raising nominal aggregate demand. A similar phenomenon can arise in the new Keynesian model, though the dynamics are more interesting.
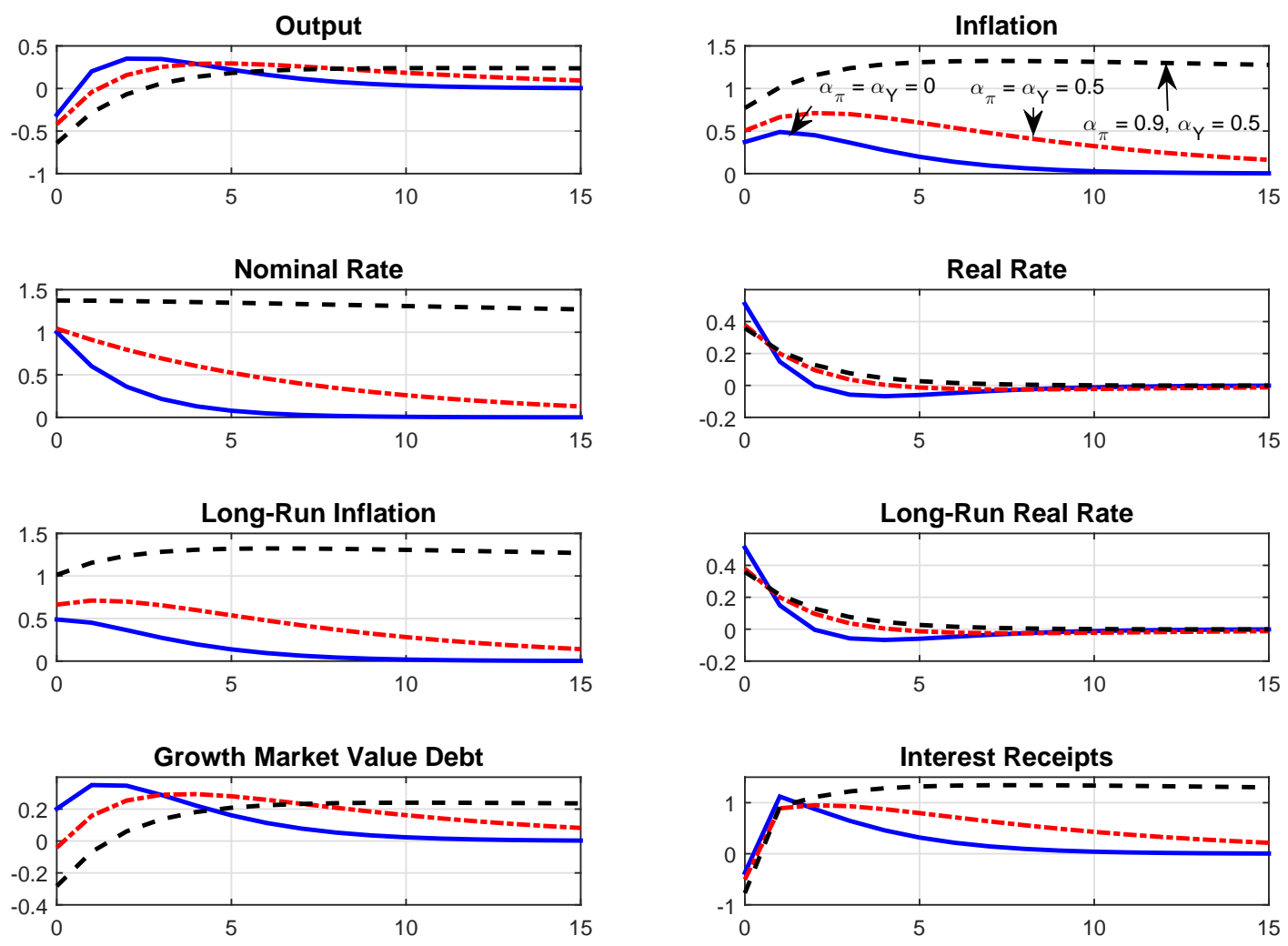

Figure 5: Responses to a 1 percent monetary contraction under alternative monetary policy rules with only one-period government debt. Calibration reported in footnote 33 . The monetary policy shock follows the $A R(1)$ process $\varepsilon_{t}^{M}=\rho_{M P} \varepsilon_{t-1}^{M}+\zeta_{t}^{M}$ with $\rho_{M P}=0.6$.

Figure 5 reports the impacts of an exogenous monetary policy action that raises the nominal interest rate. To highlight the behavior of monetary policy in regime $\mathrm{F}$, we consider three different monetary policy rules. A rule that doesn't respond to inflation (solid lines) raises the short-term real interest rate and depresses output in the short run. Despite the 
drop in output, inflation rises immediately, even in a model where the Phillips curve implies a strong positive relationship between output and inflation contemporaneously $(\kappa=0.3)$.

This seemingly anomalous outcome underscores the centrality of wealth effects in regime F. Higher nominal interest rates raise households' interest receipts in the future, triggering an expectation of higher future demand and inflation. ${ }^{37}$ Through the Phillips curve, the higher expected inflation dominates the deflationary effects of lower output to raise inflation on impact. Expectations are critical to output effects as well. After an initial decline, output always eventually rises because the real interest rate declines at longer horizons.

More aggressive monetary policy behavior (dashed lines) transforms the transitory increase in the policy rate into larger and more persistent increases. Those higher nominal interest rates raise both the growth rate of the nominal market value of debt and real interest receipts. The resulting wealth effects raise and prolong the higher inflation.

That an exogenous monetary policy "contraction," which raises the nominal interest rate, also raises inflation may seem to contradict evidence from the monetary VAR literature. This pattern, dubbed the "price puzzle" by Eichenbaum (1992), is sometimes taken to indicate that monetary policy behavior is poorly identified, perhaps by misspecifying the central bank's information set, as Sims (1992) argues. Figure 5 makes clear that there is nothing puzzling about the pattern from the perspective of the fiscal theory.

Introducing long debt makes impulse responses accord better with VAR evidence because bond prices absorb much of the monetary shock. Figure 6 contrasts one-period (dotteddashed lines) with 5-year (solid lines) and consol debt (dashed lines). By reducing growth in the market value of debt, longer maturities attenuate the inflationary effects and make the short-run decline in output longer lasting. Inflation does eventually rise, as it must if bond prices are lower. Sims (2011) calls the pattern of falling, then rising inflation following a monetary contraction "stepping on a rake."

While figure 6 shows how the response of short-run inflation to a monetary contraction varies with debt maturity, table 3 reports how other model parameters affect this relationship. Following a monetary contraction, $\xi_{t} \equiv 0$ in expression (37), so if the monetary shock hits at time $t$, we have that

$$
\hat{\pi}_{t}-\beta \rho \hat{P}_{t}^{m}-E_{t} \sum_{j=1}^{\infty} \beta^{j} \hat{r}_{t+j}^{m}=0
$$

so the three sources of fiscal financing - higher current inflation, lower current bond prices, and lower future real bond returns - must sum to zero.

The first row of table 3 shows that for the benchmark calibration with five-period average bond maturity, the monetary contraction initially lowers inflation along with the price of

\footnotetext{
${ }^{37}$ Real interest receipts are defined as $\left[\left(1+\rho P_{t}^{m}\right) / P_{t-1}^{m}\right]\left(b_{t-1}^{m} / \pi_{t}\right)$.
} 

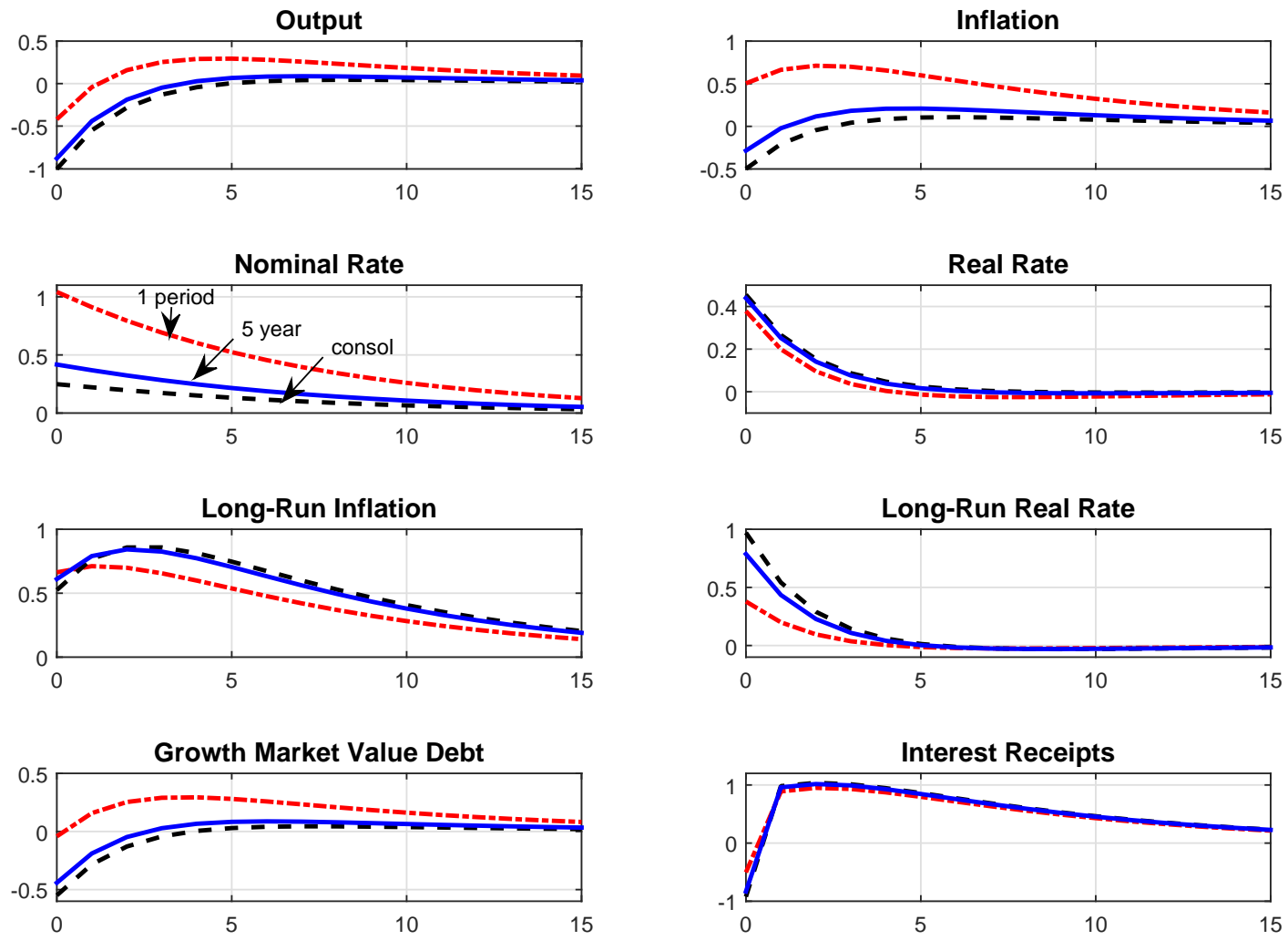

Figure 6: Responses to a 1 percent monetary contraction under alternative maturity structures. Calibration reported in footnote 33. The monetary policy shock follows the $A R(1)$ process $\varepsilon_{t}^{M}=\rho_{M P} \varepsilon_{t-1}^{M}+\zeta_{t}^{M}$ with $\rho_{M P}=0.6$.

bonds, while it raises discounted real interest rates. As prices become more flexible $(\kappa \rightarrow \infty)$, the impact on inflation becomes more pronounced, while that on real rates diminishes. A higher intertemporal elasticity of substitution $(\sigma \rightarrow 0)$ pushes more of the adjustment into the future, reducing the effect on current inflation and raises the impacts on bond prices and future real rates.

\section{Endowment Economies with Optimal Monetary and Fiscal POLICIES}

In this section we turn to consider the nature of optimal policy in our simple endowment economy. In doing so we cut across various strands of the literature addressing optimal monetary and fiscal policy issues. 


\begin{tabular}{|c|c|c|c|c|}
\hline$\kappa$ & $\sigma$ & $\hat{\pi}_{t}$ & $\hat{P}_{t}^{m}$ & $\hat{r}_{t+j}^{m}$ \\
\hline 0.3 & 1.0 & -0.29 & 1.12 & -0.83 \\
$\infty$ & 1.0 & -1.54 & 1.54 & 0.0 \\
0.1 & 1.0 & -0.09 & 1.03 & -0.94 \\
0.3 & 5.0 & -0.50 & 0.76 & -0.26 \\
0.3 & 0.5 & -0.17 & 1.32 & -1.15 \\
\hline
\end{tabular}

Table 3: A 1 percent monetary shock initially raises the short-term nominal interest rate. " $\pi_{t}$ " and " $\hat{P}_{t}^{m}$ " are impacts of the monetary policy shock on contemporaneous inflation and bond prices; " $\hat{r}_{t+j}^{m}$ " are the impacts on discounted real returns to bonds from expression (38). Calibration reported in footnote 33 plus $\alpha_{\pi}=\alpha_{Y}=0.5$ and maturity set at 5 periods.

\subsection{Connections to the Optimal Policy Literature}

We begin by considering Ramsey policies where the policymaker has an ability to make credible promises about how they will behave in the future, before turning to time-consistency issues below. We start by building on Sims's (2013) analysis. He considers a simple linearized model of tax smoothing under commitment in the face of transfer shocks and long-term debt where the policymaker can use costly inflation surprises as an alternative to distortionary taxation to ensure fiscal solvency. We extend that work in several ways. Specifically, we allow for a geometric maturity structure which nests single-period debt and consols as special cases, employ non-linear model solution techniques and allow for anticipated and unanticipated government spending shocks, in addition to transfer shocks. Non-linear solutions allow us to consider the way in which the size of the debt stock, together with its maturity structure, influences the optimal combination of monetary and fiscal policy in debt stabilization. Innovations to the expected path for inflation can affect bond prices in a way which helps to satisfy the bond valuation equation even without any fiscal adjustment. These bond price movements are effective only if applied to a non-zero stock of outstanding liabilities such that the optimal balance between inflation and tax financing of fiscal shocks is likely to depend on both the level of government debt and its maturity structure.

Without an ability to issue state-contingent debt or use inflation surprises to stabilize debt, Barro (1979) showed that debt and taxes should follow martingale processes to minimize the discounted value of tax distortions. While Barro did consider the impact of surprise inflation on the government's finances, these were treated as exogenous shocks rather than something that can be optimally employed to further reduce tax distortions. Lucas and Stokey (1983) is an equally influential paper that reaches quite different conclusions on the optimal response of tax rates to shocks. Lucas and Stokey consider an economy where the government can issue real state-contingent debt and show that it is optimal for a government to issue a portfolio of debt where the state-contingent returns to that debt isolate the 
government's finances from shocks so that there is no need for taxes to jump in the manner of Barro's tax smoothing result. Instead, taxes are largely flat and inherit the dynamic properties of the exogenous shocks hitting the economy.

A large part of the post-Lucas and Stokey literature considers the implications of debt that is not state-contingent, as well as ways of converting the payoffs from portfolios of nonstate contingent debt into state-contingent payoffs. A key result is that when debt payoffs are not (or cannot be made) state contingent, then the optimal policy looks more like Barro's tax smoothing result. Aiyagari, Marcet, Sargent, and Seppälä (2002) show this by assuming that debt is single period and non-contingent in a model otherwise identical to that of Lucas and Stokey. How might non-contingent debt instruments be made to mimic the payoffs that would be generated by state-contingent debt? Two approaches have been suggested in the literature. First, surprise inflation can render the real payoffs from risk-free nominal bonds state contingent. For example, Chari, Christiano, and Kehoe (1994) use a model where surprise inflation is costless to show that the real contingencies in debt exploited by Lucas and Stokey could be created through monetary policy via the mechanism of surprise inflation when government debt is nominal. This underpins Sims's (2001) results in a model with costless inflation in which tax rates should be held constant to finance any fiscal shocks solely with surprise movements in inflation.

When we start to introduce a cost to surprise inflation, the optimal policy can be strikingly different. For a jointly determined optimal monetary and fiscal policy operating under commitment, Schmitt-Grohé and Uribe (2004) show that in a sticky-price stochastic production economy, even a miniscule degree of price stickiness will result, under the optimal policy, in a steady-state rate of inflation marginally less than zero, with negligible inflation volatility. In other words, although the optimal policy under flexible prices would be to follow the Friedman rule and use surprise inflation to create the desired state-contingencies in the real pay-offs from nominal debt, even a small amount of nominal inertia heavily tilts optimal policy towards zero inflation with little reliance on inflation surprises to insulate the government's finances from shocks. As in Benigno and Woodford (2004), Schmitt-Grohé and Uribe (2004) return to the tax smoothing results of Barro (1979) thanks to the effective loss of state-contingent returns to debt when prices are sticky. Sims (2013) argues that this may be due to fact that Schmitt-Grohe and Uribe only consider single-period debt, and that with longer term debt the efficacy of using innovations to the expected path of inflation to affect bond prices would be enhanced. This is the first issue to which we turn: to what extent will the optimizing policymaker rely on fiscal theory-type revaluations of debt through innovations to the expected path of prices?

While the state-contingencies in real bond payoffs can be generated through the impact 
of surprise inflation on nominal bonds, an alternative approach when bonds are real is to exploit variations in the yield curve to achieve the same contingencies for the government's whole bond portfolio. With single period risk-free real bonds, Ramsey policy in the Lucas and Stokey model possesses a unit root as in Barro. Angeletos (2002) and Buera and Nicolini (2004) use the maturity structure of non-state contingent real bonds to render the overall portfolio state contingent. With two states for government spending, for example, a portfolio of positive short-term assets funded by issuing long-term debt can insulate the government's finances from government spending shocks. More generally, with a sufficiently rich maturity structure the policymaker can match the range of the stochastic shocks hitting the economy and achieve this hedging. The second broad optimal policy question we consider is: what is the role of debt management in insulating the government's finances from shocks?

Having looked at the ability of the Ramsey policymaker to both hedge against shocks and utilize monetary policy as a debt stabilization tool when complete hedging is not possible, we turn to consider the time-inconsistency problem inherent in such policies. We find that constraining policy to be time consistent radically affects the policymaker's ability to hedge against fiscal shocks and generates serious "debt stabilization bias" problems, as in Leith and Wren-Lewis (2013), that are akin to the inflationary bias problems analyzed in the context of monetary economies.

We begin by considering the role inflation surprises play in optimal policy in our sim-

ple endowment economy with a geometrically declining maturity structure. We shall then generalize these results to a more general maturity structure and consider the role of debt management in hedging for fiscal shocks. We then turn to a simple example where complete hedging is feasible.

\subsection{The Model}

We follow Sims (2013) in defining the inverse of inflation as $\nu_{t}=\pi_{t}^{-1}$, and assuming the policymaker's objective function is given by

$$
-E_{0} \frac{1}{2} \sum_{t=0}^{\infty} \beta^{t}\left[\tau_{t}^{2}+\theta\left(\nu_{t}-1\right)^{2}\right]
$$

which the policymaker maximizes subject to the constraints given by the resource constraint in our endowment economy,

$$
y=c_{t}+g_{t}
$$


the bond valuation equation (after assuming a specific form for per-period utility, $u\left(c_{t}\right)=$ $\left.\frac{c_{t}^{1-\sigma}}{1-\sigma}\right)$

$$
\beta E_{t} \frac{\left(1+\rho P_{t+1}^{m}\right)}{P_{t}^{m}} \nu_{t+1}\left(\frac{c_{t+1}}{c_{t}}\right)^{-\sigma}=1
$$

the government's flow budget identity

$$
b_{t} P_{t}^{m}=\left(1+\rho P_{t}^{m}\right) b_{t-1} \nu_{t}+g_{t}-\tau_{t}-z_{t}
$$

and the associated transversality condition

$$
\lim _{j \rightarrow \infty} E_{t}\left(\prod_{i=0}^{j} \frac{1}{R_{t+i+1}^{m} \nu_{t+i+1}}\right) \frac{P_{t+j}^{m} B_{t+j}^{m}}{P_{t+j}} \geq 0
$$

where $R_{t+1}^{m} \equiv\left(1-\rho P_{t+1}^{m}\right) / P_{t}^{m}$, and government spending and/or transfers follow exogenous stochastic processes. Our adopted objective function is clearly ad hoc in the context of our simple endowment economy. However, it can easily be motivated as capturing the trade-off between the costs of tax versus inflation financing in richer production economies. Indeed, many of the insights this analysis offers will reappear when considering optimal policy in a fully-microfounded economy subject to distortionary taxation and nominal inertia in section 5 below.

\subsection{Ramsey Policy}

We analyze the time-inconsistent Ramsey policy for our endowment economy given the policymaker's objective function by forming the following Lagrangian

$$
\begin{aligned}
L_{t}= & E_{0} \frac{1}{2} \sum_{t=0}^{\infty} \beta^{t}\left[-\frac{1}{2}\left(\tau_{t}^{2}+\theta\left(\nu_{t}-1\right)^{2}\right)\right. \\
& +\mu_{t}\left(\beta E_{t} \frac{\left(1+\rho P_{t+1}^{m}\right)}{P_{t}^{m}} \nu_{t+1}\left(\frac{c_{t+1}}{c_{t}}\right)^{-\sigma}-1\right) \\
& \left.+\lambda_{t}\left(b_{t} P_{t}^{m}-\left(1+\rho P_{t}^{m}\right) b_{t-1} \nu_{t}-g_{t}-z_{t}+\tau_{t}\right)\right]
\end{aligned}
$$


which yields the first-order conditions

$$
\begin{aligned}
\tau_{t} & : \quad-\tau_{t}+\lambda_{t}=0 \\
\nu_{t} & : \quad-\theta\left(\nu_{t}-1\right)+\mu_{t-1} \frac{\left(1+\rho P_{t}^{m}\right)}{P_{t-1}^{m}}\left(\frac{c_{t}}{c_{t-1}}\right)^{-\sigma}-\left(1+\rho P_{t}^{m}\right) \lambda_{t} b_{t-1}=0 \\
P_{t}^{m}: & -\frac{\mu_{t}}{P_{t}^{m}}+\mu_{t-1} \rho \frac{\nu_{t}}{P_{t-1}^{m}}\left(\frac{c_{t}}{c_{t-1}}\right)^{-\sigma}+\lambda_{t}\left(b_{t}-\rho \nu_{t} b_{t-1}\right)=0 \\
b_{t} & : \quad \lambda_{t} P_{t}^{m}-\beta E_{t}\left(1+\rho P_{t+1}^{m}\right) \nu_{t+1} \lambda_{t+1}=0
\end{aligned}
$$

Defining $\tilde{\mu}_{t} \equiv \frac{\mu_{t}}{P_{t}^{m} c_{t}^{-\sigma}}$ the system to be solved for $\left\{P_{t}^{m}, \tilde{\mu}_{t}, \nu_{t}, \tau_{t}, b_{t}, c_{t}\right\}$ is given by

$$
\begin{aligned}
-\theta\left(\nu_{t}-1\right)+\tilde{\mu}_{t-1}\left(1+\rho P_{t}^{m}\right) c_{t}^{-\sigma}-\left(1+\rho P_{t}^{m}\right) \tau_{t} b_{t-1} & =0 \\
\tau_{t} b_{t}-\tilde{\mu}_{t} c_{t}^{-\sigma}-\rho \nu_{t}\left(\tau_{t} b_{t-1}-\tilde{\mu}_{t-1} c_{t}^{-\sigma}\right) & =0 \\
\tau_{t} P_{t}^{m}-\beta E_{t}\left(1+\rho P_{t+1}^{m}\right) \nu_{t+1} \tau_{t+1} & =0 \\
\beta E_{t} \frac{\left(1+\rho P_{t+1}^{m}\right)}{P_{t}^{m}}\left(\frac{c_{t+1}}{c_{t}}\right)^{-\sigma} \nu_{t+1}-1 & =0 \\
b_{t} P_{t}^{m}-\left(1+\rho P_{t}^{m}\right) b_{t-1} \nu_{t}-g_{t}+\tau_{t}-z_{t} & =0 \\
g_{t}-\left(1-\rho_{g}\right) g^{*}-\rho_{g} g_{t-1}-\varepsilon_{t}^{g} & =0 \\
z_{t}-\left(1-\rho_{z}\right) z^{*}-\rho_{z} z_{t-1}-\varepsilon_{t}^{z} & =0 \\
y-c_{t}-g_{t} & =0
\end{aligned}
$$

with two exogenous shocks describing the evolution of government consumption, $g_{t}$, and transfers, $z_{t}$ and two endogenous state variables, $\tilde{\mu}_{t-1}$ and $b_{t-1}$, where the former captures the history dependence in policymaking under commitment.

To obtain some intuition for how policy operates under commitment, it is helpful to consider three polar cases. First, where inflation is costless, so that $\theta=0$. Second, where inflation is so costly that the economy can be considered to be real, $\theta \rightarrow \infty$. Third, we allow inflation to be costly $\theta>0$, but assume that taxes have reached the peak of the Laffer curve so that they are no longer available to engage in tax smoothing and instead are held constant, $\tau_{t}=\bar{\tau}$.

\subsubsection{Costless Inflation}

In the former case, where inflation is costless $(\theta=0)$, the first two first-order conditions imply

$$
\widetilde{\mu}_{t-1} c_{t}^{-\sigma}=\tau_{t} b_{t-1}
$$


and

$$
\tau_{t} b_{t}-\widetilde{\mu}_{t} c_{t}^{-\sigma}=\rho \nu_{t}\left(\tau_{t} b_{t-1}-\widetilde{\mu}_{t-1} c_{t}^{-\sigma}\right)
$$

Substituting the first into the second, lagging one period and comparing the first condition yields

$$
\tau_{t}=\left(\frac{c_{t}}{c_{t-1}}\right)^{-\sigma} \tau_{t-1}
$$

In the absence of government spending shocks (the only source of variation in private consumption in our simple endowment economy) taxes are unchanged. But taxes are higher whenever government spending is higher. In the case of transfer shocks, inflation jumps to satisfy the bond valuation equation and this is a pure case of the fiscal theory. But when bonds have a maturity beyond a single period, there are an infinite number of patterns of inflation which can satisfy this, due to the impact inflation has on bond prices. While there is a unique required discounted magnitude of surprise inflation needed to satisfy the government debt valuation condition, there are a variety of paths which can achieve that magnitude. When the fiscal shock is a shock to government consumption, this affects real interest rates so that even although inflation can costlessly stabilize debt at its initial steady state level, there is still tilting of tax rates: during periods of high real interest rates, it is desirable to suffer the short-run costs of higher taxation to avoid the longer run costs of supporting the higher steady-state level of debt that would emerge when higher interest rates raise the rate of debt accumulation. In this case it is only because of the commitment to honour the past promises not to deflate away the government's outstanding liabilities that there are positive tax rates at all.

\subsubsection{Real Economy}

In the second case, inflation is so costly it would never be used under the optimal policy, $\theta \rightarrow \infty$ and $\nu_{t}=1$. As a result, we rely on jumps in the tax rate to satisfy government solvency and we return to a world of pure tax smoothing, where the tax rate follows the path implied by the first-order condition

$$
\tau_{t} P_{t}^{m}=\beta E_{t}\left(1+\rho P_{t+1}^{m}\right) \tau_{t+1}
$$

Under a perfect foresight equilibrium this reduces to

$$
\frac{\tau_{t}}{c_{t}^{-\sigma}}=\frac{\tau_{t+1}}{c_{t+1}^{-\sigma}}
$$


This tax rate is constant in the face of transfer shocks, but will be tilted in the presence of government spending shocks - the tax rate at $t$ is higher (lower) when public consumption is anticipated to rise (fall). The fact that it is purely forward looking captures the usual tax smoothing result that the tax rate will jump to the level required to satisfy the government's budget identity, although we have tilting in the tax rate to capture changes in real interest rates induced by government spending shocks. Eventually the tax rate will achieve a new long-run value consistent with servicing the new steady-state level of debt.

\subsubsection{Intermediate CASE}

In the intermediate case where $0<\theta<\infty$, the tax smoothing condition remains as above, but will be combined with a pattern of inflation described by

$$
\begin{aligned}
-\theta\left(\nu_{t}-1\right)+\frac{\mu_{t-1}}{P_{t-1}^{m}}\left(1+\rho P_{t}^{m}\right)-\left(1+\rho P_{t}^{m}\right) \tau_{t} b_{t-1} & =0 \\
\tau_{t} b_{t}-\frac{\mu_{t}}{P_{t}^{m}}-\rho \nu_{t}\left(\tau_{t} b_{t-1}-\frac{\mu_{t-1}}{P_{t-1}^{m}}\right) & =0 \\
b_{t} P_{t}^{m}-\left(1+\rho P_{t}^{m}\right) b_{t-1} \nu_{t}-g_{t}-z_{t}+\tau_{t} & =0
\end{aligned}
$$

which will deliver initial jumps in inflation, bond prices and tax rates to ensure fiscal solvency. These first-order conditions also imply that gross inflation returns to 1 in steady state, so the optimal commitment policy makes any inflation only temporary. But there is a continuum of steady state debt levels, each with an associated optimal tax rate, that would be consistent with the steady state of the first-order conditions under commitment.

When we consider a variant on the third case where taxes are no longer available for tax smoothing, either for political reasons or because the tax rate has reached the peak of the Laffer curve, the relevant optimality conditions become

$$
\begin{aligned}
\lambda_{t} P_{t}^{m}-\beta E_{t}\left(1+\rho P_{t+1}^{m}\right) \nu_{t+1} \lambda_{t+1} & =0 \\
-\theta\left(\nu_{t}-1\right)+\widetilde{\mu}_{t-1}\left(1+\rho P_{t}^{m}\right) c_{t}^{-\sigma}-\left(1+\rho P_{t}^{m}\right) \lambda_{t} b_{t-1} & =0 \\
\lambda_{t} b_{t}-\widetilde{\mu}_{t} c_{t}^{-\sigma}-\rho \nu_{t}\left(\lambda_{t} b_{t-1}-\widetilde{\mu}_{t-1} c_{t}^{-\sigma}\right) & =0
\end{aligned}
$$

where the tax rate is fixed at $\bar{\tau}$.

Here the unit root in government debt is no longer present because taxes cannot adjust to support a new steady state debt level, and inflation cannot influence future surpluses. Instead, inflation must be adjusted to ensure fiscal solvency by returning debt to the steady state level consistent with the unchanged tax rate. The pattern of inflation also depends on the maturity structure of the inherited debt stock. To see this more clearly we consider the 
perfect foresight solution in the face of a transfers shock in which the first-order condition for debt implies that $\lambda_{t}=\lambda_{t+1}$ since $g_{t}=g^{*}$. Combining the second and third conditions yields

$$
\nu_{t}\left(\nu_{t}-1\right)=\left[1+\left(\rho P_{t}^{m}\right)^{-1}\right] \beta \nu_{t+1}\left(\nu_{t+1}-1\right)
$$

which describes the dynamics of inflation. Inflation rises following a fiscal shock that would otherwise make debt initially higher and then decline towards its steady state value. The rate of convergence depends on the inverse of the maturity parameter multiplied by the bond price, which initially falls, but then recovers as the period of inflation passes. When $\rho=0$ the inflation only occurs in the initial period, but becomes more protracted the longer is the maturity of government debt. Similar inflation dynamics are observed when taxes are smoothed, although the magnitude of the initial jump in inflation will be reduced to the extent that tax rates rise to stabilize debt at a higher level in the face of a given shock.

\subsection{Numerical Results}

The grid-based approach to solving the stochastic version of the model under the simple rules works well when the economy has a well defined steady-state to which it returns. With commitment policies the model enters a new steady state following the realization of a shock, which makes the model difficult to solve using these techniques. For this reason, when considering commitment we restrict attention to perfect foresight equilibrium paths following an initial shock. These paths are computed as follows. We guess the new steadystate value of debt and solve the steady state of the Ramsey problem conditional on that guess. This serves as a terminal condition on the model solution 800 periods in the future. The Ramsey first order conditions are then solved for 800 periods conditional on this guess for the ultimate steady state. If the solution exhibits a discontinuity between the final period of the solution and the imposed terminal condition, the steady-state guess is revised. This process continues until the guessed new steady state is indeed the steady state to which the economy now settles.

We begin by considering the same transfers shock considered above for various degrees of maturity and different initial debt to GDP ratios. The autocorrelated shock to transfers reduces the discounted value of future surpluses and requires a monetary and/or fiscal adjustment. These adjustments are plotted in figure 7 for various initial debt-to-GDP ratios and debt maturities. The first column starts from an initial debt to GDP ratio of zero. When debt is initially zero and the initial tax rate of $\tau=0.39$ can support the initial level of transfers and public consumption, under the optimal policy there is no inflation, regardless of the maturity of debt. This is due to the fact that surprise changes in inflation or bond 
prices only help satisfy the government's intertemporal budget identity if there is already an initial debt stock for them to act on. Even though the debt that will be issued as a result of the transfer shock is of different maturities across the experiments reported in the first column of the figure, this will not affect the optimal policy response to the transfers shock when there is initially no debt. The tax rate jumps to a permanently higher level to support a higher steady state debt level, as under Barro's (1979) original tax smoothing result.
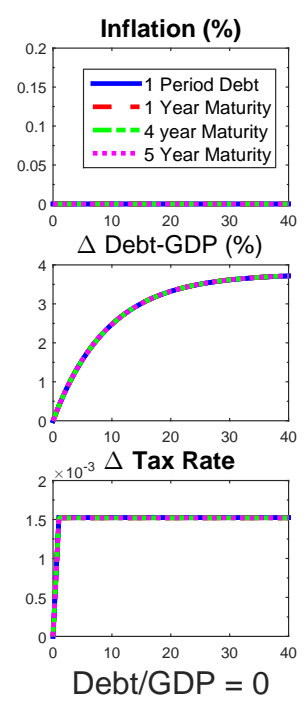
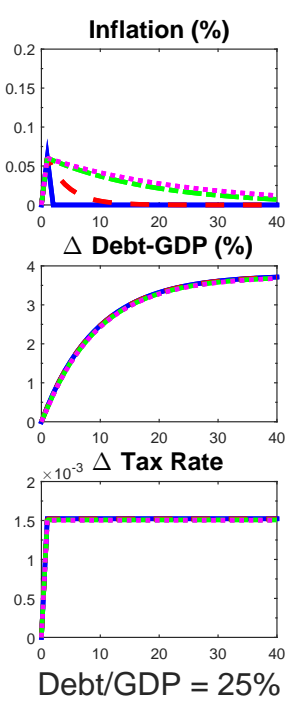
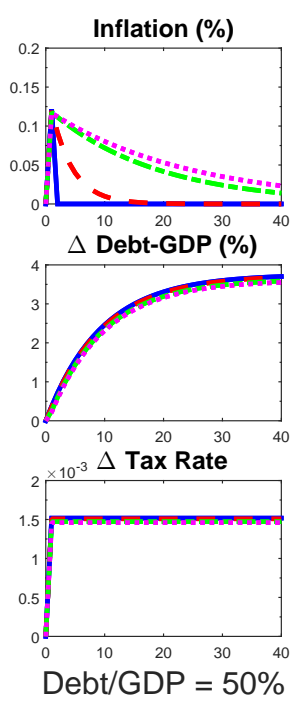
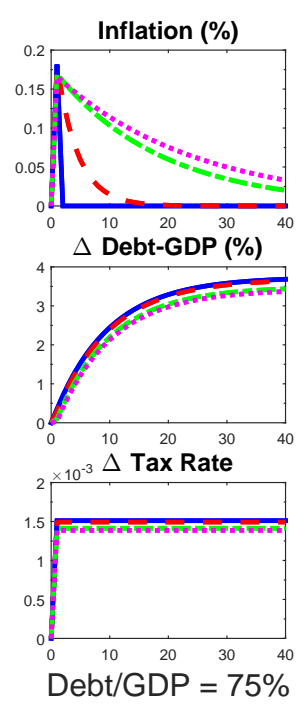

Figure 7: Optimal policy in response to higher transfers with different debt levels and maturities.

The second column begins from an initial steady state with a debt to GDP ratio of 25 percent (and a supporting initial tax rate of $\tau=0.4$ ). Now there is mild use of inflation to offset the effects of the transfers shock. Inflation is smaller but more sustained the longer is the average maturity of debt. As maturity lengthens, inflation surprises play an increasingly important role in stabilizing debt, with smaller adjustments in taxes. At higher debt levels, the role of inflation and maturity grow in importance as substitutes for distorting taxes. Ultimately, the increase in inflation is unwound (it serves no purpose as the initial debt stock matures) and there is a permanent increase in both the debt stock and tax rates. These examples underscore that optimal policy is highly state dependent, particularly with respect to the level and maturity of debt at the time the shock hits.

When we turn to government spending shocks in figure 8, the story is similar except that now, through the stochastic discount factor, public consumption tilts the optimal path of taxes and affects the magnitude of the fiscal and inflation adjustments needed to satisfy the debt valuation equation. With no initial stock of debt, the subsequent debt maturity structure is irrelevant and the optimal policy does not generate any inflation. But for a 
positive initial debt level, the spike in inflation for one-period debt is several orders of magnitude larger than for the portfolio of bonds with an average maturity of 8 years. With only short debt, the inflation is immediately eliminated, while the slight rise in inflation is sustained in the presence of longer term debt. Sustained inflation decreases bond prices that reduce the value of debt to for the more mature bonds, permitting the policymaker to reduce the required jump in the tax rate needed to support the higher level of steady-state debt. Interestingly, the higher tax rates during the period of raised public consumption end up reducing the new steady-state level of debt so that the new steady-state tax rate is actually lower than before the shock. This contrasts to the case of the transfer shock where debt levels were raised following the shock.

Figure 9 reports optimal responses to news of a sustained increase in government spending five years in the future. Initially inflation falls and the tax rate jumps down in support of a debt level that is ultimately lower, despite the increase in government spending. This occurs because the policymaker raises the tax rate for the duration of the rise in public consumption to avoid the rapid accumulation of government debt in a period when real interest rates are relatively high. Bond prices rise as the anticipated increase in government spending approaches and then drop dramatically when the spending is realized.
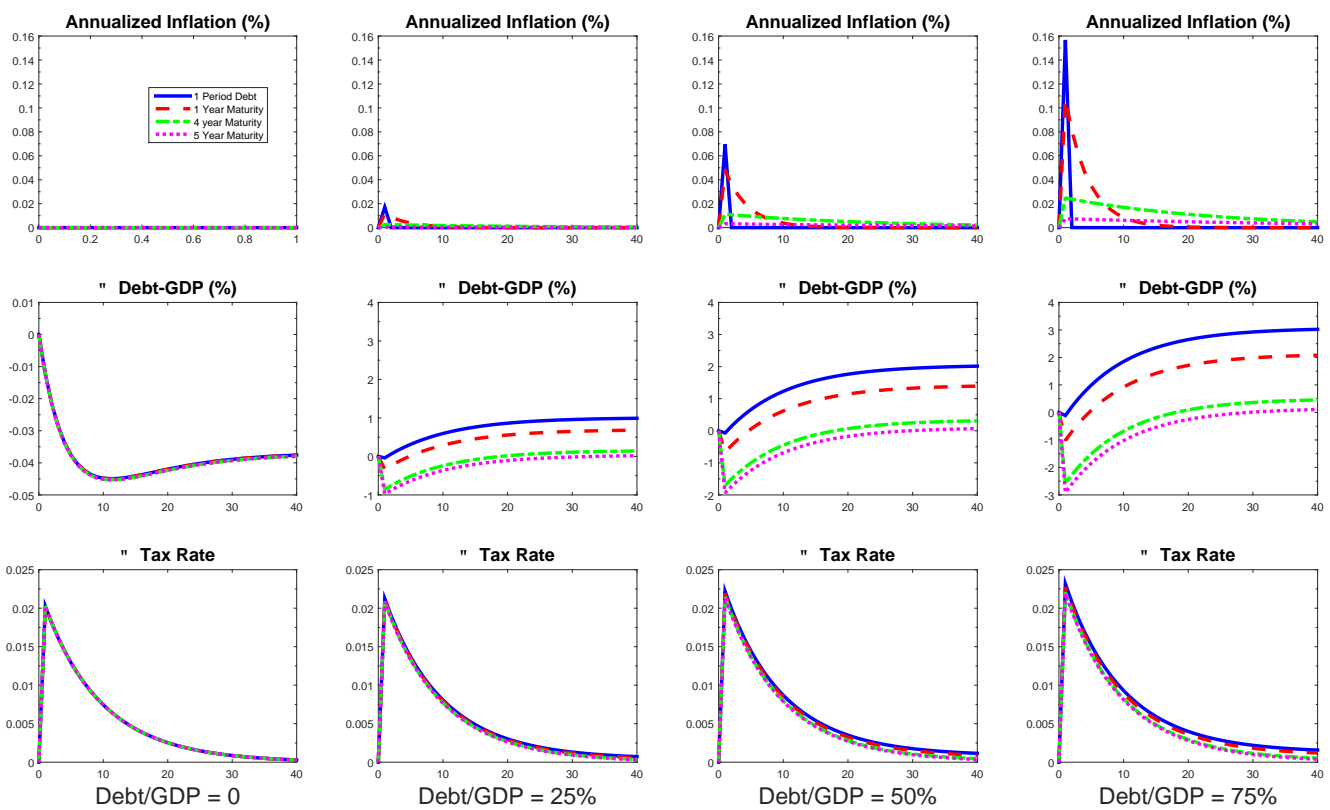

Figure 8: Optimal policy in response to higher government spending with different debt levels and maturities.

In this experiment the cost of inflation is quite high, $\theta=10$. A lower cost would lead 

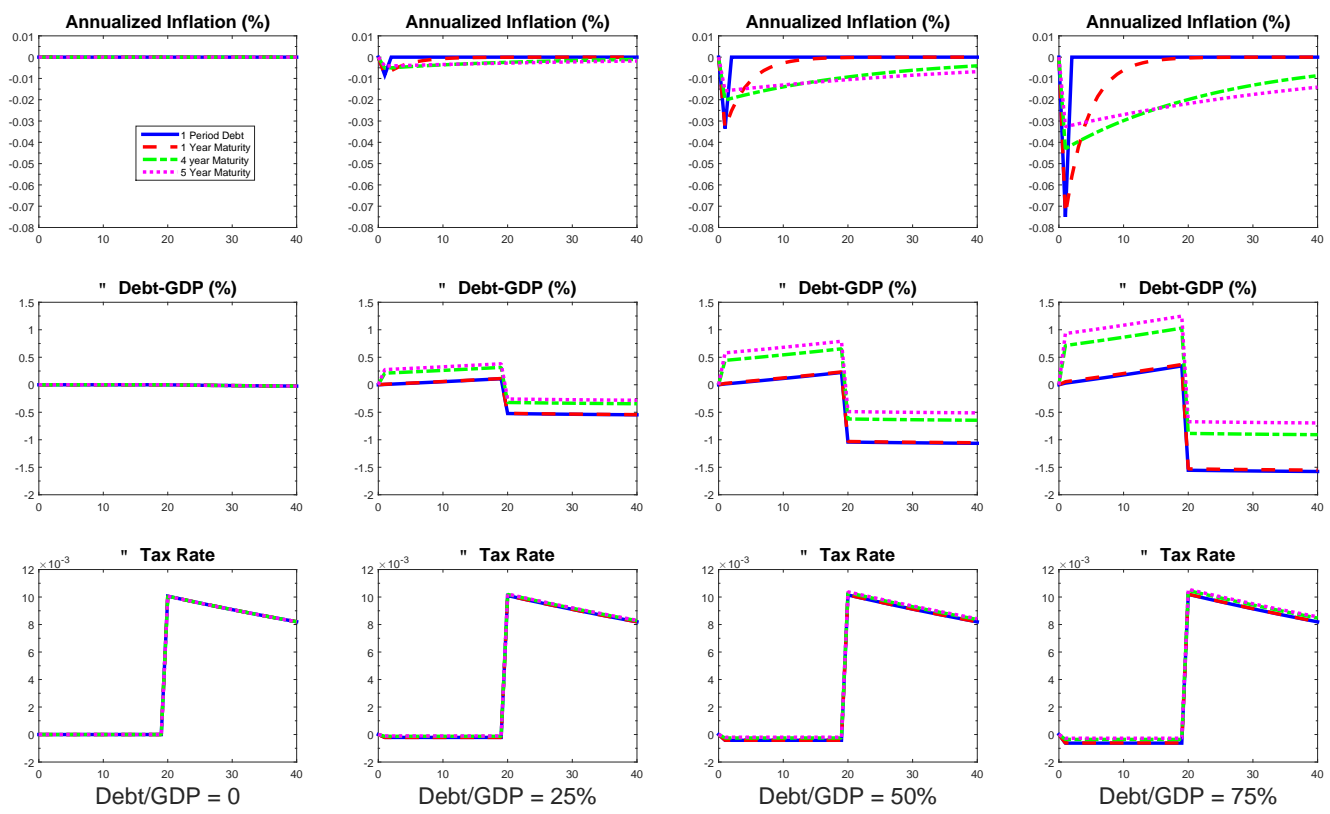

Figure 9: Optimal policy in response to an anticipated increase in government spending with different debt levels and maturities.

to greater reliance on the use of monetary policy and innovations in the anticipated path of prices to stabilize debt. As we show below, even this relatively conservative weight on the costs of inflation still generates a sizeable inflation bias when we consider time-consistent policy.

\subsection{Ramsey Policy with a General Maturity Structure}

Although the geometrically declining maturity structure is a tractable and plausible description of the profile of government debt for many economies, it is useful to broaden the analysis with a more general description of the maturity structure. This generalization refines the description of the role of optimal inflation surprises in stabilizing debt and begins to consider the role of debt management in insulating the government's finances from fiscal shocks. We employ Cochrane's (2001) notation, allowing the bond valuation equation to be written as in equation (19) in section 2.2.1. The government's optimization problem becomes

$$
\begin{aligned}
L_{0}= & E_{0} \sum_{t=0}^{\infty} \beta^{t}\left[-\frac{1}{2}\left(\tau_{t}^{2}+\theta\left(\nu_{t}-1\right)^{2}\right)\right. \\
& \left.+\lambda_{t}\left(-\sum_{j=0}^{\infty} E_{t}\left[\beta^{j} u^{\prime}\left(c_{t+j}\right) \prod_{s=0}^{j} \nu_{t+s}\right]\left[\frac{B_{t}(t+j)}{P_{t-1}}-\frac{B_{t-1}(t+j)}{P_{t-1}}\right]-u^{\prime}\left(c_{t}\right)\left(\tau_{t}-g_{t}-z_{t}\right)\right)\right]
\end{aligned}
$$


The first-order condition for taxation is

$$
-\tau_{t}=u^{\prime}\left(c_{t}\right) \lambda_{t}
$$

The debt management problem optimally chooses the maturity structure of debt issued in period $t$ which is repayable at future dates, $B_{t}(t+j)$, to yield the optimality condition

$$
\begin{gathered}
-\beta^{t} \lambda_{t} \beta^{j} E_{t} u^{\prime}\left(c_{t+j}\right) \prod_{s=0}^{j} \nu_{t+s} \frac{1}{P_{t-1}} \\
=-\beta^{t+1} E_{t} \lambda_{t+1} \beta^{j-1} u^{\prime}\left(c_{t+j}\right) \prod_{s=0}^{j} \nu_{t+s} \frac{1}{P_{t-1}}
\end{gathered}
$$

which can be simplified as

$$
\frac{\tau_{t}}{u^{\prime}\left(c_{t}\right)} E_{t} u^{\prime}\left(c_{t+j}\right) \prod_{s=0}^{j} \nu_{t+s}=E_{t} \frac{\tau_{t+1}}{u^{\prime}\left(c_{t+1}\right)} u^{\prime}\left(c_{t+j}\right) \prod_{s=0}^{j} \nu_{t+s}
$$

which implies

$$
E_{t}\left[\left[\frac{u^{\prime}\left(c_{t}\right)}{u^{\prime}\left(c_{t+1}\right)} \tau_{t+1}-\tau_{t}\right] \frac{u^{\prime}\left(c_{t+j}\right)}{u^{\prime}\left(c_{t}\right)} \frac{P_{t-1}}{P_{t+j}}\right]=0
$$

The covariance between the payoff of debt instrument of maturity $j$ periods and next period's tax rate is zero [Bohn (1990)]. This is the hedging across states that Angeletos (2002) and Buera and Nicolini (2004) explore. By structuring debt in this way the policymaker minimizes the fiscal and monetary adjustments required in the face of shocks; those policy adjustments then depend on the magnitude and maturity of the outstanding debt stock. To see how debt management can mitigate the need for adjusting tax rates and generating inflation in the face of fiscal shocks, we construct a simple example in the next sub-section where the policymaker can completely insulate the government's finances from government spending shocks.

The final first-order condition is for deflation

$$
-\beta^{t} \theta\left(\nu_{t}-1\right) \nu_{t}+\sum_{i=0}^{t} \beta^{i} \lambda_{i}\left(-\sum_{j=0}^{\infty}\left[\beta^{j} u^{\prime}\left(c_{i+j}\right) \prod_{s=0}^{j} \nu_{i+s}\right]\left[\frac{B_{i}(i+j)}{P_{i-1}}-\frac{B_{i-1}(i+j)}{P_{i-1}}\right]\right)
$$

This can be combined with the condition for debt management and quasi-differenced to obtain, under perfect foresight

$$
\left(\nu_{t}-1\right) \nu_{t}=\beta\left(\nu_{t+1}-1\right) \nu_{t+1}+\theta^{-1} \lambda_{0} u^{\prime}\left(c_{t}\right)\left[\frac{B_{-1}(t)}{P_{t}}\right]
$$


This expression highlights more clearly the link between inflation and the maturity structure of the pre-determined debt stock, than does the geometrically declining maturity structure. The inflation dynamics under the optimal policy are in a very similar form to the non-linear new Keynesian Phillips curve when price stickiness results from Rotemberg (1982) quadratic adjustment costs. The key difference is that the forcing variable is the element of the predetermined debt stock that matures in period $t$. Deflation/inflation anticipates the rate at which the debt stock issued at time $t=-1$ when the plan was formulated, matures. This makes current inflation reflect the discounted value of future debt as it matures. As debt matures, the effectiveness of inflation diminishes and inflation falls: the optimal rate of inflation jumps and gradually erodes until all the initial outstanding debt stock has matured. Notice that this Ramsey plan for inflation is only affected by debt dated at time $t=-1$, and the maturity structure of debt issued after this initial period is irrelevant in a perfect foresight environment. Future maturities will affect the government's ability to insure against fiscal shocks in a stochastic environment. We can see this latter point more clearly by considering a simple example.

\subsection{Commitment And Hedging}

Angeletos and Buera and Nicolini argue that debt maturity should be structured to insure the economy against shocks by having the government issue long-term liabilities, but hold an almost offsetting portfolio of short term assets (the net difference being the government's overall level of indebtedness). In the face of fluctuating spending needs and interest rates, bond prices adjust to help finance debt without requiring any change in taxation. In these papers the short and long positions are constant over time, so that they do not require active management, although numerically they are extremely large positions (for example, 5 or 6 times the value of GDP in Buera and Nicolini (2004)). This approach amounts to another way to introduce the contingency in overall debt payments even although these individual assets/liabilities are not state contingent.

To construct a simple example of the use of debt management for hedging purposes we consider an environment where taxes and transfers are at their steady state values $\left(\tau_{t+j}=\tau^{*}\right.$ and $z_{t+j}=z^{*}$. Government spending can either take the value of $g^{h}>g^{*}$, with probability $1 / 2$, or $g^{l}<g^{*}$ with complementary probability. Government debt takes the form of a singleperiod bond of quantity $b^{s}$ issued in period $t$, repayable in period $t+1$ and a portfolio of longer term bonds of geometrically declining maturity, so that the quantity of debt issued in period $t$ maturing in period $t+j$ is $\rho^{j} b^{m}$. With a single $i . i . d$. shock all that is required for complete hedging is that the maturity structure contain both one- and two-period debt to enable us to perfectly hedge, as in Buera and Nicolini. With additional i.i.d. shock processes, complete 
hedging is not possible, as we would require some persistence in the shock process and longer term debt. Because we wish to contrast this case with a scenario where a time-consistent policymaker seeks to use debt management for the purposes of hedging and mitigating timeconsistency problems, we allow for a combination of longer term bonds and short-term bonds in which varying proportions of the two types can act as a proxy for changes in average debt maturity. In this example, transfer shocks, which amount to shocks that do not directly affect bond prices and interest rates, cannot be completed hedged, although movements in inflation as part of the optimal policy response could provide some hedging opportunities.

Generalizing the Ramsey policy considered above to include a single-period nominal bond as well as the portfolio of bonds with geometrically declining maturity, the system of firstorder conditions to be solved as part of the Ramsey problem is

$$
\begin{aligned}
& -\theta\left(\nu_{t}-1\right)+\widetilde{\mu}_{t-1}\left(1+\rho P_{t}^{m}\right) c_{t}^{-\sigma}+\widetilde{\gamma}_{t-1} c_{t}^{-\sigma}-\left(1+\rho P_{t}^{m}\right) \tau_{t} b_{t-1}-\tau_{t} b_{t-1}^{s}=0 \\
& \tau_{t} b_{t}-\widetilde{\mu}_{t} c_{t}^{-\sigma}-\rho \nu_{t}\left(\tau_{t} b_{t-1}-\widetilde{\mu}_{t-1} c_{t}^{-\sigma}\right)=0 \\
& \tau_{t} b_{t}^{s}-\widetilde{\gamma}_{t} c_{t}^{-\sigma}=0 \\
& \tau_{t} P_{t}^{m}-\beta E_{t}\left(1+\rho P_{t+1}^{m}\right) \nu_{t+1} \tau_{t+1}=0 \\
& \tau_{t} P_{t}^{s}-\beta E_{t} \nu_{t+1} \tau_{t+1}=0 \\
& \beta E_{t} \frac{\left(1+\rho P_{t+1}^{m}\right)}{P_{t}^{m}}\left(\frac{c_{t+1}}{c_{t}}\right)^{-\sigma} \nu_{t+1}-1=0 \\
& \beta E_{t}\left(\frac{c_{t+1}}{c_{t}}\right)^{-\sigma} \nu_{t+1}-P_{t}^{s}=0 \\
& b_{t} P_{t}^{m}+b_{t}^{s} P_{t}^{s}-\left(1+\rho P_{t}^{m}\right) b_{t-1} \nu_{t}-b_{t-1}^{s} \nu_{t}-g_{t}-z^{*}+\tau_{t}=0 \\
& g_{t}=g^{i}, i=h, l \text { with prob } 1 / 2
\end{aligned}
$$

where $\widetilde{\mu}_{t-1}=\frac{\mu_{t-1}}{P_{t-1}^{m} c_{t-1}^{-\sigma}}, \widetilde{\gamma}_{t-1}=\frac{\gamma_{t-1}}{P_{t-1}^{s} c_{t-1}^{-\sigma}}$ and $\gamma_{t}$ is the Lagrange multiplier associated with the pricing of single-period bonds, $P_{t}^{s}=\beta E_{t}\left(\frac{c_{t+1}}{c_{t}}\right)^{-\sigma} \nu_{t+1}$. There are four state variables$\widetilde{\mu}_{t-1}, \widetilde{\gamma}_{t-1}, b_{t}, b_{t}^{s}$ - the first two of which capture the history dependence in policymaking under commitment. Despite the complexity of these first-order conditions, the policymaker can fulfill this Ramsey program with a constant tax rate and no inflation by buying an appropriate quantity of single-period assets paid for by issuing longer-term bonds. Shocks to public consumption then induce fluctuations in the prices of these assets/liabilities which perfectly insulate the government's finances.

With i.i.d. fluctuations in government spending, the current level of spending is also a state variable: we are either in the high- or low-government spending regime and may exit that regime with a probability of $1 / 2$ each period. 
The pricing equation for geometrically declining coupon bonds is

$$
P_{t}^{m}=\beta E_{t}\left(1+\rho P_{t+1}^{m}\right)\left(\frac{c_{t+1}}{c_{t}}\right)^{-\sigma} \nu_{t+1}
$$

With government spending fluctuating between high and low states, bond prices will fluctuate depending on the spending state. Define $u_{i j}=\frac{u^{\prime}\left(1-g^{i}\right)}{u^{\prime}\left(1-g^{j}\right)}=\frac{\left(1-g^{i}\right)^{-\sigma}}{\left(1-g^{j}\right)^{-\sigma}}, i, j=l, h$, and $\mathrm{i} \neq j$ bond prices in spending regime $i, i=h, l$ are given by

$$
\begin{aligned}
P_{i}^{m} & =\beta \frac{1}{2}\left(1+\rho P_{i}^{m}\right)+\beta \frac{1}{2}\left(1+\rho P_{j}^{m}\right) u_{j i} \\
& =A_{i}+B_{i} P_{j}^{m}
\end{aligned}
$$

where $A_{i}=\left(1-\frac{1}{2} \beta \rho\right)^{-1}\left(\frac{1}{2} \beta+\frac{1}{2} \beta u_{j i}\right)$ and $B_{i}=\left(1-\frac{1}{2} \beta \rho\right)^{-1} \frac{1}{2} \beta \rho u_{j i}, i, j=l, h$, and $i \neq j$, which can be solved as

$$
P_{i}^{m}=\frac{A_{i}+B_{i} A_{j}}{1-B_{i} B_{j}}
$$

For one-period debt this reduces to

$$
P_{i}^{s}=\frac{1}{2} \beta+\frac{1}{2} \beta u_{j i}
$$

Optimal hedging uses these fluctuations in bond prices to construct of portfolio of government debt that negates the need to vary taxes or induce inflation surprises, despite the random movements in government consumption.

The flow budget identity conditional on the government spending regime, but with constant tax rates and no inflation, is

$$
P_{i}^{m} b^{m}+P_{i}^{s} b^{s}=\left(1+\rho P_{i}^{m}\right) b^{m}+b^{s}-\left(\tau^{*}-g^{i}-z^{*}\right)
$$

We choose $b^{m}$ and $b^{s}$ to ensure this equation holds regardless of the government spending regime, so that the government does not need to issue or retire debt as it moves between low and high spending regimes. This portfolio is given by

$$
\left[\begin{array}{c}
b^{m} \\
b^{s}
\end{array}\right]=-\left[\begin{array}{cc}
P_{i}^{m}(1-\rho)-1 & P_{i}^{s}-1 \\
P_{j}^{m}(1-\rho)-1 & P_{j}^{s}-1
\end{array}\right]^{-1}\left[\begin{array}{c}
\tau^{*}-g^{i}-z^{*} \\
\tau^{*}-g^{j}-z^{*}
\end{array}\right]
$$

We can achieve the same portfolio by considering the debt valuation equation in a given period, which is contingent on the government spending state. If government spending is 
currently high, that equation is

$$
\begin{aligned}
& b^{s}\left(u^{\prime}\left(c^{h}\right)\right)+b^{m}\left(u^{\prime}\left(c^{h}\right)\right)+\sum_{j=1}^{\infty}(\rho \beta)^{j}\left[\frac{1}{2} u^{\prime}\left(c^{l}\right)+\frac{1}{2} u^{\prime}\left(c^{h}\right)\right] b^{m} \\
= & u^{\prime}\left(c^{h}\right)\left(\tau^{*}-g^{h}-z^{*}\right)+\sum_{j=1}^{\infty} \beta^{j}\left[\frac{1}{2} u^{\prime}\left(c^{l}\right)\left(\tau^{*}-g^{l}-z^{*}\right)+\frac{1}{2} u^{\prime}\left(c^{h}\right)\left(\tau^{*}-g^{h}-z^{*}\right)\right]
\end{aligned}
$$

and if government spending is low it is

$$
\begin{aligned}
& b^{s}\left(u^{\prime}\left(c^{l}\right)\right)+b^{m}\left(u^{\prime}\left(c^{l}\right)\right)+\sum_{j=1}^{\infty}(\rho \beta)^{j}\left[\frac{1}{2} u^{\prime}\left(c^{l}\right)+\frac{1}{2} u^{\prime}\left(c^{h}\right)\right] b^{m} \\
= & u^{\prime}\left(c^{l}\right)\left(\tau^{*}-g^{l}-z^{*}\right)+\sum_{j=1}^{\infty} \beta^{j}\left[\frac{1}{2} u^{\prime}\left(c^{l}\right)\left(\tau^{*}-g^{l}-z^{*}\right)+\frac{1}{2} u^{\prime}\left(c^{h}\right)\left(\tau^{*}-g^{h}-z^{*}\right)\right]
\end{aligned}
$$

subtracting one from the other implies

$$
\left[b^{s}+b^{m}\right]\left(u^{\prime}\left(c^{h}\right)-u^{\prime}\left(c^{l}\right)\right)=u^{\prime}\left(c^{h}\right)\left(\tau^{*}-g^{h}-z^{*}\right)-u^{\prime}\left(c^{l}\right)\left(\tau^{*}-g^{l}-z^{*}\right)
$$

Without any change in taxation or inflation, government solvency is ensured, provided that debt maturing in the current period has the value implied by this equation. Assuming a sufficiently low level of net indebtedness, the primary budget will swing between deficit and surplus as government spending moves from high to low regimes, implying that the right side of (39) is negative. Since $u^{\prime}\left(c^{h}\right)>u^{\prime}\left(c^{l}\right)$, this condition requires that the Ramsey policymaker buys short term assets to such an extent that $b^{s}<-b^{m}$. The budget identity is insulated from the effects of government spending shocks, which can be absorbed by bond prices without any need to issue new debt, change taxes or generate inflation surprises.

The size of the longer term liabilities must, equivalently, satisfy the solvency conditions conditional on the current level of government consumption. For example

$$
\begin{aligned}
& b^{s}\left(u^{\prime}\left(c^{h}\right)\right)+b^{m}\left(u^{\prime}\left(c^{h}\right)\right)+\sum_{j=1}^{\infty}(\rho \beta)^{j}\left[\frac{1}{2} u^{\prime}\left(c^{l}\right)+\frac{1}{2} u^{\prime}\left(c^{h}\right)\right] b^{m} \\
= & u^{\prime}\left(c^{h}\right)\left(\tau^{*}-g^{h}-z^{*}\right)+\sum_{j=1}^{\infty} \beta^{j}\left[\frac{1}{2} u^{\prime}\left(c^{l}\right)\left(\tau^{*}-g^{l}-z^{*}\right)+\frac{1}{2} u^{\prime}\left(c^{h}\right)\left(\tau^{*}-g^{h}-z^{*}\right)\right]
\end{aligned}
$$


which can be written as

$$
\begin{aligned}
& \frac{\rho \beta}{1-\rho \beta}\left[\frac{1}{2} u^{\prime}\left(c^{l}\right)+\frac{1}{2} u^{\prime}\left(c^{h}\right)\right] b^{s}+b^{s} u^{\prime}\left(c^{h}\right)+b^{m} u^{\prime}\left(c^{h}\right) \\
= & \frac{\beta}{1-\beta}\left[\frac{1}{2} u^{\prime}\left(c^{l}\right)\left(\tau^{*}-g^{l}-z^{*}\right)+\frac{1}{2} u^{\prime}\left(c^{h}\right)\left(\tau^{*}-g^{h}-z^{*}\right)\right]+u^{\prime}\left(c^{h}\right)\left(\tau^{*}-g^{h}-z^{*}\right)
\end{aligned}
$$

This expression can either define the steady-state level of long term debt given the tax rate or the tax rate given the long-term debt stock. Either interpretation is consistent with a steadystate solution to the Ramsey tax smoothing plan where the solution of the remainder of the Ramsey problem is $\tau_{t}=\tau^{*}, z_{t}=z^{*}=0.18 y, \nu_{t}=1, \frac{\gamma_{i}}{P_{i}^{s}}=\tau^{*} b^{s}, \frac{\mu_{i}}{P_{i}^{m}}=\tau^{*} b^{m}, i=h, l$ with probability of $1 / 2$. In other words, the steady-state tax rate can support the average level of government spending, steady-state transfers and the steady-state net debt stock, while fluctuations in bond prices mitigate the need for further tax adjustments to compensate for fluctuations in government spending.

Figure 10 reveals the pattern of bond returns and the underlying asset positions for a series of random draws across the two spending regimes. The figure's bottom right panel describes a particular realization of the government spending shocks. Despite these movements in spending the budget identity can be satisfied with a constant tax rate and no inflation surprises by buying short-term assets that are funded by issuing longer-term debt. The portfolio that achieves this implies that the government holds short-term assets of around 22 percent of GDP, with longer term liabilities of around 70 percent of GDP and a net debt of around 48 percent. Although large, these positions are less than those typically found for richer stochastic processes, where positions often exceed the economy's total endowment by several factors [Buera and Nicolini (2004)]. Since the ability to hedge relies on variation in the yield curve having longer term liabilities to set against the short-term assets is most effective. Then a portfolio of single-period assets matched with 1-year liabilities requires far more short-term assets, compared to a portfolio made up of the same assets and bonds with an average maturity of five years. Hedging in this way implies that a positive shock to government spending, which raises the primary deficit actually leads to a reduction in the value of government indebtedness, rather than to an increase. This is a general prediction of models that have achieved financial market completeness which Marcet and Scott (2009) use as the basis of an empirical test, but the data strongly reject.

Faraglia, Marcet, and Scott (2008) extend Buera and Nicolini's analysis to move away from an endowment economy to consider a production economy with capital. This makes the size of the extreme portfolio positions even larger, and now the liability/asset positions are no longer constant, but highly volatile, possibly even reversing the issue-long-buy-short 

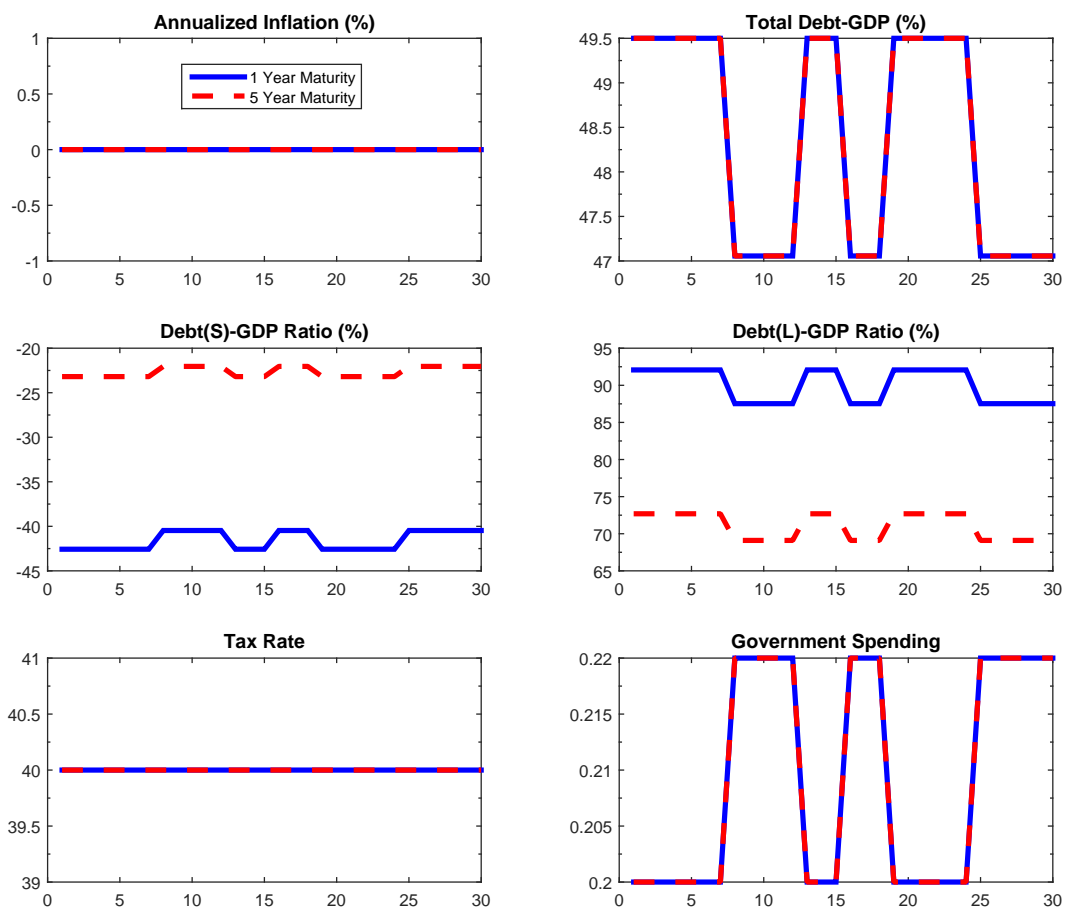

Figure 10: Optimal hedging under commitment.

recommendation. Because yield premia are not very volatile, they are therefore not very effective as a source of insurance. They then consider what happens if the government is unsure about the specification of some element of the model. The sensitivity of results to small changes in model specification means that it is often better to run a balanced budget than run the risk of getting the portfolio composition wrong. Similarly, even modest transaction costs would make it undesirable to construct such huge portfolios.

\subsection{Discretion}

A large part of the literature that extends Lucas and Stokey's (1983) analysis focuses on the importance of having access to state-contingent debt either directly or by using inflation surprises and debt management to render state dependent the real payoffs from government debt. When the policymaker can replicate the Ramsey policy in Lucas and Stokey through such devices, there remains the issue of whether the underlying policy is time consistent. In the original Lucas and Stokey model, the Ramsey policy can be made time-consistent by adhering to a particular debt maturity structure. Lucas and Stokey then conjecture that allowing debt to be nominal would make the policy problem trivial: positive debt would be costlessly deflated by positive surprise inflation and negative debt would be adjusted by 
surprise deflation to the level sufficient to support the first-best allocation (the interest on the debt paying for government consumption, consistent with any fiscal taxes/subsidies required by offset other market distortions). This reasoning suggests that the only interesting case is when the outstanding debt stock is zero.

Persson, Persson, and Svensson (1987) initiated a debate exploring the Lucas and Stokey conjecture. $^{38}$ Alvarez, Kehoe, and Neumeyer (2004) conclude that the Lucas and Stokey structure of state-contingent indexed debt, in combination with a condition that net nominal debt is zero so that government debt liabilities equal the stock of money, can ensure the timeconsistency of the original Lucas and Stokey Ramsey policy in a monetary economy that follows the Friedman rule. As Persson, Persson, and Svensson (2006) note, these conditions essentially reduce the monetary version of the Lucas and Stokey economy to its real version.

Bohn (1988) argues that in issuing nominal debt the policymaker trades-off the ability to use inflation surprises as a hedging device when debt is nominal against the inflation bias that a positive stock of debt creates. In models where the problem is not constructed to mimic the Lucas and Stokey Ramsey policy, the time-consistent policy typically implies a mean reverting steady state level of debt. Debt can be positive or negative, depending on the nature of the time-inconsistency problem. The issue of the time-consistency of policy is also dependent on the cost of inflation surprises. Persson, Persson, and Svensson (2006) use beginning- rather than end-of-period money balances in the provision of liquidity services to make unexpected inflation costly, which allows them to construct a time-consistent portfolio of indexed and nominal debt. Martin (2009) adopts the cash-credit good distinction in Lucas and Stokey to generate a cost to inflation which is then balanced against the gains from using inflation to reduce the value of single-period nominal debt. This generates a mean reverting steady-state level of debt under discretion, rather than the random walk in steady-state debt, which is a feature of the Ramsey tax smoothing policy without state contingent debt. Martin (2011) combines the Lagos and Wright (2005) monetary search model with fiscal policy and explores the time-consistency problem to find that the welfare costs of an inability to commit are small. This conclusion likely reflects the nature of the costs of surprise inflation; as noted above, when Schmitt-Grohé and Uribe (2004) introduce even a tiny degree of nominal inertia, the time-inconsistent Ramsey policy tilts very firmly in favour of price stability, away from the Friedman rule and the use of inflation surprises.

We now turn to consider the impact on the balance between monetary and fiscal policy of constraining the policymaker to be time-consistent. We continue to use the endowment economy where inflation is assumed to be costly as a short-cut to introducing nominal inertia.

The policymaker cannot make credible promises about how they will behave in the future

\footnotetext{
${ }^{38}$ Persson, Persson, and Svensson (2006) chart the course of this debate.
} 
in order to improve policy trade-offs today. However, even in this simple model there is an endogenous state variable in the form of government debt, so that policy actions today will affect future expectations through the level of debt that the policy bequeaths to the future. We define the auxiliary variable

$$
M\left(b_{t-1}, g_{t-1}\right)=\left(1+\rho P_{t}^{m}\right) \nu_{t}\left(c_{t}\right)^{-\sigma}
$$

to write the Bellman equation of the associated policy problem as

$$
\begin{aligned}
V\left(b_{t-1}, g_{t-1}\right)= & -\frac{1}{2}\left(\tau_{t}^{2}+\theta\left(\nu_{t}-1\right)^{2}\right)+\beta E_{t} V\left(b_{t}, g_{t}\right) \\
& +\mu_{t}\left(\beta \frac{c_{t}^{\sigma}}{P_{t}^{m}} E_{t} M\left(b_{t}, g_{t}\right)-1\right) \\
& +\lambda_{t}\left(b_{t} P_{t}^{m}-\left(1+\rho P_{t}^{m}\right) b_{t-1} \nu_{t}-g_{t}-z_{t}+\tau_{t}\right)
\end{aligned}
$$

We have replaced the expectations in the bond-pricing equation with the auxiliary variable to indicate that the policymaker cannot influence those expectations directly by making policy commitments. But those expectations are a function of the state variables. We take government spending and transfers to be exogenous autoregressive processes.

The implies the first-order conditions

$$
\begin{aligned}
\tau_{t} & : \quad-\tau_{t}+\lambda_{t}=0 \\
\nu_{t} & :-\theta\left(\nu_{t}-1\right)-\lambda_{t}\left(1+\rho P_{t}^{m}\right) b_{t-1}=0 \\
P_{t}^{m} & : \quad-\frac{\mu_{t}}{P_{t}^{m}}+\lambda_{t}\left(b_{t}-\rho b_{t-1} \nu_{t}\right)=0 \\
b_{t} & : \quad \frac{\mu_{t}}{P_{t}^{m}} c_{t}^{\sigma} \beta E_{t} \frac{\partial M\left(b_{t}, g_{t}\right)}{\partial b_{t}}+\lambda_{t} P_{t}^{m}+\beta E_{t} \frac{\partial V\left(b_{t}, g_{t}\right)}{\partial b_{t}}=0
\end{aligned}
$$

From the envelope theorem

$$
\frac{\partial V\left(b_{t-1}, g_{t-1}\right)}{\partial b_{t-1}}=-\left(1+\rho P_{t}^{m}\right) \nu_{t} \lambda_{t}
$$

which can be led one period and substituted into the first-order condition for government debt

$$
\frac{\mu_{t}}{P_{t}^{m}} c_{t}^{\sigma} \beta E_{t} \frac{\partial M\left(b_{t}, g_{t}\right)}{\partial b_{t}}+\lambda_{t} P_{t}^{m}-\beta E_{t}\left(1+\rho P_{t+1}^{m}\right) \nu_{t+1} \tau_{t+1}=0
$$

Combining the condition for the bond price $P_{t}^{m}$ with the Fisher equation implies

$$
\frac{\mu_{t}}{P_{t}^{m}}=\lambda_{t}\left(b_{t}-\rho \nu_{t} b_{t-1}\right)
$$


which can be used to eliminate $\frac{\mu_{t}}{P_{t}^{m}}$ from the condition for debt. The system to be solved for $\left\{P_{t}^{m}, \nu_{t}, \tau_{t}, b_{t}, g_{t}\right\}$ is

$$
\begin{array}{ll}
\nu_{t} & : \quad-\theta\left(\nu_{t}-1\right)-\tau_{t}\left(1+\rho P_{t}^{m}\right) b_{t-1}=0 \\
b_{t} & : \quad \tau_{t}\left(b_{t}-\rho \nu_{t} b_{t-1}\right) \beta c_{t}^{\sigma} E_{t} \frac{\partial M\left(b_{t}, g_{t}\right)}{\partial b_{t}}+\tau_{t} P_{t}^{m}-\beta E_{t}\left(1+\rho P_{t+1}^{m}\right) \nu_{t+1} \tau_{t+1}=0
\end{array}
$$

along with the bond pricing equation and the government's budget constraint.

The first-order condition for inflation is now

$$
-\theta\left(\nu_{t}-1\right)=\left(1+\rho P_{t}^{m}\right) b_{t-1} \tau_{t}
$$

Under commitment, inflation persisted only for as long as the maturity structure of the predetermined debt stock at the time a shock hit. Under time-consistent policy, outside of the policymaker's bliss point (of zero inflation and no taxation), with a non-zero debt stock there will always be a state-dependent mix of taxation and inflation. A positive stock of debt delivers positive inflation, regardless of the maturity structure of that debt. This reflects the inflation bias inherent in the time-consistent policy in the presence of nominal debt.

We can see some more differences between discretion and commitment by contrasting the equivalent expressions describing the evolution of the tax rate. Under commitment we obtain the standard tax-smoothing result adjusted for the tilting implied by variations in the stochastic discount factor

$$
\tau_{t} P_{t}^{m}=\beta E_{t}\left(1+\rho P_{t+1}^{m}\right) \nu_{t+1} \tau_{t+1}
$$

The equivalent condition under discretion is

$$
\tau_{t} P_{t}^{m}=\beta E_{t}\left(1+\rho P_{t+1}^{m}\right) \nu_{t+1} \tau_{t+1}-\tau_{t}\left(b_{t}-\rho \nu_{t} b_{t-1}\right) \beta c_{t}^{\sigma} E_{t} \frac{\partial M\left(b_{t}, g_{t}\right)}{\partial b_{t}}
$$

The additional term captures the effects of the tax rate on expectations of inflation and bond prices through the level of debt carried into the future. Increased debt raises expected inflation and lowers expected bond prices, so $E_{t} \frac{\partial M\left(b_{t}, g_{t}\right)}{\partial b_{t}}<0$. This captures the debtcontingent nature of the time-consistency problem facing the policymaker. As debt levels rise the policymaker faces a greater temptation to utilize surprise inflation to reduce the debt burden. Economic agents anticipate this and raise their inflationary expectations until the temptation to induce surprises is offset. However, unlike in the standard analysis of the inflationary bias problem this bias is not static since the policymaker can raise additional distortionary taxes to reduce debt and its associated inflation. Therefore the additional term 
in the above expression raises the tax rate above the level implied by the tax-smoothing condition observed under commitment. Where the tax rate under commitment was carefully constructed to allow debt levels to permanently rise, under discretion the tax rate prevents debt from rising permanently. ${ }^{39}$ Moreover, the rate at which the policymaker reduces debt under discretion depends crucially on the term, $\left(b_{t}-\rho \nu_{t} b_{t-1}\right)$ which in turn depends on the maturity structure of the debt stock. Effectively the lower bond prices mean the policymaker must issue more bonds to finance a given deficit, but pays less to buy back the existing debt stock. As debt maturity is increased this latter effect comes to dominate the former and the speed of debt reduction is reduced. Therefore, in contrast to the random walk in steady-state debt observed under commitment, the time-consistent policymaker returns debt to a steadystate value that is very close to zero, but slightly negative where the speed of adjustment depends crucially on average debt maturity. This cannot be seen entirely analytically, so we need to analyze the numerical solution to the time-consistent policy problem to gain further insight.

The numerical solution under discretion is radically different from that under commitment [figure 11]. Under commitment, policy allows the steady state level of debt to follow a random walk and the use of inflation to offset shocks is relatively modest. Under discretion there is a unique steady state at which the policy supporting the steady-state debt level is time consistent, and this occurs at a slightly negative debt stock with a mild deflation. The negative steady-state debt stock falls far short of the negative debt levels that would be needed to support the first-best allocation - that is, the stock of government-held assets generates interest income sufficient to pay for all transfers and government spending without levying any distortionary taxes. Private-sector expectations ensure that the policymaker does not accumulate such a level of assets. Bondholders know that once the government has accumulated a positive stock of assets, it has an incentive to introduce surprise deflation to increase the real value of those assets. This knowledge reduces agents' inflation expectations until the policymaker no longer wishes to introduce such deflationary surprises. Accumulating more assets would then worsen this incentive to deflate confronting the policymaker with a trade-off between accumulating assets to reduce tax rates and the expected deflation that the accumulation of assets implies. In the steady state a balance is struck with a mild deflation and small negative debt stock, although both are extremely close to zero.

At positive debt levels there is a significant desire to reduce debt through inflation surprises. Economic agents anticipate this and raise their inflationary expectations. Positive debt levels raise inflation in a highly nonlinear way because they introduce a state-dependent

\footnotetext{
${ }^{39}$ Calvo and Guidotti (1992) label this the "debt aversion" effect and Leith and Wren-Lewis (2013) call it the "debt-stabilization bias."
} 

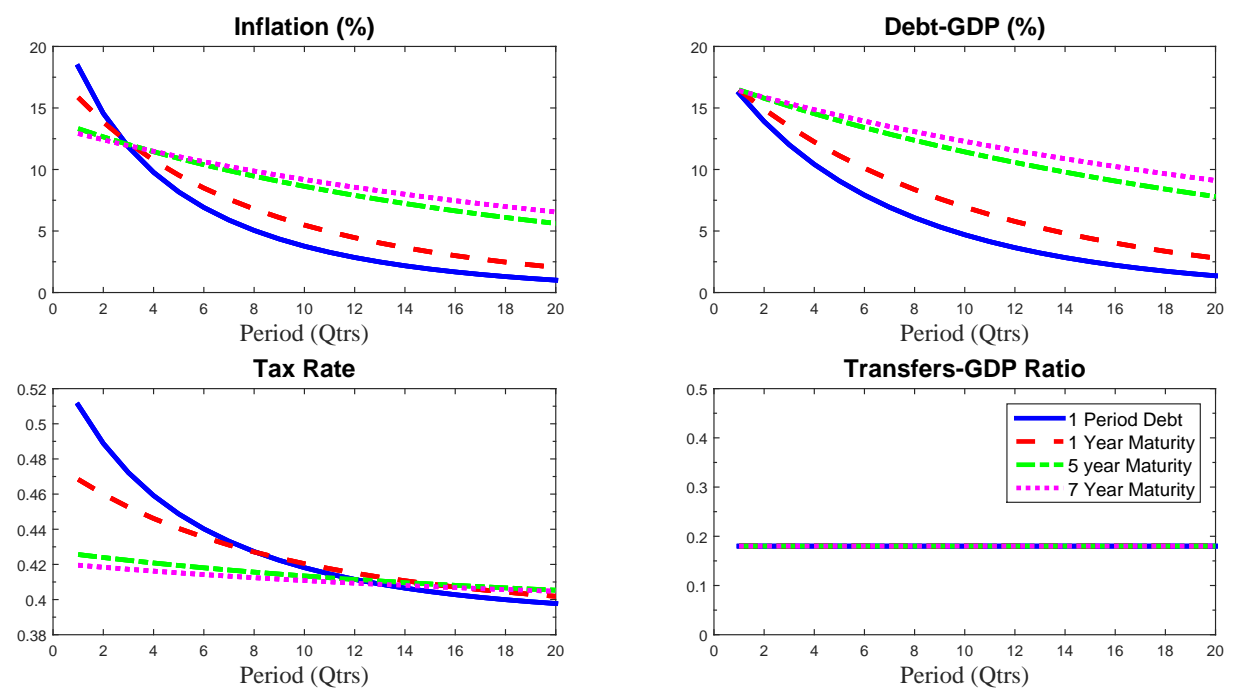

Figure 11: Optimal time-consistent policy when debt is above its steady-state level.

inflationary bias which can be very large. Even modest debt-to-GDP ratios can imply double digit inflation. This is a surprising outcome since the same model and parameterization under commitment implies no inflation at all in the absence of shocks and only small inflation with shocks and positive debt levels.

As noted above, the policymaker's desire to mitigate this bias leads to a deviation from tax smoothing where the policymaker raises distortionary taxation above the tax smoothing level to not only stabilize debt, but to reduce it towards its steady-state value. Debt maturity lessens this debt stabilization bias problem so that for a given debt-to-GDP ratio inflation is lower the longer is debt maturity. The debt stabilization bias is heavily dependent on the magnitude of the government debt stock. When debt is high, the efficacy of surprise inflation - either current inflation or through bond prices - is also much higher and this raises the government's incentives to use this device to stabilize debt. As a result the debt stabilization bias rises dramatically with debt levels.

In the absence of innovations to the fiscal surplus, this higher inflation does not actually stabilize debt. As in the original inflation bias problem, there is a pure cost in the form of higher inflation which does not generate any reduction in debt. ${ }^{40}$ But unlike the original inflation bias problem, in our case the magnitude of the bias is endogenous and depends on the size and maturity of the government debt. The policymaker can choose to reduce debt through taxation to gradually reduce the bias. Under discretion the reduction in debt can be a quite rapid, particularly when the debt stock is large and of short maturity. The costs of the policymaker being unable to commit in this context are not that debt is unstable,

\footnotetext{
${ }^{40}$ Analogously, in Barro and Gordon (1983) this additional inflation does not reduce unemployment.
} 
but that the policymaker too aggressively returns government debt to its steady state level following shocks. This message resonates when thinking about actual fiscal austerity policies in many countries after the 2008 global financial crisis.

\subsection{Debt Management under Discretion}

The above results highlight the time consistency issues created by nominal debt. The existing optimal policy literature also considers time-consistency issues in relation to debt management issues. Specifically, in the Lucas and Stokey model with state-contingent debt, the maturity structure is key in ensuring that the Ramsey policy described in Lucas and Stokey is time consistent. At the same time, the optimal hedging analysis shows that the maturity structure can create a portfolio of government bonds that features the right state-contingent payoffs even when the underlying bonds are not state contingent. In the context of a real model, Debortoli, Nunes, and Yared (2014) also allow the government to hold short-term assets and longer term liabilities (which are individually not state contingent), but require the policy to be time-consistent. They show that the optimal policy results in a relatively flat maturity structure that offsets the costs of not being able to commit even although this removes the tilting in maturity that is beneficial in terms of insurance effects.

To assess the trade-offs between optimal hedging and time-consistency, we use the same model that delivered complete hedging of government expenditure shocks under commitment, and solve that model under discretion. In introducing single-period bonds to the timeconsistent policy problem we need to define an additional auxiliary variable

$$
N\left(b_{t-1}, b_{t-1}^{s}, g_{t-1}\right)=\nu_{t}\left(c_{t}\right)^{-\sigma}
$$

All expectations are now a function of three state variables, longer term bonds, $b_{t-1}$, single period bonds, $b_{t-1}^{s}$ and government spending, $g_{t-1}$, which will either equal $0.22 y$ in the high spending regime, or $0.2 y$ in the low spending case.

The policy problem is

$$
\begin{aligned}
V\left(b_{t-1}, b_{t-1}^{s}, g_{t-1}\right)= & -\frac{1}{2}\left(\tau_{t}^{2}+\theta\left(\nu_{t}-1\right)^{2}\right)+\beta E_{t} V\left(b_{t}, b_{t}^{s}, g_{t}\right) \\
& +\mu_{t}\left(\beta \frac{c_{t}^{\sigma}}{P_{t}^{m}} E_{t} M\left(b_{t}, b_{t}^{s}, g_{t}\right)-1\right) \\
& +\gamma_{t}\left(\beta E_{t} \frac{c_{t}^{\sigma}}{P_{t}^{s}} E_{t} N\left(b_{t}, b_{t}^{s}, g_{t}\right)-1\right) \\
& +\lambda_{t}\left(b_{t} P_{t}^{m}+b_{t}^{s} P_{t}^{s}-\left(1+\rho P_{t}^{m}\right) b_{t-1} \nu_{t}-b_{t-1}^{s} \nu_{t}-g_{t}+\tau_{t}-z_{t}\right)
\end{aligned}
$$

which has an additional constraint associated with the pricing of short-term bonds, and the 
government's flow budget identity contains both single-period and declining coupon bonds. After applying the envelope theorem this implies the first-order conditions. For inflation

$$
-\theta\left(\nu_{t}-1\right)=\tau_{t}\left[\left(1+\rho P_{t}^{m}\right) b_{t-1}+b_{t-1}^{s}\right]
$$

The level of inflation depends on the total level of indebtedness across short and long bonds, so that a positive level of net indebtedness implies an inflationary bias. As before, this bias serves no purpose in terms of reducing the real debt burden, but reflects economic agents' expectations than if inflation were any lower, the policy would be tempted to introduce a surprise inflation to facilitate debt reduction.

The tax smoothing conditions are

$$
\begin{aligned}
\tau_{t} P_{t}^{m}= & \beta E_{t}\left(1+\rho P_{t+1}^{m}\right) \nu_{t+1} \tau_{t+1}-\tau_{t}\left(b_{t}-\rho \nu_{t} b_{t-1}\right) \beta c_{t}^{\sigma} E_{t} \frac{\partial M\left(b_{t}, b_{t}^{s}, g_{t}\right)}{\partial b_{t}} \\
& -\tau_{t} b_{t}^{s} \beta c_{t}^{\sigma} E_{t} \frac{\partial N\left(b_{t}, b_{t}^{s}, g_{t}\right)}{\partial b_{t}}
\end{aligned}
$$

and

$$
\begin{aligned}
\tau_{t} P_{t}^{s}= & \beta E_{t} \nu_{t+1} \tau_{t+1}-\tau_{t}\left(b_{t}-\rho \nu_{t} b_{t-1}\right) \beta c_{t}^{\sigma} E_{t} \frac{\partial M\left(b_{t}, b_{t}^{s}, g_{t}\right)}{\partial b_{t}^{s}} \\
& -\tau_{t} b_{t}^{s} \beta c_{t}^{\sigma} E_{t} \frac{\partial N\left(b_{t}, b_{t}^{s}, g_{t}\right)}{\partial b_{t}^{s}}
\end{aligned}
$$

The first two terms of these expressions reflect the same tax-smoothing conditions found under commitment, where the choice of short-term assets and longer-term bonds could satisfy these conditions while perfectly insulating the government's finances from the fluctuations in government spending. The final two terms in each condition capture the impact that another unit of short or long debt has on long- and short-term bond prices through the impact of debt on inflation expectations. These effects highlight the incentives that the policymaker has to reduce indebtedness to reduce inflation, given the inflationary bias problem created by a positive stock of government debt. The magnitude of the effect of reducing either short or long-term debt by one bond may vary depending on the relative proportions of the two bonds. In other words, by varying the relative proportions of single period and longer term debt, the policymaker can vary the average debt maturity and thereby influence the inflationary bias problem implied by a given level of indebtedness.

Solving the model without switching in government spending generates a steady state with near zero debt and inflation [figure 12]. Introducing government spending switches induces fluctuations in all variables. The movements in spending are largely matched with 
movements in tax rates (even although these could have been eliminated by issuing an appropriately constructed portfolio of short-term assets and longer-term liabilities), although with some increase in the debt/deficit when we are in the high spending regime. The stochastic steady state asset and liability positions are only slightly positive for assets, and slightly negative for liabilities, but quite distant from the magnitude of the positions required for perfect hedging. Inflation follows the level of indebtedness, giving rise to a positive (negative) inflation bias when the level of indebtedness is positive (negative).

Starting from a positive level of indebtedness, figure 13 plots the mix of short- and long-term debt as the economy transitions toward the stochastic steady-state. Calvo and Guidotti's (1992) debt aversion appears as the policymaker fairly rapidly reduces indebtedness in an attempt to eliminate the inflationary bias that debt induces. The fluctuations in debt induced by the changing spending regime are small relative to the general debt dynamics implied by the transition to steady state. The fact that the single-period debt does not rise dramatically when overall indebtedness increases implies that there is an effective lengthening of maturity as overall debt levels increase. This echoes the results of Calvo and Guidotti, which are also discussed in Missale (1999).
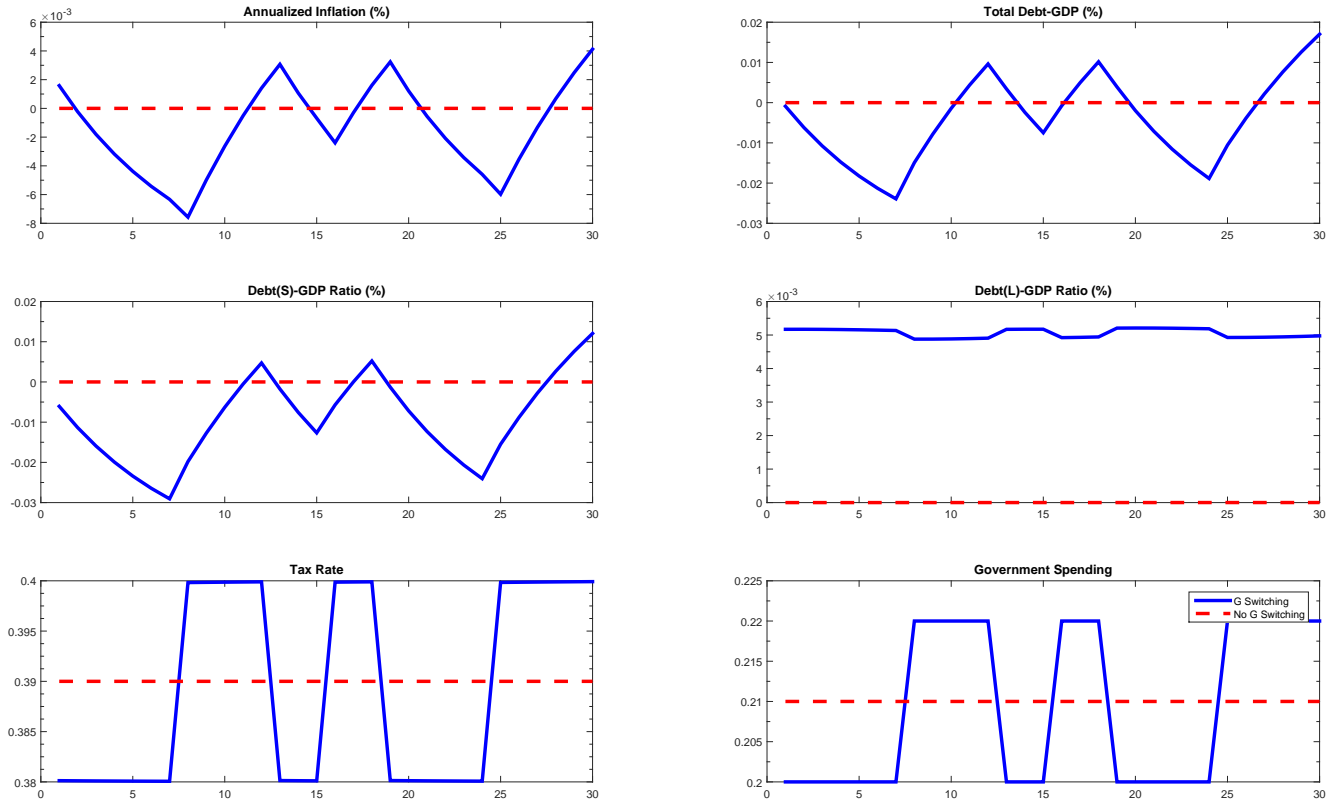

Figure 12: Hedging under discretion. 

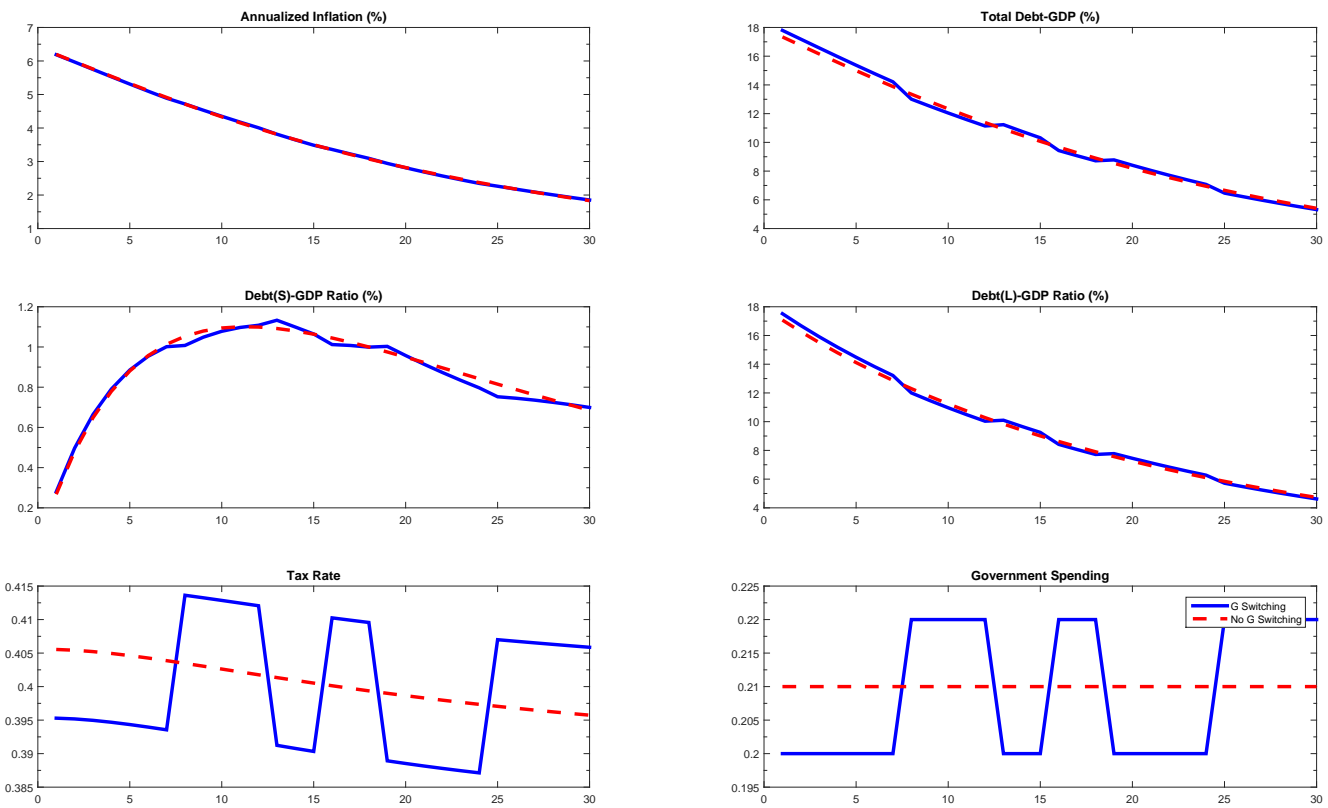

Figure 13: Hedging and time-consistent policy.

\section{Production Economies with Optimal Monetary and Fiscal POLICIES}

\subsection{The Model}

Until now our analysis of optimal policy has been based on a simple flexible price endowment economy, where we have captured the costs of inflation and distortionary taxation by adding quadratic terms in these variables to the policymaker's objective function. We now attempt to generalize these results by considering a production economy where households supply labour to imperfectly competitive firms who are subject to quadratic costs in changing prices as in Rotemberg (1982). The government levies a tax on sales to finance exogenous processes for transfers and government consumption. The policymaker aims to maximize the utility of the representative household. This section therefore endogenizes the welfare costs of both inflation and distortionary taxation. We also widen the scope for monetary and fiscal policy interactions because monetary policy not only generates revaluations of government bonds, but also affects real debt service costs and the size of the tax base. Changes in distortionary taxation not only influence the government's budget identity, they affect production decisions and have a direct cost-push effect on inflation.

This basic set-up is similar to that in Benigno and Woodford (2004) and Schmitt-Grohé 
and Uribe (2004) but with some differences. ${ }^{41}$ We model price stickiness using Rotemberg's (1996) adjustment costs rather than Calvo (1983) pricing because this reduces the number of state variables when solving the model non-linearly. We also consider a richer maturity structure rather than single-period bonds.

\subsubsection{HouseHolds}

There is a continuum of households of size one. We assume complete asset markets, so that through risk sharing households face the same budget constraint. The typical household seeks to maximize

$$
E_{0} \sum_{t=0}^{\infty} \beta^{t}\left(\frac{c_{t}^{1-\sigma}}{1-\sigma}-\frac{N_{t}^{1+\varphi}}{1+\varphi}\right)
$$

where $c$ and $N$ are a consumption aggregate and labor supply respectively. The consumption basket is made up of a continuum of differentiated products, $c_{t}=\left(\int_{0}^{1} c(j)_{t}^{\frac{\epsilon-1}{\epsilon}} d j\right)^{\frac{\epsilon}{\epsilon-1}}$ and the basket of public consumption takes the same form.

The budget constraint at time $t$ is given by

$$
\int_{0}^{1} P_{t}(j) c_{t}(j) d j+P_{t}^{m} B_{t}^{m}=\Pi_{t}+\left(1+\rho P_{t}^{m}\right) B_{t-1}^{m}+W_{t} N_{t}+Z_{t}
$$

where $P_{t}(j)$ is the price of variety $j, \Pi$ is the representative household's share of profits in the imperfectly competitive firms (after tax), $W$ are wages, and $Z$ are lump sum transfers and the bonds the household can invest in are the geometrically declining coupon bonds used above.

We maximize utility subject to the budget constraint (40) to obtain the optimal allocation of consumption across time and the associated pricing of declining coupon bonds

$$
\beta E_{t}\left[\left(\frac{c_{t}}{c_{t+1}}\right)^{\sigma}\left(\frac{P_{t}}{P_{t+1}}\right)\left(1+\rho P_{t+1}^{m}\right)\right]=P_{t}^{m}
$$

Notice that when these reduce to single-period bonds, $\rho=0$, the price of these bonds is $P_{t}^{m}=R_{t}^{-1}$.

The second first-order condition relates to the labour supply decision

$$
\left(\frac{W_{t}}{P_{t}}\right)=N_{t}^{\varphi} c_{t}^{\sigma}
$$

\footnotetext{
${ }^{41}$ Leeper and Zhou (2013) study a linear-quadratic version of this setup.
} 


\subsubsection{FIRMS}

Firms produce output using to a linear production function, $y(j)_{t}=A N(j)_{t}$, where $a_{t}=$ $\ln \left(A_{t}\right)$ is time varying and stochastic, such that the real marginal costs of production are $m c_{t}=\frac{W_{t}}{P_{t} A_{t}}$. Household demand for their product is given by, $y(j)_{t}=\left(\frac{P(j)_{t}}{P_{t}}\right)^{-\epsilon} y_{t}$ and firms are also subject to quadratic adjustment costs in changing prices

$$
v_{t}^{j} P_{t}=\frac{\phi}{2}\left(\frac{p_{t}(j)}{\pi^{*} p_{t-1}(j)}-1\right)^{2} P_{t} y_{t}
$$

where $\pi^{*}=1$ is the steady-state gross inflation rate. In a symmetric equilibrium where $p_{t}(j)=P_{t}$ the first-order condition for firms' profit maximization implies

$$
(1-\theta)\left(1-\tau_{t}\right)+\theta m c_{t}-\phi \frac{\pi_{t}}{\pi^{*}}\left(\frac{\pi_{t}}{\pi^{*}}-1\right)+\phi \beta E_{t}\left(\frac{c_{t}}{c_{t+1}}\right)^{\sigma} \frac{\pi_{t+1}}{\pi^{*}} \frac{y_{t+1}}{y_{t}}\left(\frac{\pi_{t+1}}{\pi^{*}}-1\right)=0
$$

which is the non-linear version of the Phillips curve and includes the effects of a distortionary tax on sales revenues, $\tau_{t}$.

\section{1 .3 EqUILIBRIUM}

Goods market clearing requires, for each good $j$

$$
y(j)_{t}=c(j)_{t}+g(j)_{t}+v(j)_{t}
$$

which allows us to write

$$
y_{t}\left[1-\frac{\phi}{2}\left(\frac{\pi_{t}}{\pi^{*}}-1\right)^{2}\right]=c_{t}+g_{t}
$$

There is also market clearing in the bonds market where the longer term bond portfolio evolves according to the government's budget identity which we now describe.

\subsubsection{Government Budget Identity}

Combining the series of the representative consumer's flow budget constraints, (40), and noting the equivalence between factor incomes and national output, we obtain the government's flow budget identity

$$
P_{t}^{m} b_{t}=\left(1+\rho P_{t}^{m}\right) \frac{b_{t-1}}{\pi_{t}}-y_{t} \tau_{t}+g_{t}-z_{t}
$$

where real debt is defined as $b_{t} \equiv \frac{B_{t}^{M}}{P_{t}}$. 


\subsection{Commitment Policy in the New Keynesian Model}

Setting up the Lagrangian

$$
\begin{aligned}
L_{t}= & E_{0} \sum_{t=0}^{\infty} \beta^{t}\left[\left(\frac{c_{t}^{1-\sigma}}{1-\sigma}-\frac{N_{t}^{1+\varphi}}{1+\varphi}\right)\right. \\
& +\lambda_{1 t}\left(y_{t}\left(1-\frac{\phi}{2}\left(\frac{\pi_{t}}{\pi^{*}}-1\right)^{2}\right)-c_{t}-g_{t}\right) \\
& +\lambda_{2 t}\left(\beta\left(\frac{c_{t}}{c_{t+1}}\right)^{\sigma}\left(\frac{P_{t}}{P_{t+1}}\right)\left(1+\rho P_{t+1}^{m}\right)-P_{t}^{m}\right) \\
& +\lambda_{3 t}\left((1-\theta)\left(1-\tau_{t}\right)+\theta y_{t}^{\varphi} c_{t}^{\sigma} A_{t}^{-1-\varphi}-\phi \pi_{t}\left(\pi_{t}-1\right)+\phi \beta\left(\frac{c_{t}}{c_{t+1}}\right)^{\sigma} \pi_{t+1} \frac{y_{t+1}}{y_{t}}\left(\pi_{t+1}-1\right)\right) \\
& \left.+\lambda_{4 t}\left(P_{t}^{M} b_{t}-\left(1+\rho P_{t}^{M}\right) \frac{b_{t-1}}{\pi_{t}}+y_{t} \tau_{t}-g_{t}-t r_{t}\right)\right]
\end{aligned}
$$

and differentiating with respect to $\left\{c_{t}, y_{t}, \tau_{t}, P_{t}^{m}, b_{t}^{m}, \pi_{t}\right\}$ yields the first-order conditions for the Ramsey program. Those conditions are sufficiently complex to afford little additional insight that was not already gained from the analysis of the comparable problem for our simple endowment economy. But when we solve the model numerically, several interesting results relating to the optimal monetary and fiscal policy mix emerge.

\subsection{Numerical Results}

The first experiment considers a transfers shock at different initial levels of debt [figure 14]. ${ }^{42}$ Transfers start at 18 percent of GDP and then increase with an autocorrelated shock, but do not respond further to GDP. When, as in the first column, the initial debt level is zero the maturity structure of the debt issued after the shock has hit is irrelevant. There is an initial one-period burst in inflation caused by the rise in the tax rate and not fully offset by the tightening of monetary policy. Then a coordinated use of monetary and fiscal policy stabilizes debt at its new steady state level. The tax rate does not jump immediately to its new steady state, but follows a dynamic path which captures the movement in the real interest rate in the sticky price economy, while monetary policy ensures that inflation is zero outside of the initial period.

Moving to column 2, at a higher initial debt level radically different policy responses emerge that depend on debt levels and maturity structures. As in Leith and Wren-Lewis (2013) with single-period debt and a sufficiently high debt stock, the transfers shock results in the policymaker relaxing monetary policy to reduce debt service costs and fuel the initial

\footnotetext{
${ }^{42}$ In all cases we solve the model non-linearly under perfect foresight following an initial perturbation from the steady state.
} 

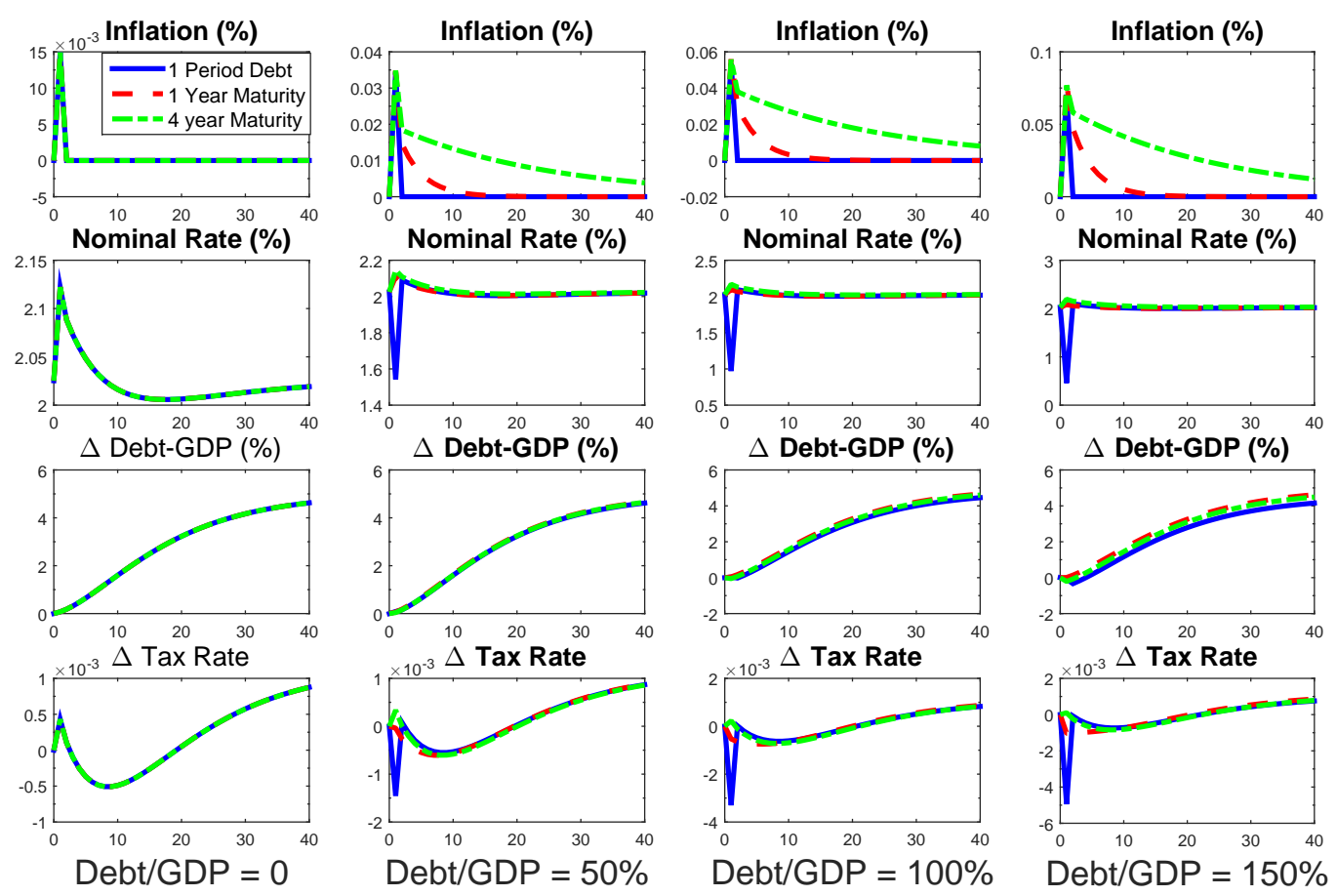

Figure 14: Optimal policy response to higher transfers with different debt levels and maturities.

burst in inflation. Monetary policy stabilizes the debt - just as in the fiscal theory - while tax rates fall to moderate the rise in inflation. Thereafter a combination of monetary and fiscal policy stabilize the debt without generating any further inflation. When the debt is of longer term maturity ( 1 or 5 years), the initial policy response is quite different, with a tighter monetary policy and higher tax rates. The initial rise in inflation extends beyond the first period to help stabilize debt through reduced bond prices.

We now turn to the government spending shock in figure 15. The first column sets the initial tax rate at $\tau=0.39$, sufficient to pay for both the initial value of transfers and public consumption, so there is no debt. In this case, as in the simple endowment economy, debt maturity doesn't matter and the policy response is the same regardless of the maturity of the debt. Unlike the endowment economy, there is surprise inflation, but this plays no direct role in stabilizing debt. Here the inflation reflects initial jumps in tax rates and interest rates that deliver the optimal balance between monetary and fiscal policy. There is a tax-smoothing jump in taxation that would fuel inflation, but which is offset by a tighter monetary policy that makes inflation zero after the initial period. As private consumption recovers, the tax rate rises, and ultimately there is a high tax rate to support an increased level of debt.

As we increase the initial level of debt, maturity structure generates differences in policy 
responses. As before, longer maturity delivers a smaller, but more sustained increase in inflation that stabilizes debt by reducing bond prices. But there are differences in the policy mix behind this result. When initial debt-to-GDP is just under 50 percent, with only singleperiod debt the policymaker actually cuts taxes to reduce the inflationary consequences of the government spending shock.

At higher initial debt, more radical differences in the policy mix arise across maturities. Sticky prices mean that not only surprises in the path of inflation influence debt dynamics: the policymaker can also influence real ex-ante interest rates and, through the Phillips curve, the size of the tax base. At a debt level near 100 percent, we observe a substantial fall in both tax rates and interest rates when debt is only single period. This amounts to a reversal of the conventional assignment of monetary and fiscal policy: monetary policy acts to stabilize debt by cutting real interest rates, while fiscal policy mitigates the inflationary consequences of this by reducing tax rates. For an average debt maturity of 5 years we retain the conventional assignment, with tax rates rising and monetary policy tightening to offset the rise in inflation that higher tax rates would generate.
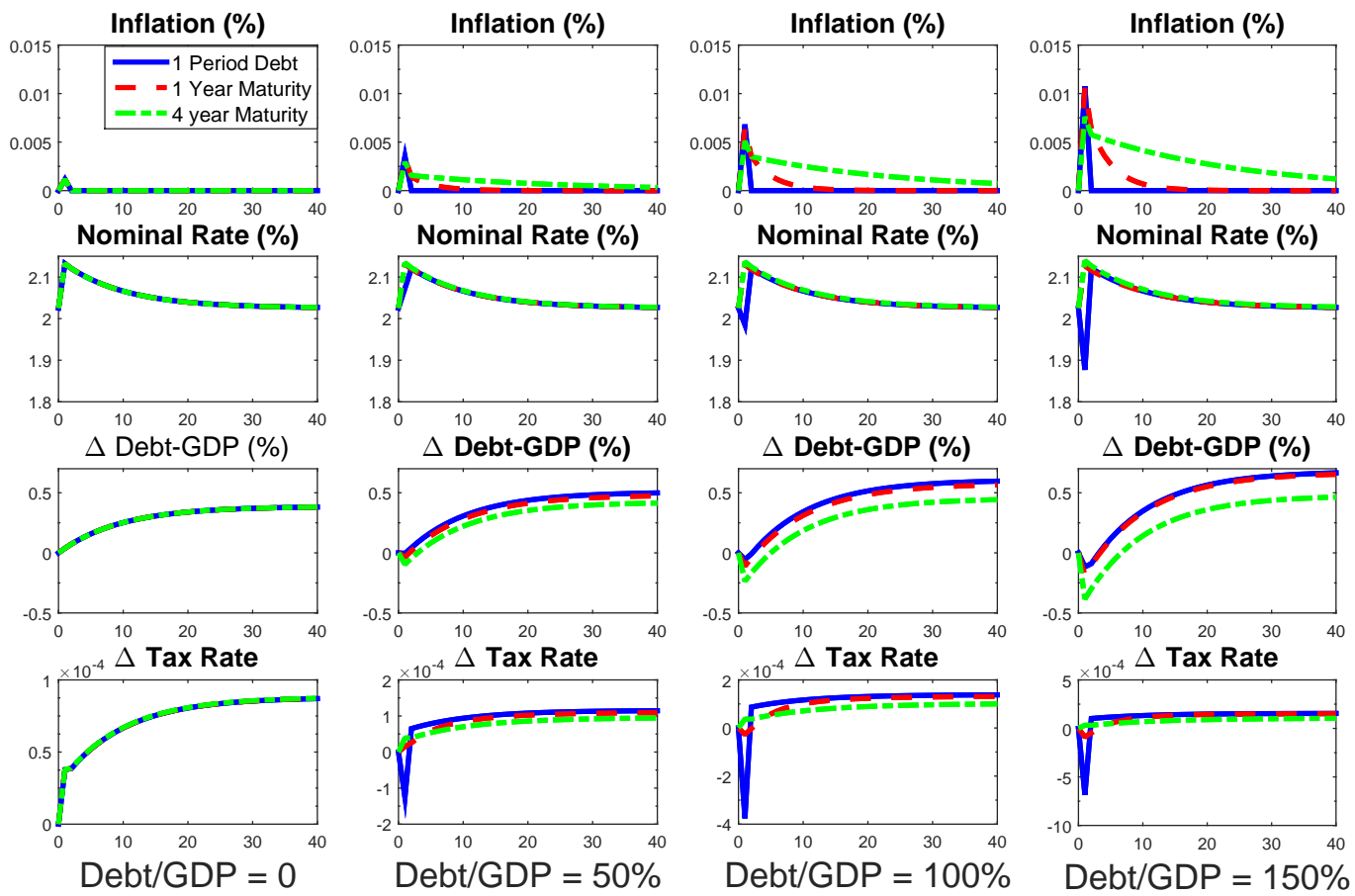

Figure 15: Optimal policy response to an increase in government spending. 


\subsection{An Independent Central Bank}

Two key features of jointly optimal policy are worth highlighting. First, price level control, which is typically a feature of optimal monetary policy in the new Keynesian model, is absent in the presence of fiscal policy and the associated tax smoothing objective. Typical analyses have policymakers commit not only to return inflation to target after a shock hits, but to return the price level back to its pre-shock level. This commitment reduces inflation expectations and improves the trade-off between stabilization of inflation and the real economy. When fiscal policy enters the picture, the initial inflation becomes a desirable means of stabilizing debt through the revaluation effects that are a distinguishing feature of the fiscal theory.

Second, the policy mix depends on the size and maturity of government debt. With short maturity and high debt levels, optimal policy reverses the usual policy assignment - raising taxes and interest rates in the face of higher transfers or government consumption - and instead, cuts interest rates to reduce debt interest dynamics and cuts taxes to offset the inflation that the relaxation in monetary policy would otherwise induce. Many economists would be uncomfortable with using monetary policy as a tool of fiscal stabilization in this way and would argue in favour of independent central banks to avoid this policy mix.

We assess the implications of independent monetary policy by deriving the optimal fiscal policy conditional on a given monetary policy rule. We assume that the central bank follows a simple Taylor rule with a coefficient on inflation of $\alpha_{\pi}=1.5$. The fiscal authority faces the same optimization described above, but with the additional constraint that monetary policy follows this rule. Figure 16 reports that the policy response to higher government spending exhibits some notable differences from the outcome when monetary and fiscal policies are jointly optimal. Inflation's increase is far more prolonged under an independent central bank. When monetary and fiscal policy operate cooperatively, even for the largest stock of debt we analyzed, inflation is less than half that observed when decoupling monetary from fiscal policy. This gives rise to the second surprising result. The active independent monetary policy results in the fiscal policymaker cutting rather than raising taxes in response to the government spending shock. The magnitude of the tax cut increases with the stock of debt, but does not vary much across maturities. Optimal fiscal policy counteracts the higher debt service costs that active monetary policy generates by cutting tax rates. This offsets the increase in inflation and under the policy rule mitigates the rise in real interest rates. Because this action is more important the higher the debt, the magnitude of the tax cuts increases with rising debt levels. Similar inflation paths across all debt levels imply that the value of longer maturity debt gets reduced through revaluation effects by more than 
the other maturities. This also has the implication that the spillovers from monetary policy shocks to the government's finances are likely to be greater at higher and longer maturity debt levels.

These results point to the ubiquity of a central feature of the fiscal theory - debt revaluation through surprise changes in inflation and bond prices. Whether policies are jointly optimal or optimal fiscal policy is constrained by an independent central bank, debt revaluation continues to characterize optimal policy behavior.
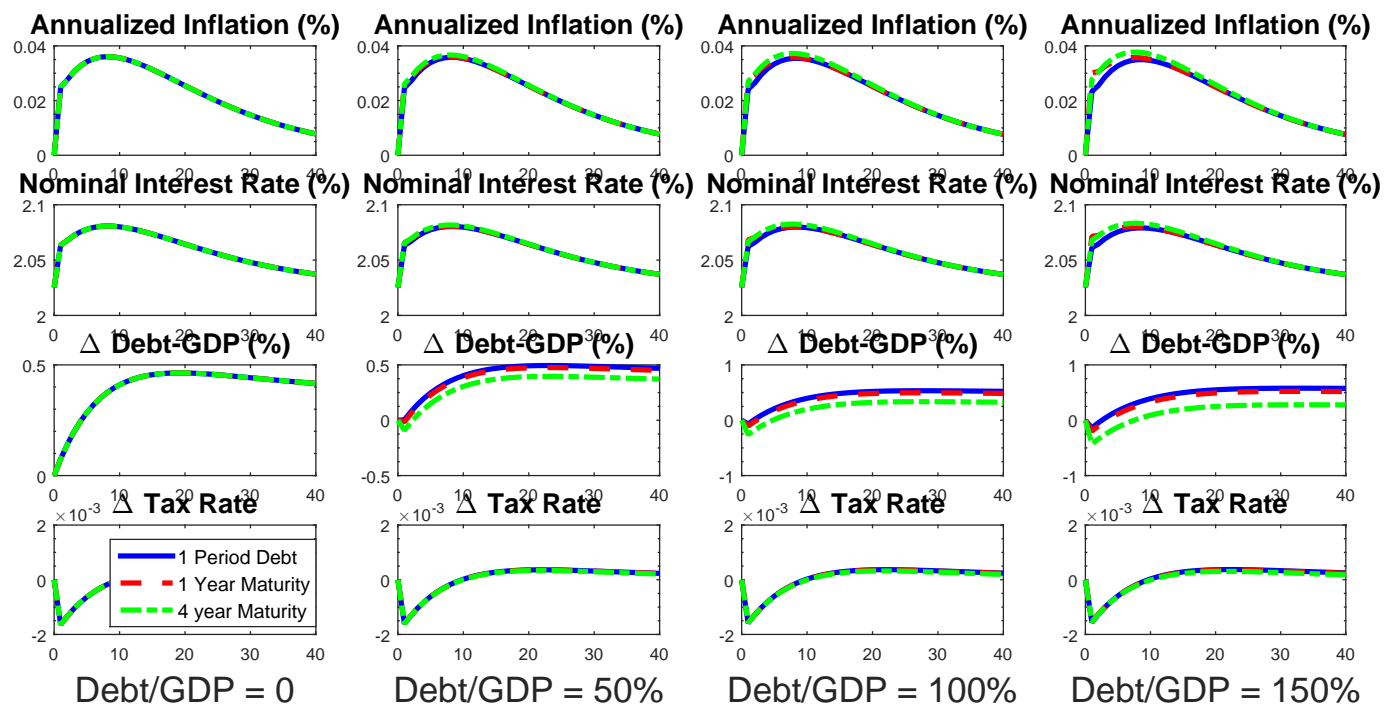

Figure 16: Optimal fiscal policy response to an increase in government spending with an independent central bank.

\subsection{Discretion in the New Keynesian Economy}

This subsection turns to optimal discretionary policy, following the setup in Leeper, Leith, and Liu (2015). That setup employs a new Keynesian model in which the tax applies to labor income rather than sales revenue and government spending is treated as an endogenous policy instrument rather than an exogenous stream of purchases that need to be financed. There are no transfers. The policy under discretion is a set of decision rules for $\left\{c_{t}, y_{t}, \pi_{t}, b_{t}, \tau_{t}, g_{t}, P_{t}^{M}\right\}$ that maximize

$$
V\left(b_{t-1}, A_{t}\right)=\max \left\{\frac{c_{t}^{1-\sigma}}{1-\sigma}+\chi \frac{g_{t}^{1-\sigma_{g}}}{1-\sigma_{g}}-\frac{\left(y_{t} / A_{t}\right)^{1+\varphi}}{1+\varphi}+\beta E_{t}\left[V\left(b_{t}, A_{t+1}\right)\right]\right\}
$$


subject to the resource constraint

$$
y_{t}\left(1-\frac{\phi}{2}\left(\frac{\pi_{t}}{\pi^{*}}-1\right)^{2}\right)-c_{t}-g_{t}
$$

the Phillips curve

$$
(1-\epsilon)+\epsilon\left(1-\tau_{t}\right)^{-1} y_{t}^{\varphi} c_{t}^{\sigma} A_{t}^{-1-\varphi}-\phi \frac{\pi_{t}}{\pi^{*}}\left(\frac{\pi_{t}}{\pi^{*}}-1\right)+\phi \beta c_{t}^{\sigma} y_{t}^{-1} E_{t}\left[c_{t+1}^{-\sigma} \frac{\pi_{t+1}}{\pi^{*}}\left(\frac{\pi_{t+1}}{\pi^{*}}-1\right)\right]=0
$$

and the government's budget identity

$$
\begin{aligned}
& \beta E_{t}\left[\left(\frac{c_{t}}{c_{t+1}}\right)^{\sigma}\left(\frac{P_{t}}{P_{t+1}}\right)\left(1+\rho P_{t+1}^{M}\right)\right] b_{t} \\
= & \left\{1+\rho \beta E_{t}\left[\left(\frac{c_{t}}{c_{t+1}}\right)^{\sigma}\left(\frac{P_{t}}{P_{t+1}}\right)\left(1+\rho P_{t+1}^{M}\right)\right]\right\} \frac{b_{t-1}}{\pi_{t}} \\
& -\left(\frac{\tau_{t}}{1-\tau_{t}}\right)\left(\frac{y_{t}}{A_{t}}\right)^{1+\varphi} c_{t}^{\sigma}+g_{t}
\end{aligned}
$$

where we have used the bond-pricing equation to eliminate the current value of the portfolio of bonds.

Leeper, Leith, and Liu (2015) solve the nonlinear system consisting of seven first-order conditions and the three constraints to yield the time-consistent optimal policy using the Chebyshev collocation method. In contrast to the case of commitment where steady-state inflation is zero, discretion implies a steady state with a mildly negative debt stock and a mild deflation. Figure 17 shows that starting from high debt levels produces significant policy differences across differing bond maturities. These impulse responses reflect the timeconsistent adjustment from a high debt level to the ultimate steady state debt level, which is slightly negative. The most notable element in these dynamic paths is the very high levels of inflation. This inflation does not serve to reduce the real value of debt; instead, it reflects the state-dependent inflationary bias problem generated by high debt levels. When debt levels are raised, the policymaker faces a temptation to use surprise inflation or surprise reductions in bond prices to reduce the real value of government debt. Knowing this, economic agents raise their inflationary expectations until this temptation is no longer present. At empirically plausible debt levels, this temptation is very strong and very high rates of inflation are required to ensure the policy remains time consistent. The shorter the debt maturity, the greater the temptation to inflate and reduce debt levels quickly - what we label "the debt stabilization bias." The steady state the economy eventually achieves a small negative longrun optimal value for debt and a slight undershooting of the inflation target. This falls far short of the accumulated level of assets that would be needed to finance government 
consumption and eliminate tax and other distortions.
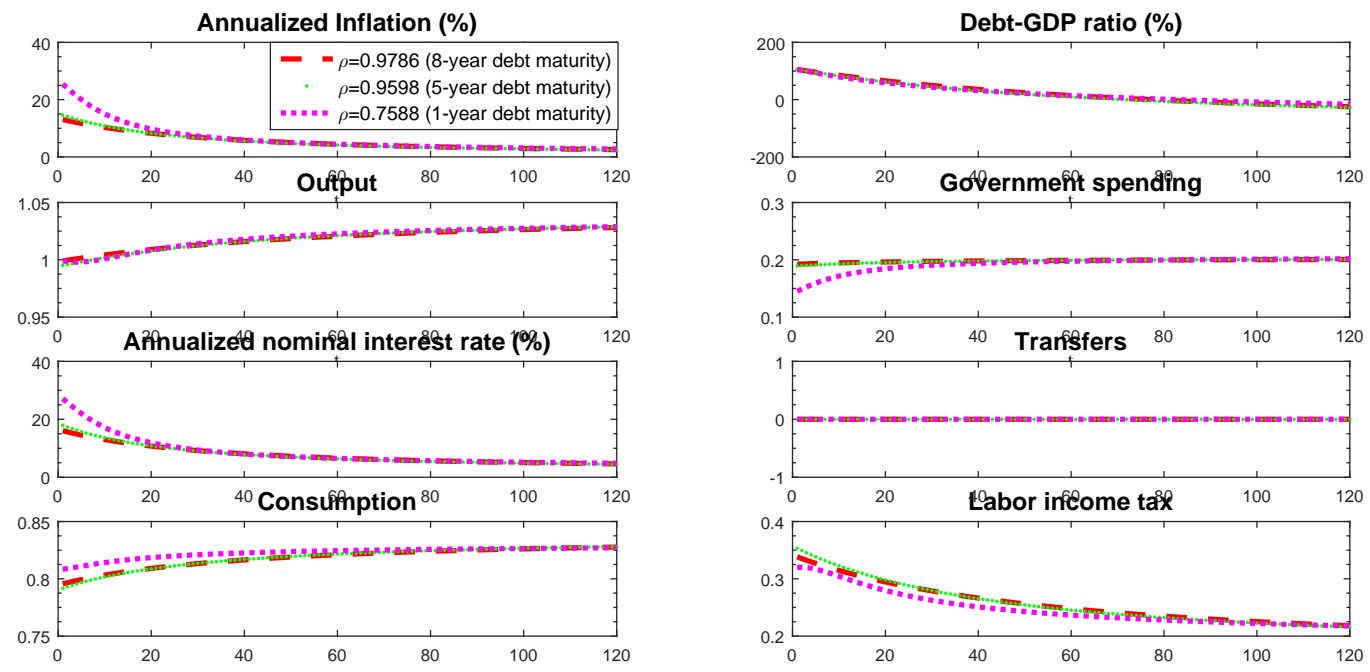

Figure 17: New Keynesian model under discretionary policy.

\section{Empirical Considerations}

The chapter's emphasis to this point reflects the bulk of the literature on the fiscal theory in its theoretical focus. This section discusses a set of empirical considerations that arise from work on monetary and fiscal interactions. First, we briefly explain why it is difficult to distinguish whether time series data were generated by regime $\mathrm{M}$ or by regime $\mathrm{F}$. Then we turn to both reduced-form and structural evidence about the prevailing policy regime, including work on regime-switching policies. We end the section by clarifying some common misperceptions about the nature of equilibrium under regime $\mathrm{F}$.

\subsection{Distinguishing Regimes M And F}

It is well established that regimes $\mathrm{M}$ and $\mathrm{F}$ can generate equivalent (or nearly equivalent) equilibrium processes. Cochrane (1999) discusses this point and Woodford's (1999) comments on Cochrane's paper elaborate on the issue in some detail. Leeper and Walker (2013) display a simple theoretical example in which the two regimes are observationally equivalent.

Observational equivalence of the two regimes may be surprising. After all, sections 2 and 3 went to great length to show that monetary and fiscal disturbances produce strikingly different dynamic responses in the two regimes. To understand the equivalence, consider the linearized new Keynesian model that section 3.1 describes. That model's economic state 
in period $t$ is the triple $X_{t} \equiv\left(\varepsilon_{t}^{M}, \varepsilon_{t}^{F}, \hat{b}_{t-1}\right)$ and in regime $\mathrm{M}$, each endogenous variableincluding the policy variables $\hat{R}_{t}$ and $\hat{s}_{t}$-is a linear function of $X_{t}$ in equilibrium. But those mappings from $X_{t}$ to the policy variables are consistent with regime $\mathrm{F}$ policy behavior: the interest rate depends only on $\varepsilon_{t}^{M}$ and the surplus depends on $\varepsilon_{t}^{F} .{ }^{43}$

Some critics argue that this equivalence result renders the fiscal theory "untestable" and therefore empirically vacuous. Naturally, equivalence implies that the conventional viewregime $\mathrm{M}$ - is also "untestable." But the critics' nihilism is unwarranted. Observational equivalence merely implies that in the absence of identifying restrictions it is impossible to discern which regime produced observed data. But this is nearly a truism. No set of simple correlations - among debt, deficits, inflation, and interest rates - can tell us whether the underlying policy behavior comes from regime $\mathrm{M}$ or regime $\mathrm{F}{ }^{44}$

Yet correlation-based "tests" of the fiscal theory abound in the literature. Canzoneri, Cumby, and Diba (2001b) argue that if a positive shock to surpluses both raises future surpluses and lowers the real value of government debt, regime M prevails; if the positive surplus shock raises the value of debt, then regime F prevails. Cochrane (1999) succinctly explains why this isn't a "test" of regime. Like any asset, government debt has both a "backward-looking" and a "forward-looking" representation. Let $b_{t} \equiv B_{t} / P_{t}$ denote the real market value of debt. Debt's law of motion - the budget identity - yields the backward view

$$
b_{t+1}=r_{t+1}\left(b_{t}-s_{t}\right)
$$

where $r_{t+1} \equiv R_{t} P_{t} / P_{t+1}$ is ex-post real return on bonds between $t$ and $t+1$ and $s_{t}$ is the primary surplus at $t$. Higher $s_{t}$ seems to imply a lower value for debt at $t+1$. But the forward view, which determines the asset value of debt yields

$$
b_{t}=E_{t} \sum_{j=0}^{\infty}\left(\frac{1}{r}\right)^{j} s_{t+j}
$$

to suggest that a persistent increase in surpluses raises the value of debt. ${ }^{45}$ Evidently, manipulations of identities do not impose enough structure to distinguish between regimes.

A second branch of the correlation-based "testing" literature follows Bohn (1998) in using

\footnotetext{
${ }^{43}$ If the economy starts with an initial level of debt, the $\left\{\hat{s}_{t}\right\}$ process must be chosen to be consistent with that level.

${ }^{44}$ Much of the evidence that Friedman and Schwartz (1963a,b) compiled in favor of the quantity theory sought to show that erratic monetary policy drove nominal income movements. But that evidence came from efforts to identify "exogenous" or "autonomous" changes in the money stock, as Sims (1972) later showed. Friedman and Schwartz recognized that reduced-form correlations alone cannot establish causality.

${ }^{45}$ For convenience, (41) assumes a constant real return.
} 
limited-information techniques to estimate

$$
s_{t}=\gamma b_{t-1}+\delta^{\prime} Z_{t}+\varepsilon_{t}^{F}
$$

where $s_{t}$ is the primary surplus at $t, b_{t-1}$ is the real value of government debt at $t-1, Z_{t}$ is a vector of control variables, and $\varepsilon_{t}^{F}$ is a possibly serially correlated disturbance. This line of work interprets estimates of (42) as descriptions of fiscal policy behavior. ${ }^{46}$ When $\widehat{\gamma}>0$, researchers infer fiscal behavior is passive, while if $\widehat{\gamma}>$ net real interest rate, fiscal policy reacts sufficiently to stabilize debt. Based on such estimates, researchers conclude the economy resides in regime $\mathrm{M}$, so the fiscal theory does not apply. ${ }^{47}$

Missing from this analysis is the bond valuation equation, which is an equilibrium condition that holds regardless of the prevailing policy regime. As condition (41) makes clear, $b_{t-1}$ must be positively correlated with future surpluses in any equilibrium. When (42) is estimated without imposing this equilibrium condition, estimates of $\gamma$ are subject to simultaneous equations bias.

Leeper and $\mathrm{Li}$ (2015) use a linearized variant on the endowment economy in section 2 to study the nature of the simultaneity bias. If the policy disturbance is serially uncorrelated or a lagged dependent variable is added to the regression in (42), then the limited-information procedure is valid only if the underlying monetary and fiscal policies are in regime M. Serious biases can arise when data are equilibria in regime $\mathrm{F}$. The sign and severity of bias in $\widehat{\gamma}$ depend on monetary policy behavior: the weaker is the reaction of monetary policy to inflation, the stronger is the positive bias. In periods like the aftermath of the 2008 financial crisis, when central banks pegged the nominal interest rate, estimates of $\gamma$ are more likely to imply a strong response of surpluses to debt. This finding is consistent with Bohn's (1998) estimates, which rarely find evidence that the surplus response is weak.

There are two natural solutions to the simultaneous equations bias. The first is to impose the bond valuation equation on estimates of the fiscal rule, as Chung and Leeper (2007) and Hur (2013) do in a structural VAR, and estimate monetary and fiscal rules jointly. The second solution is to estimate a fully specified DSGE model.

\subsection{Some Suggestive Empirical Evidence}

A complete account of empirical evidence about policy regime is beyond the scope of this chapter, so we will briefly recount two kinds of evidence that regime $\mathrm{F}$ has prevailed in

\footnotetext{
${ }^{46}$ See, for example, Mendoza and Ostry (2008). Ghosh, Kim, Mendoza, Ostry, and Qureshi (2012) employ such estimates to compute a country's "fiscal space." Woodford (1999) raises issues with this interpretation.

${ }^{47}$ Canzoneri, Cumby, and Diba (2001b) estimate an unrestricted bivariate VAR for the primary surplus and the real value of debt, a technique that is equivalent to estimating a version of (42).
} 
some historic periods. The first is suggestive evidence that points to empirical facts that are consistent with regime $\mathrm{F}$; then we turn to more formal econometric analysis.

Cochrane (1999) was the first to suggest that U.S. post-World War II inflation could be interpreted through the lens of the fiscal theory. He stresses that readily available fiscal data do not line up well with the theoretical concepts and constructs a data series for the real market value of government debt, from which he infers two different real primary surplus series. Not surprisingly, substantial differences emerge between the primary surplus and conventionally-measured surplus (inclusive of debt service), particularly in periods of high debt or high interest rates. He further contrasts his computed surplus series with the Treasury's reported net-of-interest surplus, which does not account for capital gains and losses incurred from bond transactions. Cochrane's calculations make the broad methodological point that scrutiny of regime $\mathrm{F}$ equilibria requires careful data construction.

But Cochrane's substantive contribution lies in interpreting the data correlations. He specifies an exogenous - regime $\mathrm{F}$ - process for primary surpluses from which he computes the real value of debt as the present value of those artificial surpluses. Processes are chosen to match correlations in the data. Simulations produce observed gross movements in postwar U.S. inflation when the equilibrium price level sequence emerges from the debt valuation equation. ${ }^{48}$ As it happens, the chosen processes would pass either the Bohn (1998) or the Canzoneri, Cumby, and Diba (2001b) "test" that those authors claim refutes the fiscal theory. Cochrane's analysis illustrates the difficulties in distinguishing between regimes M and F. ${ }^{49}$

Woodford (2001) argues that Federal Reserve policy from World War II until the TreasuryFed Accord in March 1951 is a clear example in which monetary policy was explicitly assigned the task of maintaining the value of government debt, as it is in regime F. Beginning in April 1942, as Woodford writes

The yield on ninety-day Treasury bills was pegged at $3 / 8$ of a percent; this peg was maintained through June 1947, and ... until that point the price of bills was completely fixed, as the Treasury offered both to buy and sell bills at that price. An intention was also announced of supporting one-year Treasury certificates at a price corresponding to a $7 / 8$ percent annual yield; this policy continued after 1947, though at a slightly higher yield. Finally, the prices of twenty-five-year Treasury bonds were supported at a price corresponding to a 2 and $1 / 2$ percent

\footnotetext{
${ }^{48}$ Shim (1984) is an early effort to use VAR analysis to find cross-country evidence of a link between fiscal deficit innovations and inflation.

${ }^{49}$ Cochrane (2011b) uses the government debt valuation condition to interpret monetary and fiscal policy actions in the wake of the 2008 global recession. He argues that recent policy developments suggest that in coming years the equilibrium condition is likely to have a stronger influence on economies than it has in the past.
} 
annual yield; this price floor was maintained up until the time of the "Accord." [Woodford (2001, pp. 672-673)]

Woodford, however, seems to regard regime $\mathrm{F}$ as the exception, arising during wartime and in special circumstances when monetary policy is subordinated to fiscal needs.

Loyo (1999) uses Brazil in the late 1970s and early 1980s as an example where the fiscal consequences of monetary policy led to explosive inflation. His case does not fall into either of the two regimes in which a determinate bounded equilibrium exists. Instead, Loyo argues that a combination of active fiscal policy and active monetary policy that aggressively sought to combat inflation by raising interest rates strongly in response to inflation produced exactly the phenomenon that section 3.2.2 describes. Higher interest rates raised bondholders' interest receipts which, in the absence of commensurately higher taxes, raised wealth and aggregate demand. Higher demand increased inflation still further, to which monetary policy responded by raising interest rates, setting off an explosive cycle that produced double-digit inflation rates per month. Importantly, this hyperinflation arose with no appreciable change in real seignorage revenues, as Loyo documents. Loyo's work illustrates a theme that runs through the chapter. If fiscal behavior is active, refusing to raise surpluses to stabilize government debt, more aggressive inflation-fighting by the central bank exacerbates the problem: when monetary policy is passive, it amplifies shocks more as it becomes more active; if it's active, those shocks lead to ever-increasing inflation. An alternative monetary policy ruleone that merely pegged the nominal interest rate, for example - would have prevented the explosive inflation.

As of 2015, Brazil may be poised to rerun the experience that Loyo describes. Brazil's 1988 Constitution mandates that government benefits are indexed to inflation, effectively putting 90 percent of expenditures out of the legislature's reach. With sizeable tax adjustments apparently politically unviable, the budget deficit reached over 10 percent of GDP in 2015. Consumer price inflation rose steadily through the year to breach double digits by year-end, despite the Banco Central do Brasil's aggressive anti-inflationary efforts that raised the policy interest rate to 14.25 percent in the second half of 2015 [Banco Central do Brasil (2015)]. As The Economist (2016) put it: "Fiscal dominance has left arcane discussions among economic theorists and burst onto newspaper columns." As in the period that Loyo studies, rising inflation is driven by the combination of active fiscal behavior and single-minded inflation targeting by the central bank. Coupling that fiscal behavior with passive monetary policy, as in regime F, would not generate explosive inflation rates.

Another recurring theme of the chapter's theory is that debt revaluation effects are a ubiquitous feature of both ad hoc and optimal policy rules. Sims (2013) calculates that since 1960 the surprise gains and losses on U.S. government debt as a percentage of GDP are 
similar in magnitude to the fluctuations in the deficit relative to GDP: debt revaluations are an important aspect of monetary-fiscal dynamics. ${ }^{50}$ Similarly, Akitoby, Komatsuzaki, and Binder (2014) calculate that there would be substantial reductions in debt-to-GDP ratios for several developed economies from raising inflation targets to 6 percent. But Hilscher, Raviv, and Reis (2014) argue that it is important to account for the maturity structure of the debt which is actually held by the private sector when undertaking such calculations, concluding that for the United States this may be lower than the maturity of the overall debt stock. Sections 4.4 and 5.3 found that the efficacy of using revaluation effects as a tool of optimal policy increases with both the size and the maturity of the outstanding debt stock. This suggests that the recent increase in debt-to-GDP ratios in most advanced economies raises the likelihood that such revaluation effects may become an increasingly important feature of policy. This doesn't establish that revaluation effects of the magnitude that Sims reports can come only from regime F-style policies. Instead, it points toward an important source of fiscal financing that formal macro models must confront.

\subsection{Some Formal Empirical Evidence}

Sims (1998) argues that to assess which part of the policy space - regime M or F-is empirically relevant, it is essential to embed alternative descriptions of policy within a general equilibrium model before taking them to the data. This leads to a more direct attack on the empirical problem of discerning policy regime, as well as the possibility of "testing" which regime is most consistent with observed data.

Leeper and Sims (1994) is an early attempt to estimate a DSGE model with a complete specification of monetary and fiscal policy. Real and nominal rigidities made the analogs to regimes $\mathrm{M}$ and $\mathrm{F}$ lie in a complicated geometry and the numerical search algorithm had to traverse regions of the parameter space in which either no equilibrium exists or the equilibrium is indeterminate - both cases where the likelihood function is not defined. These difficulties prevented the paper from reaching a conclusion about which policy combination yielded the best fit. ${ }^{51}$

Bayesian estimation methods have permitted researchers to overcome some of the limitations of earlier work to make progress on the question of the prevailing regime. Expanding on the money-only specification of Smets and Wouters (2007), the models fill in fiscal details and impose the government's budget identity to estimate monetary and fiscal behavior

\footnotetext{
${ }^{50}$ See also Taylor (1995), King (1995), and Hall and Sargent (2011) for discussions of and estimates of revaluation effects.

${ }^{51}$ Leeper (1989) is an even earlier effort that uses a calibrated DSGE model to ask whether impulse response functions from regime $\mathrm{M}$ or regime $\mathrm{F}$ best match empirical responses. When agents are endowed with foresight about future fiscal actions, there is weak evidence in favor of regime $\mathrm{F}$.
} 
jointly with private behavior. Traum and Yang (2011) impose priors that are centered on either regime $\mathrm{M}$ or regime $\mathrm{F}$ for various subperiods of U.S. data from 1955 to 2007 and find that the data least prefer the parameter space associated with regime $\mathrm{F}$.

Using a simpler new Keynesian model, but with a maturity structure for government bonds, Tan (2014) argues that rejection of regime F stems from a test procedure that Geweke (2010) calls the "strong interpretation." The strong interpretation takes literally all the cross-equation restrictions of a fully specified dynamic general equilibrium model, which necessarily includes any and all possible sources of misspecification. When Tan employs the methods that DeJong, Ingram, and Whiteman (1996) and Del Negro and Schorfheide (2004) developed, which take the DSGE model as a prior for a VAR, he finds that data no longer strongly prefer regime $\mathrm{M}$. Tan argues that tests of model fit that are robust to misspecification no longer find compelling support for one regime over the other.

Leeper, Traum, and Walker (2015) estimate medium-scale models that include additional fiscal details - government consumption that may complement or substitute for private consumption, a maturity structure for government debt, explicit rules for several fiscal instruments, and steady-state distorting taxes. For U.S. data covering 1955 to 2014, even under the strong interpretation, marginal data densities suggest nearly equivalent fits under the two regimes for the full sample and for pre- and post-Volcker subsamples. Details of model specification are as important as policy rules for determining the relative fit of the two regimes.

That paper also reports estimated revaluation effects that arise from government spending expansions that are initially financed by selling debt (partially reproduced in table 4). These are analogous to the first two columns in table 2, but the estimated model also includes many other sources of financing - capital, labor and consumption tax revenues, real interest rates, government transfers, and endogenous government spending. Over the full sample and the post-Volcker subsample, the 90-percent credible intervals display substantial overlap for both inflation and bond prices, suggesting no large differences in revaluation effects in the two regime. Intervals do not overlap in the pre-Volcker period, with larger revaluation effects in regime $\mathrm{F}$ for both components.

Both the theory in this chapter and the empirical evidence just cited make clear that revaluation effects that stabilize the value of government bonds are not solely the preserve of regime F. Even in the endowment economy with policy described by simple rules in section 2, monetary policy and government spending shocks both induce revaluation effects in the two policy regimes. Optimal policy exercises show that it is desirable to use a combination of surprise inflation and tax smoothing to stabilize the economy in the face of fiscal shocks, blurring the lines between the M and F regimes. Such exercises also suggest that the balance 


\begin{tabular}{|c|c|c|}
\hline & \% due to $\hat{\pi}_{t}$ & $\%$ due to $\hat{P}_{t}^{m}$ \\
\hline 1955q1-2014q2 & & \\
Regime M & {$[0.3,0.6]$} & {$[8.2,13.6]$} \\
Regime F & {$[0.5,0.8]$} & {$[11.8,17.0]$} \\
\hline $\begin{array}{c}\text { 1955q1-1979q4 } \\
\text { Regime M }\end{array}$ & {$[-0.3,0.3]$} & {$[0.7,12.7]$} \\
Regime F & {$[0.6,1.2]$} & {$[18.4,29.9]$} \\
\hline 1982q1-2007q4 & & \\
Regime M & {$[0.1,0.4]$} & {$[7.3,14.2]$} \\
Regime F & {$[0.1,0.9]$} & {$[13.2,22.9]$} \\
\hline
\end{tabular}

Table 4: Reports 90 percent credible intervals around posterior modes. "\% due to" are the ratios of the analogs to the right-hand components of (37) to $\xi_{t}$, which are computed from the impulse response to a shock to government spending. Source: Leeper, Traum, and Walker (2015).

between inflationary and fiscal financing is also highly state dependent. In richer production economies subject to nominal inertia, the range of monetary and fiscal policy interactions is far wider: monetary and fiscal policy jointly determine the extent to which there are inflation surprises, movements in real interest rates and bond prices and changes in the tax base. The relative magnitudes of these effects, though, depend on the nature of the policy regime and on the level and maturity of the debt stock.

\subsection{Regime Switching Policies}

A growing body of work estimates Markov-switching policy rules and embeds them in otherwise conventional DSGE models. Davig and Leeper (2006) find recurring switches between active and passive monetary and fiscal rules, with some periods in which both policies are active or both are passive. In a rational expectations model in which agents are endowed with knowledge of the policy process, no single monetary-fiscal mix determines the nature of the equilibrium. Instead, expectations of future policy regimes spillover to affect the current equilibrium. In a new Keynesian model with lump-sum taxes, Davig and Leeper show that even if regime $\mathrm{M}$ currently prevails, a tax cut can produce quantitatively important increases in output and the price level. The effects are still larger conditional on being in regime F.

Gonzalez-Astudillo (2013) uses limited-information Bayesian methods to estimate a new Keynesian model with monetary and fiscal policy rules whose coefficients are time-varying and interdependent. He finds that monetary policy switches more frequently than fiscal policy - a result that contrasts with findings from Markov switching models - and that the policies are interdependent. But other findings align closely to models with recurring Markov switching: a monetary contraction reduces inflation in the short run, but raises it over longer 
horizons; lump-sum tax changes always affect output and inflation.

Kleim, Kriwoluzky, and Sarferaz (2015b) find some provocative reduced-form support for time-varying fiscal effects. Using U.S. data from 1900 to 2011, they discovered that the low-frequency correlation between inflation and the fiscal stance-defined as the ratio of primary deficits to government debt - is significantly positive most of the time until 1980 when it becomes zero. They attribute the shift in correlation to a change in monetary policy behavior.

Those authors extend their analysis in Kleim, Kriwoluzky, and Sarferaz (2015a) to include Germany and Italy and to interpret their findings with an estimated DSGE model. Germany never exhibits a significant low-frequency correlation between fiscal stance and inflation, while in Italy the correlation is positive until the Banca d' Italia gained its independence in the 1990s.

Bianchi (2012) and Bianchi and Ilut (2014) estimate a simple new Keynesian model with fiscal policy, habits and inflation inertia and that also allows for switches in monetary and fiscal policy rules. Bianchi permits a circular movement across three regimes where policy can transition from the conventional assignment (active monetary policy/passive fiscal policy) through the fiscal theory assignment of passive monetary/active fiscal policy, to an unstable regime where both monetary and fiscal policy are active. He finds that the 1960s and 1970s featured a combination of passive monetary and active fiscal policy, before the Volcker disinflation resulted in a combination of active monetary and fiscal policies. Only around 1990 did fiscal policy turn passive. Bianchi and Ilut model a slightly different set of policy transitions that allows the two stable regimes (active monetary/passive fiscal and passive monetary/active fiscal) to briefly transition through the unstable, doubly active, regime. In their estimates, regime $\mathrm{F}$ prevails until before monetary policy turns active in 1979 and fiscal policy turns passive shortly afterwards (by 1982). These papers suggest that regime $\mathrm{M}$, though not always in place historically, has been the predominant regime in the United States from at least the early 1990s until the financial crisis.

Chen, Leeper, and Leith (2015) build on this work in two ways. First, they allow additional permutations of policy in which monetary and fiscal policy may be simultaneously passive and they make the nature of transitions across regimes less restrictive. Their estimates find that the switch to regime $\mathrm{M}$ after the Volcker disinflation is far less certain, with both monetary and fiscal policy repeatedly falling outside regime $\mathrm{M}$, even in the recent data.

Second, Chen, Leeper, and Leith (2015) move away from ad hoc rules for policy to permit monetary and, in some exercises, fiscal policy to be chosen optimally. Monetary policy turns out to be both optimal and time-consistent, but with switches in the degree of anti-inflation conservatism. Those switches imply that monetary policy was not only less conservative in 
the 1970s, but also intermittently during the 1960s and briefly after the financial market turmoil from the stock market crash of 1987, the Russian default in 1998, and the dot-com crash. At the same time, fiscal policy can rarely be described as optimal (except in the early 1990s), and instead tends to move between an active and passive rule. For the bulk of the period between 1954 and the 2008 financial crisis, fiscal policy was primarily active with the only sustained periods of passive fiscal policy from the late 1950s until the late 1960s, between 1995 and 2000, and briefly between 2005 and the financial crisis. These estimates imply that regime $\mathrm{M}$ is the exception rather than the norm.

More subtle findings emerge from examining the roles of the maturity structure and the level of debt in determining optimal policy. Sections 4.4 and 5.3 found that the Ramsey plan does resemble regime $\mathrm{M}$ in periods when debt levels are low and maturity is long: monetary policy was tightened to stabilize inflation in the face of a government spending shock, while tax rates were raised to stabilize debt. But as debt levels rise, especially when maturity is short, policy assignments get reversed: monetary policy responds weakly to higher inflation from increased government spending to reduce debt service costs and stabilize debt, while tax rates are cut to stabilize inflation. In contrast, under the institutional design of policy with an independent central bank that follows an active Taylor rule, the Ramsey policy actually cuts taxes in the face of the same government spending shock, reducing inflation and offsetting the increase in debt service costs that active monetary policy induces. Despite this anti-inflationary policy on the part of the fiscal policymaker, the equilibrium rate of inflation when the central bank was independent is an order of magnitude higher than when monetary and fiscal policy were jointly optimal. Evidently, the nature of the policy interactions in theory is complex and state-contingent, as it appears to be in the empirical regime-switching literature.

Empirical evidence and optimal policy argue that regime $\mathrm{M}$ is not the only relevant monetary-fiscal policy mix. Interactions between monetary and fiscal policy are both pervasive and changeable. Understanding the nature of the policy dynamics - both the interactions between monetary and fiscal authorities and the political conflict that drives fiscal policy choices - is likely to be critical to identifying and understanding the evolution of observed policy regimes.

\subsection{Common Misperceptions}

Economists generally agree that historical episodes of high and volatile inflation rates inevitably have fiscal roots. Building on Sargent and Wallace's (1981) unpleasant monetarist arithmetic logic, Sargent (1986) makes a forceful historical case for hyperinflation's fiscal roots. The association between fiscal dominance - exogenous primary surpluses in Sargent 
and Wallace - and rampant inflation outcomes is so ingrained, that many macroeconomists also believe that regime $\mathrm{F}$ fiscal behavior - a weak response of surpluses to debt - necessarily produces bad economic performance. ${ }^{52}$

That belief is unfounded. Bad economic policies can produce bad economic outcomes in any policy regime. And regime $\mathrm{F}$ is no more susceptible to undesirable equilibria than any other monetary-fiscal mix. Both the theoretical and the empirical results we have reviewed underscore this point.

Fiscal dominance can produce explosive inflation, as Loyo (1999) argues happened in Brazil. But explosiveness is the outgrowth of monetary behavior that is incompatible with fiscal dominance. When fiscal policy is active, ever-increasing inflation arises when the central bank aggressively raises the policy interest rate in a misguided effort to combat inflation. The active fiscal behavior transforms higher interest rates into more rapid growth in nominal government debt, higher aggregate demand, and higher inflation.

Perhaps ironically, Cochrane (2011a), Sims (2013), and Del Negro and Sims (2015b) argue that many of the monetary anomalies in the theoretical literature arise primarily because money-only analyses trivialize the role that fiscal policy can play in delivering stable price level behavior. Those anomalies include Obstfeld and Rogoff's (1983) speculative hyperinflations and Benhabib, Schmitt-Grohé, and Uribe's (2002) deflationary traps. Fiscal policy can rule out both cases by adopting behavior that deviates in some fashion from typical regime-M fiscal behavior. To eliminate hyperinflations, surpluses need to rise proportionately to excess inflation outside inflation's target range. ${ }^{53}$ To ensure that the economy will not get mired in a deflationary trap, fiscal policy must commit to running deficits or shrinking primary surpluses until inflation reaches its target. Both of these policy functions make fiscal choices explicitly contingent on inflation outcomes.

Monetary policy alone is powerless to eliminate these undesirable equilibria. Ruling out those equilibria requires fiscal policy to deviate from purely passive behavior that centers entirely on debt stabilization.

Skeptics who question whether the economic mechanisms in regime $\mathrm{F}$ have ever been observed point to instances in which government debt has grown rapidly while inflation has been low and steady as prima facie evidence that inflation is solely a monetary phenomenon. But this criticism is akin to treating the income velocity of money as constant and finding cases where monetary expansions were not followed by higher nominal spending.

Consider the U.S. experience in the aftermath of the financial crisis. Nominal government

\footnotetext{
${ }^{52}$ Cochrane (2005) and Leeper and Walker (2013) give detailed descriptions of how the fiscal theory differs from unpleasant monetarist arithmetic.

${ }^{53}$ Cochrane (2011a) points out that hyperinflations do not violate any equilibrium conditions, so they are perfectly reasonable equilibria. They are also likely to be welfare reducing and undesirable.
} 
debt grew from $\$ 4.4$ trillion to $\$ 10.6$ trillion from December 2007 and December 2014, a growth rate of 240 percent that raised the debt-GDP ratio from 30.5 percent to 61.0 percent. ${ }^{54}$ Despite this massive growth in debt, U.S. consumer price inflation averaged 1.9 percent between 2008 and 2014. With the Federal Reserve pegging the federal funds rate near zero from December 2008 onward, monetary policy behavior appears to have been passive, as in regime F. But the theory in this chapter predicts that if the debt expansion is not associated with higher taxes, private-sector wealth increases, raising aggregate demand and inflation. Where is the inflation that the fiscal theory predicts?

Like constant velocity, simple expositions of the fiscal theory serve pedagogical purposes, but severely constrain the theory's empirical predictions. Missing from the simple theory is that debt's value derives from the present value of expected surpluses and that the present value also depends on the expected path of real discount rates. Real interest rates have been decidedly negative in the United States. Kiley (2015) estimates that the real federal funds rate was negative from the onset of the recession through the middle of 2015. Even yields on 5-year Treasury inflation-indexed securities were negative or hovering around zero from September 2010 through 2015, reaching a nadir of -1.47 percent in October 2012 . To the extent that these low rates flowed into real discount rates applied to government debt, the expected present value of surpluses was very high indeed over this period, even in the absence of any anticipated increases in primary surpluses. And along with the low real interest rates that the Federal Reserve sought to achieve, the crisis brought a flight to quality in which investors fled from non-government-insured asset classes to government securities, which drove down real treasury bond yields.

Any demand stimulus created by the nominal debt expansion would be offset, at least in part, by the increase in the value of debt that low real discount rates induce. It would take a careful quantitative analysis to make this case convincingly, but we see no a priori refutation of regime $\mathrm{F}$ from these observations.

If anything, the logic of the fiscal theory may help to explain the anomaly of why inflation didn't fall as much as conventional money-only models predicted. The lack of persistent deflation during the recent recession caused some prominent economists to question the validity of conventional Phillips curve models where inflation is driven by measures of economic slack. ${ }^{55}$ Del Negro, Giannoni, and Schorfheide (2015) argue that conventional models with a new Keynesian Phillips curve can account for the lack of deflation despite a large negative output gap provided prices are sufficiently sticky and inflation expectations remain anchored

\footnotetext{
${ }^{54}$ These numbers come from the Federal Reserve Bank of Dallas's privately held gross federal debt and the U.S. Department of Commerce's annual nominal GDP data. Congressional Budget Office (2015) reports that federal debt held by the public rose from 35 percent to 74 percent over the same period.

${ }^{55}$ For example, Hall (2011) and Ball and Mazumder (2011).
} 
at positive levels. In their model, the anchoring comes from the anticipation that monetary policy will achieve future rates of inflation that are close to target. An alternative hypothesis is that expectations of future inflationary financing of the large increases in government debt are providing the necessary anchor.

A second canonical example thrown up by skeptics is Japan. Since 1993, Japanese government debt has risen from 75 to 230 percent of GDP, while inflation has averaged a mere 0.21 percent. For 20 years beginning in 1995, the Bank of Japan's overnight call rate has been below 0.5 percent and at 0.1 percent or lower for more than 12 of those years. Evidently, Japanese monetary policy has been passive. Once again, where is the inflation that the fiscal theory predicts?

Japan is a complicated case. Real interest rates have been low, just as in the United States recently, but there is more to the story. ${ }^{56}$ Japan is the poster child for inconsistency in macroeconomic policies, as Krugman (1998), Ito (2006), Ito and Mishkin (2006), and Hausman and Wieland (2014) document. Fiscal policies have see-sawed between stimulus and austerity. Even as Prime Minister Abe appeared to announce an end to the inconsistency and Japanese economic activity and inflation were showing signs of life, Japan raised the consumption tax rate from 5 to 8 percent in April 2014. Consumer price inflation fell from 2.7 percent in 2014 to below 1 percent in 2015 [Leeper (2016)].

Japan has been mired in the tradeoff between fiscal sustainability and economic reflation. To a fiscal theorist, Japan's obsession with government debt reduction is puzzling. Central to a regime $\mathrm{F}$ equilibrium is that agents' expectations are anchored on fiscal policies that do not raise surpluses when debt expands. Unsettled fiscal policies like those in Japan are unlikely to have so anchored expectations, so it is not clear that Japan resides in regime F and there is any contradiction of the fiscal theory to explain.

\section{Practical Implications}

Viewing practical issues through the joint lenses of monetary and fiscal policies sheds fresh light on policy problems. That new light can also lead to sharply different perspectives on these problems.

\subsection{Inflation Targeting}

Nearly 30 countries with independent central banks have embraced numerical inflation targeting as the operating principle for monetary policy. Very few of these countries sought

\footnotetext{
${ }^{56}$ Imakubo, Kojima, and Nakajima (2015) calculate that real yields on zero-coupon bonds at 1-, 2-, and 3 -year maturities fluctuated between 0.5 and -0.5 percent from the middle of 1995 until 2012, when they fell to almost -2.0 percent in 2014 .
} 
simultaneously to adopt fiscal policies that are compatible with the chosen inflation targets. This discussion of the policy interactions that are prerequisites for successful inflation targeting does not depend on the prevailing monetary-fiscal regime, so it applies whether policies reside in regime $\mathrm{M}$ or regime $\mathrm{F}$.

The derivations rely on a few generic first-order conditions, a government budget identity, and the condition that optimizing households will not want to over- or under-accumulate assets. For this reason, the results have broad implications that extend well beyond the details of particular models. Consider an economy with a geometrically decaying maturity structure on zero-coupon nominal government bonds. The government's budget identity is

$$
\frac{P_{t}^{m} B_{t}^{m}}{P_{t}}=\frac{\left(1+\rho P_{t}^{m}\right) B_{t-1}^{m}}{P_{t}}-s_{t}
$$

Letting $Q_{t, t+k} \equiv \beta^{k} \frac{u^{\prime}\left(c_{t+k}\right)}{u^{\prime}\left(c_{t}\right)} \frac{P_{t}}{P_{t+k}}$, asset-pricing conditions yield

$$
\begin{aligned}
\frac{1}{R_{t}} & =E_{t} Q_{t, t+1} \\
P_{t}^{m} & =E_{t} Q_{t, t+1}\left(1+\rho P_{t+1}^{m}\right)
\end{aligned}
$$

and the term structure relationship is

$$
P_{t}^{m}=E_{t} \sum_{k=0}^{\infty} \rho^{k}\left(\prod_{j=0}^{k} \frac{1}{R_{t+j}}\right)
$$

These conditions deliver the usual bond valuation equation

$$
\frac{\left(1+\rho P_{t}^{m}\right) B_{t-1}^{m}}{P_{t}}=E_{t} \sum_{i=0}^{\infty} \beta^{i} \frac{u^{\prime}\left(c_{t+i}\right)}{u^{\prime}\left(c_{t}\right)} s_{t+i}
$$

Rewrite the valuation equation by replacing $\left(1+\rho P_{t}^{m}\right)$ using

$$
1+\rho P_{t}^{m}=1+E_{t} \sum_{k=1}^{\infty}(\beta \rho)^{k} \frac{u^{\prime}\left(c_{t+k}\right)}{u^{\prime}\left(c_{t}\right)} \frac{P_{t}}{P_{t+k}}
$$

and, for simplicity, assume a constant-endowment economy, so $\frac{u^{\prime}\left(c_{t+i}\right)}{u^{\prime}\left(c_{t}\right)}=1$, to generate

$$
\left[\sum_{k=0}^{\infty}(\beta \rho)^{k}\left(\prod_{j=1}^{k} \frac{1}{\pi_{t+j}}\right)\right] \frac{B_{t-1}^{m}}{P_{t}}=E_{t} \sum_{k=0}^{\infty} \beta^{k} s_{t+k}
$$


Imagine an economy that takes as given variables dated $t-1$ and earlier, but commits to hitting an inflation target in all subsequent dates, so $\pi_{t+k} \equiv \pi^{*}$ for $k \geq 0$. Valuation equation (43) becomes

$$
\frac{B_{t-1}^{m} / P_{t-1}}{E P V_{t}(s)}=\pi^{*}-\beta \rho
$$

where $E P V_{t}(s) \equiv E_{t} \sum_{k=0}^{\infty} \beta^{k} s_{t+k}$.

This expression imposes stringent conditions on the expected present value of primary surpluses, though not on the surplus path, if the inflation target is to be achieved. For given initial real debt, if the economy adopts a policy of "too high" surpluses, then the inflation target that is achievable is lower than the desired target, $\pi^{*}$. Another way of seeing the tension between monetary and fiscal policy in this equation is to note that the condition requires the fiscal policymaker to adopt a debt target, which it passively adjusts surpluses to achieve. This means that any period of austerity that raises surpluses must induce a subsequent relaxation of policy to bring $E P V_{t}(s)$ in line with the outstanding debt stock and the inflation target. An austerity program that never took its foot off the gas would undermine the inflation target just a surely as would a myopic fiscal policymaker prone to runaway deficits. Are current fiscal frameworks consistent with such targets?

Increasingly policymakers are adopting fiscal rules that are designed to reverse recent increases in government debt. For example, following its banking crisis of 1992 Sweden adopted two fiscal rules: a net lending target of 1 percent of GDP over the economic cycle and a nominal expenditure ceiling three years ahead. This ceiling is consistent with ensuring that government expenditure falls as a share of GDP. Similarly, the "debt brake" in Switzerland requires that central government expenditure cannot grow faster than average revenue growth, while the German debt brake introduced in 2011 imposes a limit on federal net lending of 0.35 percent of GDP. In the United Kingdom, the 2015 Charter for Budget Responsibility requires the government to run a primary surplus in "normal" times. All these measures aim not only to stabilize the debt-to-GDP ratio, but to ensure that it is falling over time. And to the extent that the rules are maintained, the pace of debt reduction should increase over time as less of any surplus is devoted to servicing the existing stock of debt. Because these rules fail to include provisions to target a long-run debt-to-GDP ratio, so austerity measures would be relaxed as that target was approached, the rules run the risk of chronically undershooting the inflation target.

From a theoretical perspective, the rules do not make surpluses contingent on debt. This makes fiscal behavior active, placing it in regime F. When the fiscal policymaker adopts an active rule, as section 2.3 shows, the monetary authority's ability to control inflation depends crucially on the maturity structure of the outstanding debt and on the nature of its policy 
response. With a pegged nominal interest rate, inflationary expectations remain consistent with the inflation target and surprise deviations from that target provide the revaluation effects needed to stabilize debt. But if the central bank attempts to come as close to active as possible by setting $\alpha_{\pi}=\beta$, the rate of inflation follows a random walk, permanently deviating from the inflation target in the face of fiscal shocks. If the policy objective is to smooth the inflationary costs of revaluation effects, then the optimal policy exercises suggest that a persistent deviation from the inflation target is desirable, so long as the persistence matches the maturity structure of the government's debt portfolio. With only single-period debt, there is no advantage in having a prolonged increase or decrease in inflation following a fiscal shock because only the initial period's inflation helps to reduce the real value of government liabilities. But when debt is of longer maturity, allowing inflation to rise and then gradually decline as the predetermined debt stock matures reduces the discounted value of inflationary costs associated with the required revaluation effects.

Successful inflation targeting requires more than a resolute central bank that follows "best practice" monetary policy behavior that includes clear objectives, transparency that leads to effective communications, and accountability. Even with all these elements in place, expression (44) implies that the central bank can achieve $\pi^{*}$ only if fiscal policy is compatible with that target. If fiscal behavior requires a long-run inflation rate that differs from $\pi^{*}$, even best practice monetary policy cannot succeed in anchoring long-run inflation expectations or inflation outturns on target.

\subsection{Returning to "Normal" Monetary Policy}

The financial crisis has seen a substantial increase in debt-to-GDP ratios in many advanced economies, although the immediate need for fiscal adjustment may have been muted due to the reduced debt service costs as real interest rates have fallen since the financial crisis. To see this consider a small change to our policy problem in the endowment economy, where we allow the households' discount factor to rise temporarily to $\widetilde{\beta}>\beta$, capturing the flight to quality observed in the financial crisis. If we assume government spending is held constant, the policy problem becomes

$$
\begin{aligned}
L_{t}= & E_{0} \frac{1}{2} \sum_{t=0}^{\infty} \beta^{t}\left[-\frac{1}{2}\left(\tau_{t}^{2}+\theta\left(\nu_{t}-1\right)^{2}\right)\right. \\
& +\mu_{t}\left(\widetilde{\beta}_{t} E_{t} \frac{\left(1+\rho P_{t+1}^{m}\right)}{P_{t}^{m}} \nu_{t+1}-1\right) \\
& +\lambda_{t}\left(b_{t} P_{t}^{m}-\left(1+\rho P_{t}^{m}\right) b_{t-1} \nu_{t}-g_{t}-z_{t}+\tau_{t}\right)
\end{aligned}
$$


which yields the first order conditions

$$
\begin{aligned}
\tau_{t} & : \quad-\tau_{t}+\lambda_{t}=0 \\
\nu_{t} & : \quad-\theta\left(\nu_{t}-1\right)+\mu_{t-1} \frac{\left(1+\rho P_{t}^{m}\right)}{P_{t-1}^{m}} \beta^{-1} \widetilde{\beta}_{t-1}-\left(1+\rho P_{t}^{m}\right) \lambda_{t} b_{t-1}=0 \\
P_{t}^{m} & : \quad-\frac{\mu_{t}}{P_{t}^{m}}+\mu_{t-1} \rho \frac{\nu_{t}}{P_{t-1}^{m}} \beta^{-1} \widetilde{\beta}_{t-1}+\lambda_{t}\left(b_{t}-\rho \nu_{t} b_{t-1}\right)=0 \\
b_{t} & : \quad \lambda_{t} P_{t}^{m}-\beta E_{t}\left(1+\rho P_{t+1}^{m}\right) \nu_{t+1} \lambda_{t+1}=0
\end{aligned}
$$

Under a perfect foresight equilibrium this implies the tax smoothing result is recast as

$$
\tau_{t}=\beta \widetilde{\beta}_{t}^{-1} \tau_{t+1}
$$

which means that the tax rate will be rising during the period in which households have an increased preference for holding government bonds over consumption. Intuitively, the original tax smoothing result balances the short-run costs of raising taxes to reduce debt against the long run benefit of lower debt. These costs and benefits are finely balanced with the interest rate on the debt being exactly offset by the policymaker's rate of time preference so that steady-state debt follows a random walk in the face of shocks. When the interest on debt is less than the policymaker's rate of time preference, the policymaker prefers to delay the fiscal adjustment and will allow debt to accumulate, stabilizing debt only after the period of increased household preference for debt holdings has passed.

To the extent that a return to "normal" monetary policy is associated with a rise in debt service costs, optimal policy suggests that efforts to stabilize debt are enhanced at this point. But under the Ramsey policy, inflation surprises to revalue debt are effective only if carried out before the predetermined debt stock matures. Therefore the delay in debt stabilization also reduces the efficacy of promising to raise prices in the future placing more of the burden of adjustment on taxation. At the same time, the higher debt stock that emerges at the point of normalization raises the potential time-inconsistency problems inherent in the Ramsey policy such that it is at this point we may start to see increased pressure to inflate away the debt.

More generally, higher central bank interest rates have powerful fiscal consequences when government debt levels are elevated. In the United States, the Congressional Budget Office (2014) estimates that net interest costs will quadruple between 2014 and 2024 to reach 3.3 percent of GDP. ${ }^{57}$ Those interest costs must be financed somehow-by higher taxes and

\footnotetext{
${ }^{57}$ The CBO expects a relatively modest interest in treasury interest rates over that period, with the 10 -year rate rising from 2.8 to 4.7 percentage points and the average rate on debt held by the public rising from 1.8 to 3.9 percentage points. Cochrane (2014) considers a scenario in which the Fed raises interest rates to 5
} 
lower spending now or by faster growth in debt and other adjustments in the future. In light of the political dynamics today in the United States, it is not obvious how those costs will be financed.

Central bankers are well aware of the fiscal consequences of their actions. King (1995) refers to "unpleasant fiscal arithmetic" — a process of monetary disinflation raises real interest rates and destabilizes government debt until the credibility of the disinflation is established. But, he argues, the higher debt may actually undermine that credibility and unpleasant monetarist arithmetic may re-emerge. One interpretation is that King worries about the danger that the fiscal consequences of disinflation may force the central bank to reverse a return to "normal" interest rates.

\subsection{Why Central Banks Need to Know the Prevailing Regime}

Davig and Leeper (2006), Bianchi (2012), Bianchi and Ilut (2014) and Chen, Leeper, and Leith (2015) suggest that there have been switches in the conduct of fiscal policy between passive and active. And fiscal switches are not always associated with compensating switches in monetary policy that place the economy in either regime $\mathrm{M}$ or regime $\mathrm{F}$. If these policy permutations were permanent they would either result in indeterminacy (passive monetary and fiscal policy) or non-existence of equilibrium (active monetary and fiscal policy). But if policy is expected to return to either the $\mathrm{M}$ or F regime sufficiently often, then these policy combinations can still deliver determinate equilibria. So there are four possible permutations of monetary and fiscal policy that may coexist, but only two, if permanent, deliver unique bounded equilibria. The prevailing policy configuration can have profound implications for the conduct of monetary policy, as we illustrate in the endowment economy with section 2's policy rules. ${ }^{58}$

Regardless of regime, inflationary dynamics are

$$
E_{t}\left(\nu_{t+1}-\nu^{*}\right)=\frac{\alpha_{\pi}}{\beta}\left(\nu_{t}-\nu^{*}\right)
$$

Under regime $\mathrm{M}$ with an active monetary policy $\left(\alpha_{\pi}>\beta\right)$, monetary policy can target inflation in each period, $\nu_{t}=\nu^{*}$, while the passive fiscal policy stabilizes debt

$$
E_{t}\left(\frac{b_{t+1}}{R_{t+1}}-\frac{b^{*}}{R^{*}}\right)=\left(\beta^{-1}-\gamma\right)\left(\frac{b_{t}}{R_{t}}-\frac{b^{*}}{R^{*}}\right)-E_{t} \varepsilon_{t+1}^{F}
$$

percent and with them, real interest rates. At a 100 percent debt-GDP ratio, the increased interest costs amount to $\$ 900$ billion.

${ }^{58}$ See Davig, Leeper, and Walker (2010) and Leeper (2011) for related analyses. 
provided $\gamma>\beta^{-1}-1$.

Suppose we know the economy will enter this regime in period $T$, at which point inflation will be at its target $\nu_{T}=\nu^{*}$ and the fiscal rule will stabilize whatever debt is inherited at time $T$. In this case it does not matter whether or not the monetary policy rule is active or passive prior to period $T$, since $T$-step-ahead expected inflation is

$$
E_{t} \nu_{t+T}-\nu^{*}=\left(\frac{\alpha_{\pi}}{\beta}\right)^{T-t}\left(\nu_{t}-\nu^{*}\right)
$$

which implies that inflation will be on target between today and period $T$. If fiscal policy is active, debt will be moving off target between today and period $T$, but the passive fiscal rule will, from that point on, stabilize debt. If fiscal policy is passive before period $T$, this would facilitate the debt stabilization prior to $T$ and the targeting of inflation would be uninterrupted by any change of regime at time $T$.

We now assume that at time $T$ agents anticipate the economy will enter regime $\mathrm{F}$ where monetary policy is passive $\left(\alpha_{\pi}<\beta\right)$, and fiscal policy does not respond to debt $(\gamma=0)$. Now the period $T$ price level needs to adjust to satisfy the bond valuation equation at time $T$ given the level of inherited nominal debt $B_{T-1}$. When $\gamma=0$, the fiscal rule is $s_{t}=s^{*}+\varepsilon_{t}^{F}$ and the solution for real debt is

$$
E_{t} \frac{B_{T-1}}{R_{T-1} P_{T-1}}=\frac{b^{*}}{R^{*}}+\sum_{j=1}^{\infty} \beta^{j} E_{t} \varepsilon_{T-1+j}^{F}
$$

The price level does not jump in period $T$, but it does adjust in period $t$ when the switch to regime $\mathrm{F}$ in period $T$ is first anticipated. The implications for inflation beyond period $T$ depend on how passive the monetary policy rule is. With an interest rate peg, $\alpha=0$, inflationary expectations remain on target, $E_{t} \nu_{t+1}=\nu^{*}$, but there will be innovations to inflation to ensure the bond valuation equation holds in the face of additional fiscal shocks occurring from period $T$ onwards. With some monetary policy response to inflation, $0<$ $\alpha_{\pi}<\beta$, the initial jump in the price level will result in a temporary, but sustained rise in inflation whose evolution obeys equation (45). As section 4 shows, sustaining the rise in inflation enhance the revaluation effect, but the longer is debt maturity the greater is the reduction in distortions caused by higher inflation.

How does anticipating the $\mathrm{F}$ regime in period $T$ affect the conduct of policy prior to period $T$ ? With fiscal policy following a rule that may or may not be passive, the expected 
evolution of government debt follows

$$
E_{t}\left(\frac{B_{t+1}}{R_{t+1} P_{t+1}}-\frac{b^{*}}{R^{*}}\right)=\left(\beta^{-1}-\gamma\right)\left(\frac{B_{t}}{R_{t} P_{t}}-\frac{b^{*}}{R^{*}}\right)-E_{t} \varepsilon_{t+1}^{F}
$$

We can iterate this forward until period $T$ as

$$
E_{t}\left(\frac{B_{T-1}}{R_{T-1} P_{T-1}}-\frac{b^{*}}{R^{*}}\right)=\left(\beta^{-1}-\gamma\right)^{T-1-t}\left(\frac{B_{t}}{R_{t} P_{t}}-\frac{b^{*}}{R^{*}}\right)+\sum_{j=0}^{T-1-t}\left(\beta^{-1}-\gamma\right)^{j} E_{t} \varepsilon_{t+1+j}^{F}
$$

which defines the initial debt level $\frac{B_{t}}{R_{t} P_{t}}$ required to ensure the economy enters regime $\mathrm{F}$ in period $T$ with the appropriate level of debt $\frac{B_{T-1}}{R_{T-1} P_{T-1}}$ without any discrete jumps in the price level at that time. This depends upon the extent to which fiscal policy prior to period $T$ acts to stabilize debt as determined by the fiscal feedback parameter, $\gamma$, and the expected value of fiscal shocks over that period. If the move to the $\mathrm{F}$ regime is sufficiently long in the future and fiscal policy is sufficiently aggressive in stabilizing debt, then there will be little need for surprise inflation in the initial period to ensure the appropriate debt level is bequeathed to the future. But if the switch is more imminent or the fiscal stabilization prior to period $T$ is muted, then an initial jump in prices will be required to ensure the bond valuation equation holds. The inflationary implications of this prior to period $T$ depend on the conduct of monetary policy. If monetary policy is active prior to period $T$, any initial jump in prices will be explosive until the $\mathrm{F}$ regime is established in period $T$. This happens because the period $t$ price level jump ensures the bond valuation equation holds, while inflation dynamics are determined by equation (45), which is explosive under an active monetary policy. This is a bounded equilibrium because the process for inflation stabilizes when the policy regime changes in period $T$. But before period $T$, the active monetary policy actually destabilizes prices. Postponing the switch to the F regime means the period of explosive inflation dynamics remains in place for longer.

This analysis has the flavor of a game of chicken between the monetary and fiscal policymakers. The monetary authority can stick to an active monetary policy rule and achieve its inflation target, provided everyone is sure that policy will eventually be supported by a passive fiscal policy which stabilizes debt. Debt dynamics will be unstable in such a scenario until the fiscal authorities relent and adopt a passive fiscal policy. But when there is the suspicion that monetary policy will eventually turn passive to support a fiscal policy that doesn't stabilize debt, then conventional anti-inflation policies today may actually worsen inflation outcomes. 


\section{Critical Assessment and Outlook}

We conclude by examining the areas where further theoretical and empirical work is needed.

\subsection{Further Theoretical Developments}

This section highlights areas in which additional theoretical work on monetary-fiscal interactions would be fruitful.

\subsubsection{Default and the Open Economy}

This chapter has focused on closed-economy models, abstracting from issues of sovereign default and open-economy dimensions that have come together in the recent sovereign debt crisis in the Euro Area. In the early applications of the fiscal theory to the open economy, a key issue was whether or not individual country government budget identities were consolidated into a single global bond valuation equation. ${ }^{59}$ If so, with multiple passive monetary policies, each country's price level and exchange rate are indeterminate. In this equilibrium, one country accumulates the debt of another, an outcome whose political equilibrium Sims (1997) argues is unstable. If such equilibria are ruled out, then we return to having a bond valuation equation for each country and fiscal policies in one economy carry implications for outcomes in the second economy. For example, a determinate active/passive policy pair can be achieved across countries rather than within countries [Leith and Wren-Lewis (2008)].

Similar issues arise in a monetary union. With a single passive monetary policy, it is possible to ensure determinacy with only one active fiscal policy [Bergin (2000) and Leith and Wren-Lewis (2006)]. These analyses have the troubling feature that the tail seems to wag the dog - a small monetary union member that fails to pursue passive fiscal policy can determine the price level for the entire union. This raises questions about whether these early applications of the fiscal theory to the open economy have appropriately captured crosscountry heterogeneity - including different price-level processes across member states - and the cross-country implications of the interactions between monetary and fiscal policy. More recent work seeks to model the gross asset/liability positions of countries to capture the kinds of revaluation effects generated by price level and exchange rate movements. ${ }^{60}$ That work finds that the gross asset/liability positions can be several multiples of GDP even when

\footnotetext{
${ }^{59}$ See Sims (1997), Loyo (1997), Woodford (1998b), Dupor (2000), Canzoneri, Cumby, and Diba (2001a) and Daniel (2001).

${ }^{60}$ See Lane and Milesi-Ferretti (2001) for the first issue of a dataset of external portfolios and Devereux and Sutherland (2011) for a numerical method to endogenously embed such positions in open-economy macro models.
} 
net positions are not, implying that the revaluation effects stressed in this chapter are likely to be both quantitatively important and more complex in open-economy settings.

Recent events highlight the need to bring sovereign default into the analysis. In a model similar to our endowment economy, but augmented with an exogenous default risk, Uribe (2006) demonstrates that default can give rise to fiscal theory-type effects, with anticipated, but delayed defaults potentially destabilizing an active inflation targeting policy, in much the same way that anticipating a move to regime $\mathrm{F}$ can do.

While many analyses of strategic default focus on real economies - for example, D'Erasmo, Mendoza, and Zhang (2016) — when default through inflation is available as an alternative financing option, it is either assumed to be equivalent to outright default, or possibly less costly if it is less damaging to the balance sheets of a country's banking sector than an outright default [Gros (2011)]. Given that inflation is costly, it is not obvious that this will always be the case. A useful line of work would consider the nature of the strategic default decision in environments in which debt revaluations through surprise current inflation and bond prices are possible. Kriwoluzky, Müller, and Wolf (2014) is an interesting paper that contrasts outright default for a country engaged in a monetary union with the re-denomination of debt following exit from the union. They find that the possibility of exit significantly worsens the pre-exit/default debt dynamics. Similarly, Burnside, Eichenbaum, and Rebelo (2001) argue that the speculative attacks on fixed-currency regimes in the Asian crisis of 1997 sprung from expectations that large revaluations of debt were required to finance the projected deficits that ongoing bank bailouts were expected to engender. In richer models where default is state dependent and the economic costs of default arise through the impact of default on domestic banks' balance sheets the set of monetary and fiscal interactions is widened further [Bi, Leeper, and Leith (2015) and Bocola (2016)]. There is plenty of scope to deepen our understanding of default vs. inflation financing in a sovereign debt crisis.

\subsubsection{BetTer Rules}

Analyses of optimal monetary and fiscal policy rules in approximated economies is quite clear about the kinds of simple rules that can mimic the Ramsey policy. Fairly aggressive inflation targeting using an inertial Taylor rule, coupled with a passive fiscal policy that very gradually stabilizes debt, comes close to achieving the welfare levels that the Ramsey policy acquires [Schmitt-Grohé and Uribe (2007) and Kirsanova and Wren-Lewis (2012)]. The non-linear solutions to the optimal policy problem that this chapter described reveal that the policy mix depends crucially on both the level of debt and its maturity. With high levels of short-maturity debt, it is optimal to use monetary policy to stabilize debt 
and adjust distortionary taxation to mitigate the inflationary consequences of such a policy. This suggests that there may be a family of simple implementable rules which could improve welfare by introducing a degree of state-dependence to the policy mix.

Similarly, studies often seek to assess the importance of automatic stabilizers by adding output to the fiscal rules. Kleim and Kriwoluzky (2014) argue, though, that this is not the most data-coherent specification of policy behavior and that rules conditioned on other macroeconomic variables better capture the cyclical properties of fiscal instruments. Those proposed rules also improve welfare in DSGE models. Taken together, this suggests that there is scope for extending the range of simple rules considered in the literature to find alternatives that are both empirically and normatively more appealing.

\subsubsection{Strategic Interactions}

Estimates of regime switching policies find that the policy mix is not always aligned with either regime $\mathrm{M}$ or regime $\mathrm{F}$. There are also periods in which policies are in conflict - either doubly active or doubly passive. Introducing strategic interactions between policy authorities into optinmal policy analysis may help to put theory in better line with data. Literature that looks at such interactions often relies on linear-quadratic approximation or simplifying assumptions to obtain tractable results. ${ }^{61}$ Blake and Kirsanova (2011) consider the desirability of central bank conservatism in a standard new Keynesian economy augmented with fiscal policy and an associated independent fiscal policymaker. They consider three forms of strategic interaction: either monetary or fiscal leadership, where the leader anticipates the response of the follower,or a Nash equilibrium between the two policymakers. The striking result, which echoes section 5.4 in which the monetary authority followed a Taylor rule while the fiscal authority optimized, is that central bank conservatism always reduces welfare. Blake and Kirsanova also find that the quantitative results depend on the level of debt around which the economy is linearized. This argues that such analyses could usefully be extended to a non-linear framework to explore the state-dependencies in the strategic monetary and fiscal policy interactions. How robust is the institutional policy design to the strategic interactions implied by independent fiscal and monetary policymakers? To what extent can such interactions explain the observed policy switches in empirical analyses based on simple ad hoc rules?

\footnotetext{
${ }^{61}$ Adam and Billi (2008) and Dixit and Lambertini (2003) consider the strategic interactions between monetary and fiscal policymakers, although in abstracting from the existence of government debt they rule out the mechanisms that have been the focus of this chapter.
} 


\subsubsection{Political Economy}

Theoretical work on optimal policy, particularly fiscal policy, often implies policy behavior that bears little resemblance to observed policy. Benigno and Woodford's (2004) and Schmitt-Grohé and Uribe's (2004) analyses of jointly optimal monetary and fiscal policies suggest that when the policymaker can make credible promises about future actions, the steady-state level of debt should follow a random walk - in response to shocks, debt will be allowed to rise permanently because the short-run costs of reducing debt exactly balance the long-run benefits. This policy prescription is clearly at odds with the mounting concerns over rising debt levels in several advanced economies, which have led the IMF to predict that most governments will be involved with consolidation efforts for several years. The expected pace of consolidation is particularly rapid in the economies that are subject to pressures in the financial markets from worries over fiscal sustainability [International Monetary Fund (2011)].

If instead we assume that policymakers cannot make credible promises about how they behave in the future - policy is constrained to be time-consistent - then the implied policy outcomes can be equally unconvincing: instead of implying that debt should permanently rise following negative fiscal shocks, the theory tends to imply that the policymaker will be tempted to aggressively reduce the debt stock, often at rates that far exceed those observed in practice [Leith and Wren-Lewis (2013)]. In standard new Keynesian models, time-consistent policy will not only call for a rapid debt correction, but it will make the long-run equilibrium value of debt negative, as the fiscal authority seeks to accumulate a stock of assets to help offset other frictions in the economy. The analysis in this chapter and in Leeper, Leith, and Liu (2015), by allowing for a realistically calibrated debt maturity structure, can plausibly slow the pace of fiscal adjustments to levels which are not obviously inconsistent with those observed. And by assuming that the fiscal policymaker discounts the future more highly than households, as a crude means of capturing the short-termism that political frictions can engender, Leeper, Leith, and Liu (2015) find that the time-consistent policy can support reversion to plausible debt-GDP ratios.

Although an inability to commit can go some way towards explaining this discrepancy between actual policy and the normative prescriptions of the theoretical literature, it seems likely that the political dimensions of policymaking are also important. Political economy aspects of actual fiscal policy have recently been laid bare in the abandoning of fiscal rules in Europe during the financial crisis, the brinkmanship over the raising of the debt ceiling in the United States, and the withholding or awarding of bail-out funds to Greece and other Eurozone economies from the Troika composed of the European Commission, the ECB, and 
the IMF. In this vein the New Political Economy literature seeks to identify mechanisms that can explain the trends in debt-GDP levels in many developed economies in recent decades.

Alesina and Passalacqua (2016) identify several reasons why governments may pursue policies that raise government debt to suboptimally high levels: (1) fiscal illusion-voters misunderstand the budget identity and are enticed to vote for a party that supports unsustainable tax cuts or spending increases; (2) political business cycles - voters are unsure of the competence of potential governments, so fiscal policy can be used by incumbents to signal competence; (3) delayed stabilization - political factions squabble over who bears the costs of fiscal consolidations, thereby delaying debt stabilization; (4) debt as a strategic variablepolitical parties use debt to tie the hands of their political opponents when they are out of office; (5) bargaining over policy in heterogenous legislatures; (6) rent seeking by politicians; and (7) intergenerational redistributions. Some of these mechanisms are more naturally located in majoritarian systems - for example, political business cycles and strategic use of debt - while others are more likely to be associated with continuous strategic interactions between political actors outside of election periods - for example, delayed stabilizations and bargaining within legislatures - which are a feature of proportional/multi-party systems or heterogeneity within parties under a two party system.

This New Political Economy literature typically doesn't consider monetary and fiscal policy interactions of the type considered in this chapter, so there is a need to integrate the two literatures. Political conflict inherent in the conduct of fiscal policy may explain why it is possible to obtain a data-coherent optimal policy description of monetary policy - albeit with fluctuations in the degree of monetary policy conservatism - while a similar description for fiscal policy is less easily achieved with policy switching between active and passive rules, with only short-lived periods in which policy is optimal [Chen, Leeper, and Leith (2015)].

Despite the difficulty of allowing for strategic interactions between the monetary and fiscal policymakers, this may not be going far enough if we are to understand the evolution of the monetary-fiscal policy mix. While treating an independent central bank as a single policymaker may be an acceptable approximation, it is less obvious that fiscal policy is best described by the actions of a single benevolent policymaker. A longer-term research goal is to tractably integrate the New Political Economy literature into the analysis of monetary and fiscal policy interactions. Can we explain the changing nature of those interactions?

Political frictions vary substantially across countries. For example, in the United States and the United Kingdom debt levels fell fairly consistently following World War II until the early 1980s, before expanding consistently under Republican administrations in the United States, while not having such a clear partisan pattern in the United Kingdom. The current Conservative government in the United Kingdom is promising an aggressive austerity policy 
which seeks to run a permanent surplus from 2017. Any use of political frictions to explain the dynamics of debt and other macro variables, must also explain such cross-country differences, particularly since it is not obvious that U.S. Republicans and U.K. Conservatives have fundamentally different views on the optimal size of the state.

\subsubsection{MONEY}

By focusing on cashless economies we have side-stepped the literature that considers the role of inflation as a tool of public finance versus its impact on money as a medium of exchange [Phelps (1973)]. More recent research finds that the nature of the time-consistency problem facing a policymaker who issues nominal debt can depend crucially on the effects of inflation on the transactions technology [Martin (2009), Martin (2011) and Niemann, Pichler, and Sorger (2013)]. We have also ignored the central bank's balance sheet, which precludes an analysis of fiscal aspects of unconventional monetary policies which have been discussed in Sims (2013), Del Negro and Sims (2015a), and Reis (2013, 2015). Analyzing such unconventional monetary policies or technological developments like virtual money within frameworks that allow for interactions between such developments and fiscal policy are obvious areas for further research.

\subsection{Further EMPIRICAL WORK}

This section proposes several directions in which to take empirical work on monetary-fiscal interactions.

\subsubsection{Data NeEDS}

In the early days of real business cycle research, Prescott (1986) argued that "theory is ahead of measurement," and, in particular, that theory can guide the measurement of key economic time series. This rings especially true for research on how monetary and fiscal policies affect inflation. Empirical applications in which the debt valuation equation plays a central role require observations on objects that are not readily available: the market value of privatelyheld government liabilities - explicit debt and other commitments - the maturity structure of that debt, actual and expected primary surpluses, and actual and expected real discount rates. Compiling such data across countries and across monetary-fiscal regimes is the first step in an empirical agenda on policy interactions. 


\subsubsection{IDEntifying Regime}

Empirical work surveyed in section 6 highlights the difficulties in distinguishing whether regime $\mathrm{M}$, regime $\mathrm{F}$, or some other regimes generated observed time series. It remains to thoroughly explore which features of private and policy behavior are critical for breaking the near observational equivalence of regimes. Surprisingly little work experiments with alternative specifications of policy behavior, particularly in DSGE models. Instead, most researchers - including us - adopt the simple rules that have become "standard." There is ample room for such experimentation.

Closely related is Geweke's (2010) argument that models are inherently incomplete in the sense that they lack "some aspect of a joint distribution over all parameters, latent variables, and models under consideration [p. 3]." For example, central bank money-only models that follow Smets and Wouters (2007) impose a dogmatic prior that places zero probability mass on regime $\mathrm{F}$ parameters. This procedure rejects a priori regions of the parameter space that the work reviewed in section 6.3 finds fit data equally well. As we have seen, monetary policy actions have very different impacts in regimes $\mathrm{M}$ and $\mathrm{F}$, so it matters a great deal to a policymaker, who is using model output to reach decisions, whether regime $\mathrm{F}$ is even possible. it would be valuable to apply existing tools for confronting model uncertainty to issues of monetary-fiscal regime [Hansen and Sargent (2007) and Geweke (2010)].

A different angle on model fit pursue's DeJong and Whiteman's (1991) idea to ask: what type of prior over policy parameters is needed to support the inference that regime $\mathrm{M}$ (or regime F) generated the data? This exercise elicits the strength of a researcher's beliefs about regime when the researcher chooses to focus solely on one possible monetary-fiscal mix.

\subsubsection{Generalizing Regime Switching}

Existing work that estimates DSGE models with recurring policy regime switching tends to make simplifying assumptions about the nature both of private behavior and the policy process. Those assumptions can be systematically relaxed to arrive at more general models usable for policy analysis. And the fit of the models needs to be scrutinized in the manner that, for example, Smets and Wouter's (2007) specification has been. Until the fit of switching models is carefully evaluated, fixed-regime DSGE models will continue to dominate in policy institutions. ${ }^{62}$

Recent econometric innovations permit estimation of endogenous regime change [Chang, Choi, and Park (2015)]. That technique treats policy regime as a latent process akin to

\footnotetext{
${ }^{62}$ Sims and Zha (2006) is an exception, though they consider only monetary switching.
} 
time-varying probabilities of regime change. Generalizations of those methods to multivariate settings with multiple regimes that switch non-synchronously could be integrated with DSGE models in which agents learn about the prevailing regime. Setups like that could shed empirical light on endogenous interactions among monetary and fiscal regimes, such as those that arise from the strategic interactions and political economy dynamics that sections 8.1.3 and 8.1.4 mention. ${ }^{63}$

\subsubsection{Historical Analyses}

Friedman and Schwartz (1963a) set the standard for historical analyses of monetary policy. But fiscal policy plays almost no role in their narrative. Stein (1996) is an excellent account of the evolution of fiscal policy in the United States, but his goals are different, so he does not connect the fiscal actions on which he reports to macroeconomic activity. A thorough analysis of the monetary-fiscal history of a country that brings to bear modern macroeconomic theory is a bit ambitious, though sorely needed. Short of a "Monetary and Fiscal History" that parallels Friedman and Schwartz, there are a great many historical episodes that can be re-interpreted in light of monetary-fiscal interactions.

Across countries there have been many short- and long-lived periods in which central banks have pegged interest rates, yet inflation has remained stable, as Cochrane (2015) points out. This observation seems to contradict Friedman's (1968) warning that pegged rates produce ever-increasing inflation. Has fiscal behavior played a role in delivering stable prices during interest-rate pegs?

It would be instructive to bring fiscal behavior explicitly into a re-examination of the gold standard. What are the fiscal requirements of maintaining a fixed parity under the classical gold standard? Or of resuming convertibility after a suspension? Bordo and Hautcoeur (2007) contrast the French and British experiences after they suspended during World War I. Bordo (2011) suggests that France adopted a passive monetary/active fiscal policy mix that lead to substantially larger price-level increases in France than in Britain, which pursued active monetary and passive fiscal policies.

What role has fiscal policy played in accommodating or ending deflationary episodes? These have been well documented - Temin and Wigmore (1990), Bernanke and James (1991), Bordo and Filardo (2005), and Velde (2009) for example - but in the absence of an analytical understanding of how fiscal policy behaves under a gold standard, discussions of policy interactions remain informal [Eggertsson (2008) and Jalil and Rua (2015)].

\footnotetext{
${ }^{63}$ Chang, Kwak, and Leeper (2015) estimate single-equation models of U.S. monetary and fiscal behavior to infer how an endogenous switch in one policy's regime predicts and switch in the other policy's regime. Empirical work along these lines connects more clearly to theory than do estimates in which regimes change exogenously.
} 
How have large runups of government debt been financed historically? Hall and Sargent $(2011,2014)$ have made substantial progress on this important question in recent years. ${ }^{64}$ Although historically most large debt expansions were associated with wars, advanced economies since the financial crisis - and quite possibly going forward - are experiencing non-war-related debt growth. What does history teach about how policy can best respond to high levels of government debt?

\subsection{A Final Word}

Macroeconomists have an unfortunate history of arguing over whether monetary or fiscal policy in the primary force behind inflation. ${ }^{65}$ If a reader leaves this chapter with a single message, that message should be: the fiscal theory and the quantity theory-or its recent manifestation, the Wicksellian theory - are parts of a more general theory of price-level determination in which monetary and fiscal policies always interact with private-sector behavior to produce the equilibrium aggregate level of prices. Within a certain parametric family of monetary and fiscal rules, the two seemingly distinct perspectives arise from different regions of the policy parameter space, but there is no sense in which one view is "right" and the other is "wrong." Ultimately, it is an empirical question whether we can discern whether and under what circumstances one view is the dominant factor in inflation dynamics.

We would also encourage macroeconomists to entertain the possibility that both views are "right" most of the time and that the process of price-level determination is more complex than benchmark theories have so far described.

\footnotetext{
${ }^{64}$ But see also Bordo and White (1991) on the Napoleonic wars and Sargent and Velde (1995) on the French revolution.

${ }^{65}$ See, for example, Andersen and Jordan (1968) or Friedman and Heller (1969).
} 


\section{REFERENCES}

Adam, K., And R. M. Billi (2008): "Monetary Conservatism and Fiscal Policy," Journal of Monetary Economics, 55(8), 1376-1388.

Aiyagari, S. R., A. Marcet, T. J. Sargent, and J. Seppälä (2002): "Optimal Taxation without State-Contingent Debt," Journal of Political Economy, 110(6), 12201254.

Akitoby, B., T. Komatsuzaki, And A. Binder (2014): "Inflation and Public Debt Reversals in the G7 Countries," IMF Working Paper No. 14/96, June.

Alesina, A., And A. Passalacqua (2016): "The Political Economy of Government Debt," in forthcoming in Handbook of Macroeconomics, ed. by J. B. Taylor, and H. Uhlig, vol. 2. Elsevier Press, Amsterdam.

Alvarez, F., P. J. Kehoe, and P. A. Neumeyer (2004): "The Time Consistency of Optimal Monetary and Fiscal Policies," Econometrica, 72(2), 541-567.

Andersen, L. C., And J. L. Jordan (1968): "Monetary and Fiscal Actions: A Test of Their Relative Importance In Economic Stabilization," Federal Reserve Bank of St. Louis Review, November, 11-24.

Angeletos, G.-M. (2002): "Fiscal Policy with Non-Contingent Debt and the Optimal Maturity Structure," Quarterly Journal of Economics, 117(3), 1105-1131.

Auernheimer, L., And B. Contreras (1990): "Control of the Interest Rate with a Government Budget Constraint: Determinacy of the Price Level and Other Results," Manuscript, Texas A\&M University.

Ball, L., And S. Mazumder (2011): "Inflation Dynamics and the Great Recession," Brookings Papers on Economic Activity, Spring, 337-402.

Banco Central do Brasil (2015): "Inflation Report," 17(4), December.

Barro, R. J. (1979): "On the Determination of the Public Debt," Journal of Political Economy, 87(5), 940-971.

Barro, R. J., And D. B. Gordon (1983): "A Positive Theory of Monetary Policy in a Natural-Rate Model," Journal of Political Economy, 91(4), 589-610. 
Bassetto, M. (2002): "A Game-Theoretic View of the Fiscal Theory of the Price Level," Econometrica, 70(6), 2167-2195.

BegG, D. K. H., And B. Haque (1984): "A Nominal Interest Rate Rule and Price Level Indeterminacy Reconsidered," Greek Economic Review, 6(1), 31-46.

Benhabib, J., S. Schmitt-Grohé, and M. Uribe (2001): "The Perils of Taylor Rules," Journal of Economic Theory, 96(1-2), 40-69.

— (2002): "Avoiding Liquidity Traps," Journal of Political Economy, 110(3), 535-563.

Benigno, P., And M. Woodford (2004): "Optimal Monetary and Fiscal Policy: A Linear-Quadratic Approach," in NBER Macroeconomics Annual 2003, ed. by M. Gertler, and K. Rogoff, pp. 271-333. MIT Press, Cambridge, MA.

Bergin, P. R. (2000): "Fiscal Solvency and Price Level Determination in a Monetary Union," Journal of Monetary Economics, 45(1), 37-53.

Bernanke, B., And H. James (1991): "The Gold Standard, Deflation, and Financial Crisis in the Great Depression: An International Comparison," in Financial Markets and Financial Crises, ed. by R. G. Hubbard, pp. 33-68. University of Chicago Press, Chicago.

Bi, H., E. M. Leeper, And C. Leith (2013): "Uncertain Fiscal Consolidations," The Economic Journal, 123(566), F31-F63.

- (2015): "Financial Intermediation and Government Debt Default," Manuscript, University of Glasgow.

Bianchi, F. (2012): "Evolving Monetary/Fiscal Policy Mix in the United States," American Economic Review Papers $\&$ Proceedings, 101(3), 167-172.

Bianchi, F., And C. Ilut (2014): "Monetary/Fiscal Policy Mix and Agents' Beliefs," Manuscript, Duke University, May.

Blake, A. P., And T. Kirsanova (2011): "Inflation Conservatism and Monetary-Fiscal Interactions," International Journal of Central Banking, 7(2), 41-83.

Bocola, L. (2016): "The Pass Through of Sovereign Risk," Journal of Political Economy, forthcoming.

Bohn, H. (1988): "Why Do We Have Nominal Government Debt?," Journal of Monetary Economics, 21(1), 127-140. 
(1990): “Tax Smoothing with Financial Instruments," American Economic Review, $80,1217-1230$.

(1998): "The Behavior of U.S. Public Debt and Deficits," Quarterly Journal of Economics, 113(3), 949-963.

Bordo, M. (2011): "Comments on 'Perceptions and Misperceptions of Fiscal Inflation'," Slides, Rutgers University, June.

Bordo, M., And A. Filardo (2005): "Deflation and Monetary Policy in a Historical Perspective: Remembering the Past or Being Condemned to Repeat It," Economic Policy, October, 799-844.

Bordo, M., And E. N. White (1991): "A Tale of Two Currencies: British and French Finance During the Napoleonic Wars," Journal of Economic History, 51(2), 303-316.

Bordo, M. D., And P.-C. Hautcoeur (2007): "Why Didn't France Follow the British Stabilisation After World War I?," European Review of Economic History, 11(1), 3-37.

Brunner, K., And A. H. Meltzer (1972): "Money, Debt, and Economic Activity," Journal of Political Economy, 80(5), 951-977.

Brunnermeier, M. K., And Y. Sannikov (2013): "Redistributive Monetary Policy," in The Changing Policy Landscape, pp. 331-384. Federal Reserve Bank of Kansas City Economic Conference Proceedings, 2012 Jackson Hole Symposium.

Buera, F., And J. P. NicOlini (2004): "Optimal Maturity Structure of Government Debt without State Contingent Bonds," Journal of Monetary Economics, 51(3), 531-554.

Buiter, W. H. (2002): "The Fiscal Theory of the Price Level: A Critique," Economic Journal, 112(481), 459-480.

Burnside, C., M. Eichenbaum, and S. Rebelo (2001): "Prospective Deficits and the Asian Currency Crisis," Journal of Political Economy, 109(6), 1155-1197.

Calvo, G. A. (1983): "Staggered Prices in a Utility Maxmimizing Model," Journal of Monetary Economics, 12(3), 383-398.

Calvo, G. A., and P. Guidotti (1992): "Optimal Maturity of Nominal Government Debt," international Economic Review, 33(4), 895-919.

Canzoneri, M. B., R. E. Cumby, and B. T. Diba (2001a): "Fiscal Discipline and Exchange Rate Systems," The Economic Journal, 111(474), 667-690. 
(2001b): "Is the Price Level Determined by the Needs of Fiscal Solvency?," American Economic Review, 91(5), 1221-1238.

Carvalho, C., And A. Ferrero (2014): "What Explains Japan's Persistent Deflation?," Manuscript, University of Oxford, August.

Chang, Y., Y. Choi, and J. Y. Park (2015): "Regime Switching Model with Endogenous Autoregressive Latent Factor," Manuscript, Indiana University, April.

Chang, Y., B. Kwak, and E. M. Leeper (2015): "Monetary-Fiscal Interactions with Endogenous Regime Change," Manuscript, Indiana University, December.

Chari, V. V., L. J. Christiano, and P. J. Kehoe (1994): "Optimal Fiscal Policy in a Business Cycle Model," Journal of Political Economy, 102(4), 617-652.

Chen, X., E. M. Leeper, and C. Leith (2015): "U.S. Monetary and Fiscal Policy: Conflict or Cooperation?," Manuscript, University of Glasgow, June.

Chung, H., And E. M. Leeper (2007): "What Has Financed Government Debt?," NBER Working Paper No. 13425, September.

Cochrane, J. H. (1999): "A Frictionless View of U.S. Inflation," in NBER Macroeconomics Annual 1998, ed. by B. S. Bernanke, and J. J. Rotemberg, vol. 13, pp. 323-384. MIT Press, Cambridge, MA.

- (2001): "Long Term Debt and Optimal Policy in the Fiscal Theory of the Price Level," Econometrica, 69(1), 69-116.

(2005): "Money as Stock," Journal of Monetary Economics, 52(3), 501-528.

(2011a): "Determinacy and Identification with Taylor Rules," Journal of Political Economy, 119(3), 565-615.

(2011b): "Understanding Policy in the Great Recession: Some Unpleasant Fiscal Arithmetic," European Economic Review, 55(1), 2-30.

(2014): "Monetary Policy with Interest on Reserves," Journal of Economic Dynamics and Control, 49(December), 74-108.

— (2015): "Do Higher Interest Rates Raise or Lower Inflation?," Manuscript, Hoover Institution, October. 
Congressional Budget Office (2014): "CBO's Projection of Federal Interest Payments," http://www.cbo.gov/publication/45684, September 3.

(2015): The Long-Term Budget Outlook. U.S. Congress, Washington, D.C., June.

DAniel, B. C. (2001): "The Fiscal Theory of the Price Level in an Open Economy," Journal of Monetary Economics, 48(2), 293-308.

Davig, T., And E. M. Leeper (2006): "Fluctuating Macro Policies and the Fiscal Theory," in NBER Macroeconomics Annual 2006, ed. by D. Acemoglu, K. Rogoff, and M. Woodford, vol. 21, pp. 247-298. MIT Press, Cambridge.

Davig, T., E. M. Leeper, And T. B. Walker (2010): “Unfunded Liabilities' and Uncertain Fiscal Financing," Journal of Monetary Economics, 57(5), 600-619.

- (2011): "Inflation and the Fiscal Limit," European Economic Review, 55(1), 31-47.

Debortoli, D., R. C. Nunes, and P. Yared (2014): "Optimal Government Debt Maturity," Manuscript, Columbia University, October.

DeJong, D. N., B. F. Ingram, and C. H. Whiteman (1996): "A Bayesian Approach to Calibration," Journal of Business \& Economic Statistics, 14(1), 1-9.

DeJong, D. N., and C. H. Whiteman (1991): "Reconsidering 'Trends and Random Walks in Macroeconomic Time Series'," Journal of Monetary Economics, 28(2), 221-254.

Del Negro, M., M. P. Giannoni, and F. Schorfheide (2015): "Inflation in the Great Recession and New Keynesian Models," American Economic Journal: Macroeconomics, $7(1), 168-196$.

Del Negro, M., and F. Schorfheide (2004): "Priors from General Equilibrium Models for VARs," International Economic Review, 45(2), 643-673.

Del Negro, M., And C. A. Sims (2015a): "When Does a Central Bank's Balance Sheet Require Fiscal Support?," in Monetary Policy: An Unprecedented Predicament, ed. by M. Goodfriend, and S. E. Zin, vol. 73 of Carnegie-Rochester-NYU Conference Series on Public Policy, pp. 1-19. Amsterdam.

(2015b): "When Does a Central Bank's Balance Sheet Require Fiscal Support?," in Monetary Policy: An Unprecedented Predicament, ed. by M. Goodfriend, and S. E. Zin, vol. 73 of Carnegie-Rochester-NYU Conference Series on Public Policy, pp. 1-19. Amsterdam, On-line appendix. 
D'Erasmo, P., E. G. Mendoza, and J. Zhang (2016): "What is a Sustainable Public Debt?," in forthcoming in Handbook of Macroeconomics, ed. by J. B. Taylor, and H. Uhlig, vol. 2. Elsevier Press, Amsterdam.

Devereux, M. B., And A. Sutherland (2011): "Country Portfolios in Open Economy Macro Models," Journal of the European Economic Association, 9(2), 337-369.

Dixit, A., And L. Lambertini (2003): "Interactions of Commitment and Discretion in Monetary and Fiscal Policies," American Economic Review, 93(5), 1522-1542.

Dupor, B. (2000): "Exchange Rates and the Fiscal Theory of the Price Level," Journal of Monetary Economics, 45(3), 613-630.

Eggertsson, G. B. (2008): "Great Expectations and the End of the Depression," American Economic Review, 98(4), 1476-1516.

Eichenbaum, M. (1992): "Comment on 'Interpreting the Macroeconomic Time Series Facts: The Effects of Monetary Policy'," European Economic Review, 36, 1001-1011.

Eusepi, S., And B. Preston (2013): "Fiscal Foundations of Inflation: Imperfect Knowledge," Manuscript, Monash University, October.

Faraglia, E., A. Marcet, and A. Scott (2008): "Fiscal Insurance and Debt Management in OECD Economies," The Economic Journal, 118(527), 363-386.

Friedman, M. (1948): “A Monetary and Fiscal Framework for Economic Stability," American Economic Review, 38(2), 245-264.

(1968): "The Role of Monetary Policy," American Economic Review, 58(1), 1-17.

(1970): The Counter-Revolution in Monetary Theory. Institute of Economic Affairs, London.

Friedman, M., and W. W. Heller (1969): Monetary vs. Fiscal Policy-A Dialogue. W. W. Norton \& Company, New York.

Friedman, M., And A. J. Schwartz (1963a): A Monetary History of the United States, 1867-1960. Princeton University Press, Princeton, NJ.

- (1963b): "Money and Business Cycles," Review of Economics and Statistics, 45(1, Part 2, Supplement), 32-64. 
Galí, J. (2008): Monetary Policy, Inflation, and the Business Cycle. Princeton University Press, Princeton, NJ.

Geweke, J. (2010): Complete and Incomplete Econometric Models. Princeton University Press, Princeton, NJ.

Ghosh, A., J. I. Kim, E. G. MendozA, J. D. Ostry, and M. S. Qureshi (2012): "Fiscal Fatigue, Fiscal Space and Debt Sustainability in Advanced Economies," The Economic Journal, 123(566), F4-F30.

Gonzalez-Astudillo, M. (2013): "Monetary-Fiscal Policy Interaction: Interdependent Policy Rule Coefficients," Finance and Economics Discussion Series No. 2013-58, Federal Reserve Board, July.

Gros, D. (2011): "Speculative Attacks Within or Outside a Monetary Union: Default versus Inflation," CEPS Policy Briefs, No. 257, November.

Hall, G. J., And T. J. SARgent (2011): "Interest Rate Risk and Other Determinants of Post-WWII U.S. Government Debt/GDP Dynamics," American Economic Journal: Macroeconomics, 3(3), 1-27.

(2014): "Fiscal Discriminations in Three Wars," in Fiscal Policy in the Presence of Debt Crises, ed. by M. Goodfriend, and S. E. Zin, vol. 61 of Carnegie-Rochester-NYU Conference Series on Public Policy, pp. 148-166. Amsterdam.

Hall, R. E. (2011): "The Long Slump," American Economic Review, 101(2), 431-469.

Hansen, L. P., And T. J. Sargent (2007): Robustness. Princeton University Press, Princeton.

Hausman, J. K., and J. F. Wieland (2014): "Abenomics: Preliminary Analysis and Outlook," Brookings Papers on Economic Activity, Spring, 1-63.

Hilscher, J., A. Raviv, and R. Reis (2014): "Inflating Away the Debt? An Empirical Assessment," NBER Working Paper No 20339, July.

Hur, J. (2013): "Fiscal Financing and the Effects of Government Spending: A VAR Approach," Manuscript, California State University, Northridge, May.

Imakubo, K., H. Kojima, and J. NAKajima (2015): "The Natural Yield Curve: Its Concept and Measurement," Bank of Japan Working Paper Series No. 15-E-5, June. 
International Monetary Fund (2011): Fiscal Monitor-Shifting Gears: Tacking Challenges on the Road to Fiscal Adjustment. IMF, Washington, D.C., April.

— (2014): Fiscal Monitor-Back To Work: How Fiscal Policy Can Help. IMF, Washington, D.C., October.

Ito, T. (2006): “Japanese Monetary Policy: 1998-2005 and Beyond," in Monetary Policy in Asia: Approaches and Implementation, pp. 105-132. Bank for International Settlements.

Ito, T., And F. S. Mishkin (2006): "Two Decades of Japanese Monetary Policy and the Deflation Problem," in Monetary Policy Under Very Low Inflation in the Pacific Rim, NBER-EASE, ed. by A. K. Rose, and T. Ito, vol. 15, pp. 131-193. University of Chicago Press, Chicago.

Jalil, A., And G. RuA (2015): "Inflation Expectations and Recovery from the Depression in 1933: Evidence from the Narrative Record," Manuscript, Occidental College, April.

Kiley, M. T. (2015): "What Can the Data Tell Us About the Equilibrium Real Interest Rate?," Finance and Economics Discussion Series No. 2015-077, Federal Reserve Board, August.

KIm, S. (2003): "Structural Shocks and the Fiscal Theory of the Price Level in the Sticky Price Model," Macroeconomic Dynamics, 7(5), 759-782.

King, M. (1995): "Commentary: Monetary Policy Implications of Greater Fiscal Discipline," in Budget Deficits and Debt: Issues and Options, pp. 171-183. Federal Reserve Bank of Kansas City Economic Conference Proceedings, 1995 Jackson Hole Symposium.

Kirsanova, T., And S. Wren-Lewis (2012): "Optimal Feedback on Debt in an Economy with Nominal Rigidities," The Economic Journal, 122(559), 238-264.

Kleim, M., And A. Kriwoluzky (2014): "Toward a Taylor Rule for Fiscal Policy," Review of Economic Dynamics, 17(2), 294-302.

Kleim, M., A. Kriwoluzky, and S. Sarferaz (2015a): "Monetary-Fiscal Policy Interaction and Fiscal Inflation: A Tale of Three Countries," European Economic Review, forthcoming.

(2015b): "On the Low-Frequency Relationship Between Public Deficits and Inflation," Journal of Applied Econometrics, forthcoming. 
Kocherlakota, N., and C. Phelan (1999): "Explaining the Fiscal Theory of the Price Level," Federal Reserve Bank of Minneapolis Quarterly Review, 23, 14-23.

Kriwoluzky, A., G. J. Müller, and M. Wolf (2014): "Exit Expectations in Currency Unions," Manuscript, University of Bonn, March.

Krugman, P. R. (1998): “It's Baaack: Japan's Slump and the Return of the Liquidity Trap," Brookings Papers on Economic Activity, 2, 137-187.

Lagos, R., And R. Wright (2005): "A Unified Framework for Monetary Theory and Policy Analysis," Journal of Political Economy, 113(3), 463-484.

Lane, P. R., And G. M. Milesi-Ferretti (2001): "The External Wealth of Nations: Measures of Foreign Assets and Liabilities for Industrial and Developing Countries," Journal of International Economics, 55(2), 263-294.

LeEPer, E. M. (1989): “Policy Rules, Information, and Fiscal Effects in a 'Ricardian' Model," Federal Reserve Board, International Finance Discussion Paper No. 360.

- (1991): "Equilibria Under 'Active' and 'Passive' Monetary and Fiscal Policies," Journal of Monetary Economics, 27(1), 129-147.

(2011): "Anchors Aweigh: How Fiscal Policy Can Undermine 'Good' Monetary Policy," in Monetary Policy Under Financial Turbulence, ed. by L. F. Céspedes, R. Chang, and D. Saravia, pp. 411-453. Banco Central de Chile, Santiago.

(2016): "Fiscal Analysis is Darned Hard," in Rethinking Fiscal Policy After the Crisis, ed. by Ludovít Ódor. Cambridge University Press, Cambridge, U.K., forthcoming.

Leeper, E. M., C. Leith, and D. Liu (2015): "Optimal Time-Consistent Monetary, Fiscal and Debt Maturity Policy," Manuscript, University of Glasgow.

LeEPer, E. M., AND B. Li (2015): "On the Bias in Estimates of Fiscal Policy Behavior," Manuscript, Indiana University, October.

Leeper, E. M., And J. M. NAson (2014): "Bringing Financial Stability into Monetary Policy," Center for Applied Economics and Policy Research Working Paper No. 2014-003, Indiana University, November.

LeEper, E. M., And C. A. Sims (1994): "Toward a Modern Macroeconomic Model Usable for Policy Analysis," in NBER Macroeconomics Annual 1994, ed. by S. Fischer, and J. J. Rotemberg, pp. 81-118. MIT Press, Cambridge, MA. 
Leeper, E. M., N. Traum, and T. B. Walker (2015): "Clearing Up the Fiscal Multiplier Morass," NBER Working Paper No. 21433, July.

Leeper, E. M., And T. B. Walker (2013): "Perceptions and Misperceptions of Fiscal Inflation," in Fiscal Policy After the Financial Crisis, ed. by A. Alesina, and F. Giavazzi, pp. 255-299. University of Chicago Press, Chicago.

Leeper, E. M., And X. Zhou (2013): “Inflation's Role in Optimal Monetary-Fiscal Policy," NBER Working Paper No. 19686, November.

Leith, C., And D. LiU (2014): "The Inflation Bias Under Calvo and Rotemberg Pricing," University of Glasgow Working Paper No. 2014-6.

Leith, C., And S. Wren-Lewis (2006): "Compatibility Between Monetary and Fiscal Policy Under EMU," European Economic Review, 50(6), 1529-1556.

- (2008): "Interactions Between Monetary and Fiscal Policy Under Flexible Exchange Rates," Journal of Economic Dynamics and Control, 32(9), 2854-2882.

(2013): "Fiscal Sustainability in a New Keynesian Model," Journal of Money, Credit and Banking, 45(8), 1477-1516.

LJungqvist, L., And T. J. SARgent (2004): Recursive Macroeconomic Theory. MIT Press, Cambridge, MA, 2nd edn.

Loyo, E. (1997): "Going International with the Fiscal Theory of the Price Level," Princeton University, mimeo.

- (1999): "Tight Money Paradox on the Loose: A Fiscalist Hyperinflation," Manuscript, Harvard University.

Lucas, JR., R. E., And N. L. Stokey (1983): "Optimal Fiscal and Monetary Policy in an Economy without Capital," Journal of Monetary Economics, 12(1), 55-93.

Marcet, A., And A. Scott (2009): "Debt and Deficit Fluctuations and the Structure of Bond Markets," Journal of Economic Theory, 21(1), 473-501.

Martin, F. M. (2009): "A Positive Theory of Government Debt," Review of Economic Dynamics, 12(4), 608-631.

(2011): "On the Joint Determination of Fiscal and Monetary Policy," Journal of Monetary Economics, 58(2), 132-145. 
McCallum, B. T. (1984): “Are Bond-Financed Deficits Inflationary?," Journal of Political Economy, 92(February), 123-135.

- (2001): "Indeterminacy, Bubbles, and the Fiscal Theory of Price Level Determination," Journal of Monetary Economics, 47(1), 19-30.

MendozA, E. G., And J. D. Ostry (2008): "International Evidence on Fiscal Solvency: Is Fiscal Policy 'Responsible'?," Journal of Monetary Economics, 55(6), 1081-1093.

Missale, A. (1999): Public Debt Management. Oxford University Press, Oxford.

Niemann, S., P. Pichler, and G. Sorger (2013): "Public Debt, Discretionary Policy, and Inflation Persistence," Journal of Economic Dynamics and Control, 37(6), 1097-1109.

Obstfeld, M., and K. Rogoff (1983): "Speculative Hyperinflations in Maximizing Models: Can We Rule Them Out?," Journal of Political Economy, 91(4), 675-687.

Persson, M., T. Persson, and L. E. O. Svensson (1987): "Time Consistency of Fiscal and Monetary Policy," Econometrica, 55(6), 1419-1431.

(2006): "Time Consistency of Fiscal and Monetary Policy: A Solution," Econometrica, 74(1), 193-212.

Phelps, E. S. (1973): "Inflation in the Theory of Public Finance," Swedish Journal of Economics, 75(1), 67-82.

Prescott, E. C. (1986): "Theory Ahead of Business Cycle Measurement," CarnegieRochester Conference Series on Public Policy, North-Holland, 11-44.

REIs, R. (2013): "The Mystique Surrounding the Central Bank's Balance Sheet, Applied to the European Crisis," American Economic Review Papers 6 Proceedings, 103(3), 135-140.

(2015): "QE in the Future: The Central Bank's Balance Sheet in a Fiscal Crisis," Manuscript, Columbia University, November.

Rotemberg, J. J. (1982): "Sticky Prices in the United States," Journal of Political Economy, 90(December), 1187-1211.

- (1996): "Prices, Output, and Hours: An Empirical Analysis Based on a Sticky Price Model," Journal of Monetary Economics, 37(June), 505-533.

Sargent, T. J. (1986): "The Ends of Four Big Inflations," in Rational Expectations and Inflation, ed. by T. J. Sargent. Harper \& Row, New York. 
Sargent, T. J., And F. R. Velde (1995): "Macroeconomic Features of the French Revolution," Journal of Political Economy, 103(3), 474-518.

Sargent, T. J., And N. Wallace (1981): "Some Unpleasant Monetarist Arithmetic," Federal Reserve Bank of Minneapolis Quarterly Review, 5(Fall), 1-17.

Schmitt-Grohé, S., And M. Uribe (2004): "Optimal Fiscal and Monetary Policy under Sticky Prices," Journal of Economic Theory, 114(2), 198-230.

- (2007): "Optimal Simple and Implementable Monetary and Fiscal Rules," Journal of Monetary Economics, 54(6), 1702-1725.

SHIM, S. D. (1984): Inflation and the Government Budget Constraint: International Evidence. Department of Economics, University of Minnesota. Unpublished Ph.D. Dissertation. August.

Sims, C. A. (1972): "Money, Income, and Causality," American Economic Review, 62(4), $540-552$.

(1992): "Interpreting the Macroeconomic Time Series Facts: The Effects of Monetary Policy," European Economic Review, 36, 975-1000.

(1994): "A Simple Model for Study of the Determination of the Price Level and the Interaction of Monetary and Fiscal Policy," Economic Theory, 4(3), 381-399.

(1997): "Fiscal Foundations of Price Stability in Open Economies," Manuscript, Yale University.

- (1998): "Econometric Implications of the Government Budget Constraint," Journal of Econometrics, 83(1-2), 9-19.

- (1999a): "Domestic Currency Denominated Government Debt as Equity in the Primary Surplus," Presented at the August 1999 meetings of the Latin American region of the Econometric Society.

- (1999b): "The Precarious Fiscal Foundations of EMU," De Economist, 147(4), $415-436$.

(2001): "Fiscal Consequences for Mexico of Adopting the Dollar," Journal of Money, Credit and Banking, 33(2, Part 2), 597-616.

(2011): "Stepping on a Rake: The Role of Fiscal Policy in the Inflation of the 1970's," European Economic Review, 55(1), 48-56. 
(2013): "Paper Money," American Economic Review, 103(2), 563-584.

Sims, C. A., And T. Zha (2006): "Were There Regime Switches in US Monetary Policy?," American Economic Review, 96(1), 54-81.

Smets, F., And R. Wouters (2007): "Shocks and Frictions in US Business Cycles: A Bayesian DSGE Approach," American Economic Review, 97(3), 586-606.

Stein, H. (1996): The Fiscal Revolution in America. AEI Press, Washington, D.C., second revised edn.

Tan, F. (2014): "Two Econometric Interpretations of U.S. Fiscal and Monetary Policy Interactions," Manuscript, Indiana University, November.

(2015): "An Analytical Approach to New Keynesian Models Under the Fiscal Theory," Manuscript, Indiana University, April.

Tan, F., And T. B. Walker (2014): "Solving Generalized Multivariate Linear Rational Expectations Models," Manuscript, Indiana University, February.

TAYlor, J. B. (1993): "Discretion versus Policy Rules in Practice," Carnegie-Rochester Conference Series on Public Policy, 39, 195-214.

— (1995): "Monetary Policy Implications of Greater Fiscal Discipline," in Budget Deficits and Debt: Issues and Options, pp. 151-170. Federal Reserve Bank of Kansas City Economic Conference Proceedings, 1995 Jackson Hole Symposium.

Temin, P., And B. A. Wigmore (1990): "The End of One Big Deflation," Explorations in Economic History, 27(4), 483-502.

The Economist (2016): "Irredeemable? A Former Star of the Emerging World Faces a Lost Decade," January 2, http://www.economist.com/news/briefing /21684778-former-star-emerging-world-faces-lost-decade-irredeemable.

Tobin, J. (1963): "An Essay on the Principles of Debt Management," in Fiscal and Debt Management Policies, ed. by Commission on Money and Credit, pp. 143-218. PrenticeHall, Englewood Cliffs, NJ.

(1980): Asset Accumulation and Economic Activity. University of Chicago Press, Chicago.

Traum, N., And S.-C. S. Yang (2011): "Monetary and Fiscal Policy Interactions in the Post-War U.S.," European Economic Review, 55(1), 140-164. 
URIBE, M. (2006): "A Fiscal Theory of Sovereign Risk," Journal of Monetary Economics, 53(8), $1857-1875$.

Velde, F. R. (2009): "Chronicle of a Deflation Unforetold," Journal of Political Economy, $117(4), 591-634$.

Wallace, N. (1981): "A Modigliani-Miller Theorem for Open-Market Operations," American Economic Review, 71(3), 267-274.

Woodford, M. (1995): "Price-Level Determinacy Without Control of a Monetary Aggregate," Carnegie-Rochester Conference Series on Public Policy, 43, 1-46.

(1998a): "Control of the Public Debt: A Requirement for Price Stability?," in The Debt Burden and Its Consequences for Monetary Policy, ed. by G. Calvo, and M. King, pp. 117-154. St. Martin's Press, New York.

— (1998b): "Public Debt and the Price Level," Manuscript, Princeton University.

(1999): "Comment on Cochrane's 'A Frictionless View of U.S. Inflation'," in NBER Macroeconomics Annual 1998, ed. by B. S. Bernanke, and J. J. Rotemberg, vol. 13, pp. 390-419. MIT Press, Cambridge, MA.

(2001): "Fiscal Requirements for Price Stability," Journal of Money, Credit, and Banking, 33(3), 669-728.

- (2003): Interest and Prices: Foundations of a Theory of Monetary Policy. Princeton University Press, Princeton, NJ. 